\title{
DANICA MCGOVERN
}

\section{Towards Justice for Victims: A New Role for Victim Impact Statements in Sexual Violence Cases}

\author{
LAWS 591: DISSERTATION
}

\section{FACULTY OF LAW}

TE WHARE WĀNANGA O TE ŨPOKO O TE IKA A MĀUI

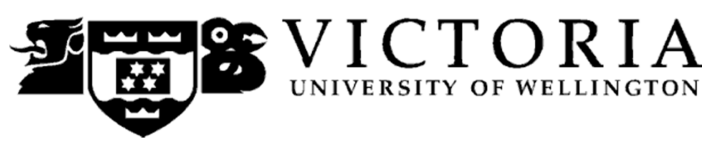

2012 


\section{Contents}

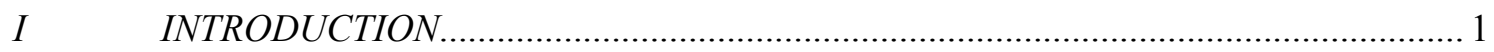

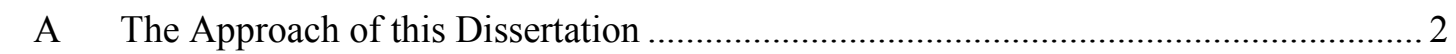

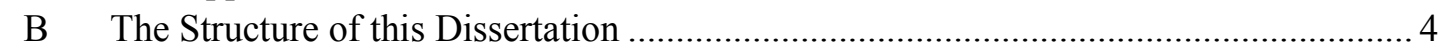

II THE CURRENT APPROACH TO VICTIM IMPACT STATEMENTS ............................ 5

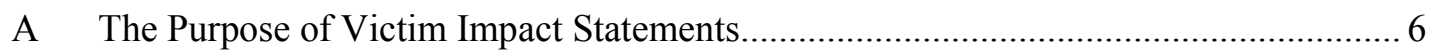

B Restrictions on the Permissible Content of Victim Impact Statements ........................ 9

1 The facts of the offending and other offending or misconduct..................... 10

2 Effects of the offending which are "too remote" ......................................... 11

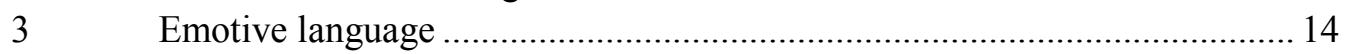

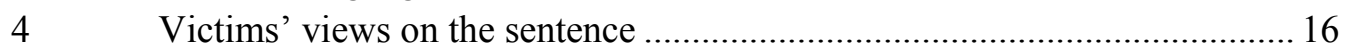

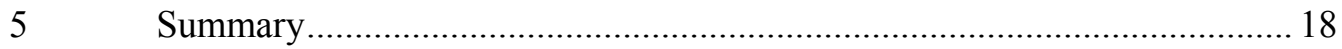

C The Limits of the Current Approach in Meeting Victims' Needs and Protecting

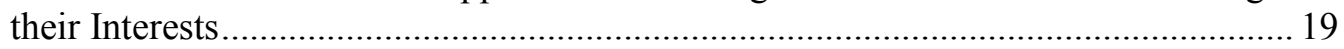

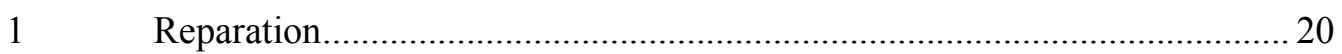

$2 \quad$ Prevention of further harm from the offender .......................................... 20

3 Prevention of further harm from the sentence imposed on the offender ...... 22

D Procedural Problems with the Current Approach .................................................... 25

1 The lack of a robust process for consideration of victims' views..................25

$2 \quad$ Risks of further harm from the current process ......................................... 28

E The Necessity of Fundamental Reform of Victim Impact Statements ............................ 29

$1 \quad$ The Victims of Crime Reform Bill ............................................................ 30

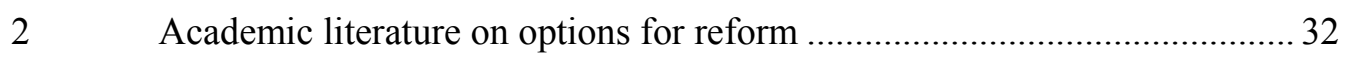

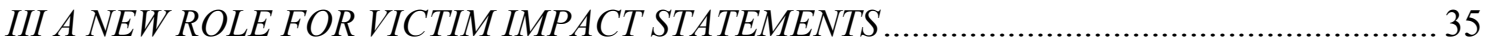

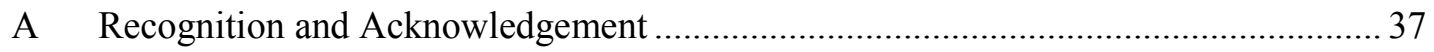

1 Formal recognition of the wrong and acknowledgement of the harm ........... 38

2 Recognition of the relationship between victim and offender ..................... 40

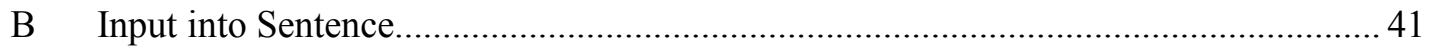

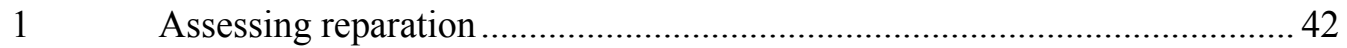

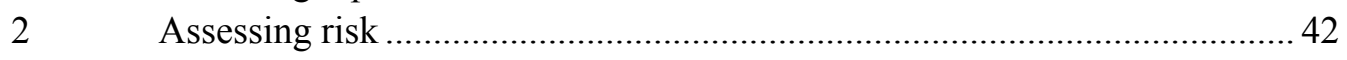

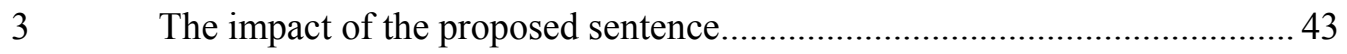

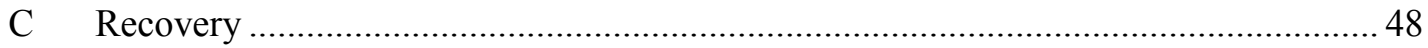

$1 \quad$ A framework for the harm caused by sexual violence.................................. 48

2 The interests interfered with by sexual violence ........................................ 52

3 Theoretical underpinnings of the proposed therapeutic goals .........................6 60

$4 \quad$ How making a victim impact statement can promote recovery.................... 64

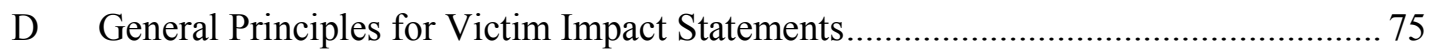

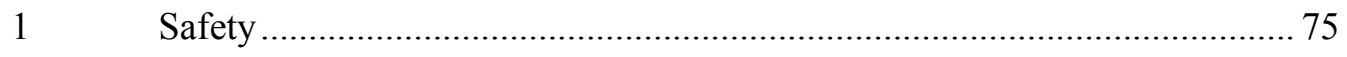

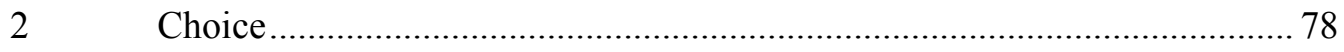

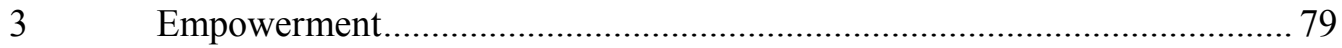

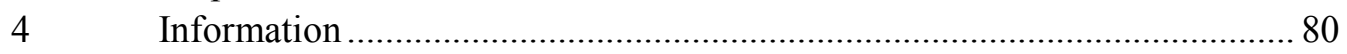

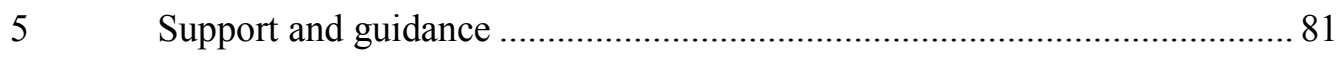

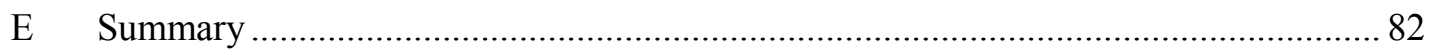


IV IMPLICATIONS OF THE PROPOSED ROLE OF VICTIM IMPACT STATEMENTS ......... 83

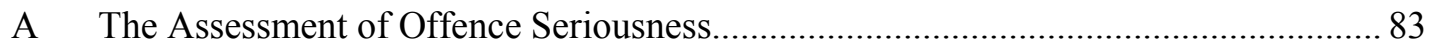

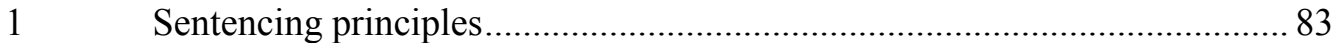

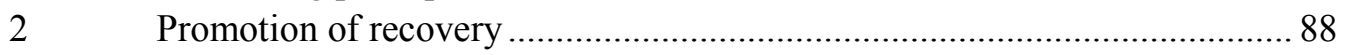

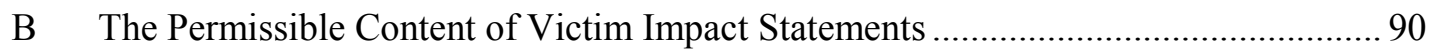

C Limitations, Likely Objections and Practical Hurdles ................................................ 93

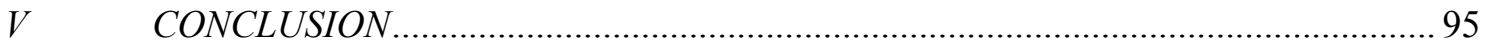




\begin{abstract}
This dissertation argues that the current approach to victim impact statements in New Zealand serves victims poorly. The primary purpose of victim impact statements is to provide information about harm, in order to assist the sentencing judge to assess the seriousness of the offending. This limits the extent to which victim impact statements can meet victims' needs and protect their interests. This dissertation proposes a new role for victim impact statements (with a focus on their use in sexual violence cases). It argues that the purpose of victim impact statements should be to meet victims' needs for recognition, acknowledgement and assistance with recovery, and to protect victims' interests in reparation and prevention of further harm from the offender and from the sentence imposed on the offender. Meeting these needs and protecting these interests is necessary to provide justice for victims. Finally, this dissertation argues that victim impact statements should not be used to assess the seriousness of the offending.
\end{abstract}

\title{
Word length
}

The text of this paper (excluding abstract, table of contents, footnotes and bibliography) comprises 35,221 words.

\section{Subjects and Topics}

Victim impact statements

Sentencing

Sexual violence 


\section{Introduction}

Over the last five years, there have been a number of stories in the media about people who have had their victim impact statements "censored". Most of these have been stories about family members of homicide victims in high profile cases. The stories illustrate the importance of victim impact statements to some crime victims, and show how deeply affected they can be by the "censorship" of what they have written. They suggest that some people devote substantial time and effort to writing their victim impact statements, and that the symbolic importance of victim impact statements is high. For example, Kevin McNeil described the victim impact statement he wrote for the sentencing of his mother's murderer as " 30 hours of work and tears that have fallen on the paper." 2 Brian Brown, whose daughter was killed, said that reading his victim impact statement was as important as giving his daughter's eulogy. Gordene Tuhoro explained the consequences of being prevented from describing her experience after her aunt's murder in a way that was meaningful to her: ${ }^{3}$

It's not really our statement if someone else is going to rewrite it. It's not real. It's not real if it's not from my heart, and how I feel, and my words... To be told that you can't read something that you feel very strongly about and is true to your heart it doesn't help with our healing. You're turning good people into bad and bitter and hateful people, against others who look like they don't give a damn.

As Brian Brown asked, "What's the point of having a victim impact statement if the impact it has on you, you can't tell the court?"4

It should be borne in mind that it is unclear to what extent these comments are representative of the effect on victims of the current approach to victim impact statements. The stories all feature family members of homicide victims, who form a very

\footnotetext{
See for example Juliet Rowan "Let victims speak out: law expert" The New Zealand Herald (online ed, Auckland, 17 May 2007) <www.nzherald.co.nz>;

"Victim impact statements censored for whose benefit?" Close Up (11 December 2009)

$<$ http://tvnz.co.nz/close-up/victim-impact-statements-censored-whose-benefit-3284219>;

"Sophie's dad says victim impact statement censored" (Wellington, 13 November 2009)

http://www.stuff.co.nz/national/crime/3059154/Sophies-dad-says-victim-impact-statementcensored $>$.

Rowan, above $\mathrm{n} 1$.

"Victim impact statements censored", above $\mathrm{n} 1$.

Rowan, above $\mathrm{n} 1$.
} 
small proportion of victims whose cases enter the criminal justice process. ${ }^{5}$ However, they do offer some insight into the kinds of adverse consequences that can result from the current approach.

The Ministry of Justice undertook a review of victims' rights in 2009 and 2010, which included consideration of the purpose and permissible content of victim impact statements. It recommended a clarification of their purpose and a relaxation of some of the current restrictions on content. ${ }^{6}$ The Victims of Crime Reform Bill 2011 came out of that review. The Select Committee report on the Bill was issued on 27 June 2012.' Despite claims that the Bill will empower victims and increase their freedom to express themselves, ${ }^{8}$ it is not clear that the Bill makes any significant changes to the permissible content of victim impact statements. In this dissertation, I propose much larger changes to victim impact statements than those included in the Bill. These changes are necessary if victim impact statements are in fact to benefit victims.

\section{A The Approach of this Dissertation}

This dissertation is multi-disciplinary. I analyse the case law on victim impact statements and aspects of sentencing, and discuss the operation of provisions in the Victims' Rights Act 2002 and the Sentencing Act 2002. I also discuss the likely effects of the Victims of Crime Reform Bill 2011. I draw on academic legal writing on sentencing and the role and experience of complainants in the criminal justice process. My discussion of the effects of sexual violence on victims and the process of recovery is based on literature from the social sciences. I draw particularly on qualitative research that uses a feminist or ecological framework. In addition to research that is specific to sexual violence, I use more general grief and trauma literature.

My dissertation sits most easily within the body of work known as therapeutic jurisprudence. This is a perspective which holds that laws, legal processes and legal professionals inevitably have an impact on people's well-being. It argues that where doing so would not conflict with other values, law-makers should try to ensure that this

$5 \quad$ Homicide formed 0.02 per cent of recorded offences in 2011. See New Zealand Crime Statistics 2011: A Summary of Recorded and Resolved Offence Statistics (Police National Headquarters, Wellington, 2011) at 7.

6 Cabinet Domestic Policy Committee “Enhancing Victims' Rights Review” (17 February 2011) at 7-8.

$7 \quad$ Victims of Crime Reform Bill 2011 (319-2) (select committee report).

8 Simon Power "Unanimous support for bill to enhance victims' rights" (press release, 4 October 2011). 
impact is positive. ${ }^{9}$ In my critique of the current approach to victim impact statements, I highlight its potential harmful effects on victims. I also argue that the extent to which making a victim impact statement can meet victims' needs and protect their interests is currently very limited. My proposal for reform aims to minimise the risk of harm to victims from making a victim impact statement, and to promote victims' physical safety and emotional well-being, and to assist with their recovery from the offending. Where I suggest changes which could conflict with other values, namely the due process rights of offenders and principles of sentencing, I highlight the conflict and discuss how it should be resolved.

Most of the existing literature on victim impact statements treats crime victims as a generic group. However, different types of offending have different effects on victims, ${ }^{10}$ and so may give rise to different needs and create different interests. I focus on sexual violence, as it causes particularly serious harm to victims and the community. My discussion of the current approach to victim impact statements is general, but the proposal for reform I make in Chapter III and my discussion of the implications of it for sentencing in Chapter IV are specific to sexual violence. I address only the role victim impact statements could play for victims who are adults or young people.

A further step in developing a model of victim impact statements which is responsive to the needs of victims would be to address differences between sexual violence victims arising from particular aspects of their identity or circumstances. The role I propose for victim impact statements is intended to be flexible enough that individual victims could use them in ways that are appropriate for their needs. However, I do not take the further step of examining the particular needs of sub-groups of sexual violence victims or the likely effectiveness of my proposal in meeting those needs. For example, I do not attend specifically to the needs of Maori victims or those who belong to other ethnic minorities, and I am writing from a Pakeha perspective. Further, the needs of male victims, victims assaulted within a same-sex relationship and victims who have a disability are not addressed specifically in my proposal. These are very important considerations but the dearth of published research and the complexity of the issues make it infeasible to undertake a comprehensive discussion of them in this dissertation.

\footnotetext{
$9 \quad$ David Wexler "An Orientation to Therapeutic Jurisprudence" (1994) 20 New Eng J on Crim and Civ Confinement 259 at 259.

10 Joanna Shapland and Matthew Hall "What Do We Know about the Effects of Crime on Victims?" (2007) 14 IRV 175 at 181-204.
} 


\section{B The Structure of this Dissertation}

In Chapter II, I discuss the current approach to victim impact statements, including their purpose and permissible content. I highlight aspects of the current approach which can be harmful for victims, and which limit the extent to which making a victim impact statement may be helpful to them. I also discuss existing suggestions for reform of victim impact statements, arguing that they are inadequate as they do not address the issues with the current approach. In Chapter III, I propose a new role for victim impact statements, which will address the problems with the current approach. In Chapter IV, I discuss the implications of this proposal for the permissible content of victim impact statements. I also canvass potential challenges for implementing the proposed new purpose.

My thesis is that the role of victim impact statements should be to meet victims' needs for recognition, acknowledgement and assistance with recovery, and to protect their interests in reparation and prevention of further harm from the offender and from the sentence imposed on the offender. 


\section{The Current Approach to Victim Impact Statements}

The state is not just the arbiter in the trial between victim and offender; the state is the victim... If the victim feels that nobody cares about their suffering, it is in part because institutionally nobody does. ${ }^{1}$

In this chapter I critique the current approach to victim impact statements. I argue that it is one aspect of victims' experience in the criminal justice process that can leave them feeling that nobody cares about the harm they suffer as a result of the offending and their involvement in the process. The central argument of this chapter is that victim impact statements have come to be understood by the courts as an instrument in the case between the state and the offender. It is my view that this conception of victim impact statements means that making one is currently of little benefit to victims, and may cause them further harm. Any reform should start from the position that victim impact statements are primarily an instrument to meet victims' needs and protect their interests.

In Part A, I discuss the current purpose of victim impact statements. I illustrate how the purpose has become increasingly centred on the provision of information required by the court for the assessment of the seriousness of the offence, moving away from any concern for the needs and interests of victims. In Part B, I outline the restrictions the courts have imposed on the permissible content of victim impact statements in accordance with this purpose. In imposing these restrictions, the courts purported to ensure that only information relevant to the assessment of the seriousness of the offending could be included in victim impact statements. However, uncertainty about the way in which offence seriousness should be assessed makes the justification for these restrictions questionable.

I then turn to a discussion of the effects on victims of the current approach to victim impact statements. In Part C, I argue that it limits the extent to which victim impact statements can meet victims' needs and protect their interests. This can leave victims feeling as if justice has not been done, and contribute to further physical, emotional, and material harm. First, I argue that the restrictions limit the extent to which victim impact statements can meet victims' needs for recognition and acknowledgement, and assistance with recovery. Secondly, the restrictions limit the extent to which victim impact statements can protect the victim's interests in the sentence. These interests are in

Doreen McBarnet "Victim in the Witness Box - Confronting Victimology's Stereotype" (1983) 7 Contemporary Crises 293 at 300 . 
reparation, prevention of further harm from the offender, and prevention of further harm from the sentence imposed on the offender. In Part D, I argue that in addition to increasing the likelihood of poor outcomes for victims, the current approach to victim impact statements is procedurally unfair to victims and may cause them further harm. The failure to give victims enough information about the purpose and permissible content of victim impact statements, the use of "censorship", and the representation to victims by criminal justice professionals that it is compulsory to make a victim impact statement can cause further harm to victims. Further, the lack of consideration for victims' needs and interests under the current approach fails to treat victims fairly and with respect, and can contribute to their sense of alienation from the criminal justice process.

Finally, in Part E I examine some proposals that have already been made for the reform of victim impact statements in New Zealand. Those proposals do not fully engage with the issues I raise in this chapter, which makes them inadequate to address the problems with the current approach.

\section{A The Purpose of Victim Impact Statements}

Neither the Victims of Offences Act 1987 nor its replacement, the Victims' Rights Act 2002, sets out the purpose of victim impact statements. However, an early conceptualisation of the purpose of victim impact statements can be found in a study undertaken by the Policy and Research Division of the Department of Justice in 1989. In this study the researchers interviewed criminal justice officials, victim support group representatives and victims who had experience with victim impact statements. ${ }^{2}$ Participants were asked what they considered the purpose of victim impact statements to be. The researchers grouped the responses into three purposes, although they noted that not all respondents agreed that all three purposes were legitimate. ${ }^{3}$ The list was as follows: ${ }^{4}$

1. To provide the court with further information. Victim impact statements were perceived as balancing the information the court received on the offender and providing some form of representation for the victim. They helped to make the case personal rather than routine and were likely to assist the judge in reaching a more informed decision. A wide range of respondents saw this as one of the purposes of victim impact statements.

\footnotetext{
$2 \quad$ Sandra Wallace Victim Impact Statements - A Monograph (Department of Justice Policy and Research Division, Wellington, 1989) at 9. A summary of the research findings appeared in Geoff Hall "Victim Impact Statements: Sentencing on Thin Ice?" (1992) 15 NZULR 143 at 148.

Wallace, at 12.

Wallace, at 11.
} 
2. To help empower the victim and aid their healing process. Victim impact statements were seen as giving victims a chance to express how they were affected, allowing them some input into the judicial process and providing them with a sense of being looked after and taken notice of. Victim support groups saw this as the main purpose of victim impact statements.

3. To help the offender. Many defence lawyers, judges, probation officers and some victims thought that victim impact statements, by forcing an offender to recognise the full effects of their actions, have the potential in some cases to aid the rehabilitation of the offender and possibly stop future reoffending.

The similarity of much of the wording suggests that Hammond $\mathrm{J}$ drew on the study in his conceptualisation of the purpose of victim impact statements in Sargeant v Police: ${ }^{5}$

A victim impact report, when prepared, serves at least four purposes. First, in a general way, the Court may be assisted with further information. Second, information about the effect of a crime on a victim helps to balance the information in the Probation Service report on the offender. Third, the victim is given input into the administration of justice. That is a form of catharsis, and may aid in the healing process. And, it assists the Court in seeing things through the victim's eyes. Fourth, the offender is forced to recognise what he or she has done, which may advance the rehabilitative process, and prevent further offending.

However, the interpretation of the purpose of victim impact statements in Sargeant left out references to the representation, empowerment and care of victims. I argue throughout this dissertation that these values should be central to the purpose of victim impact statements.

Hammond J's statement of the four purposes of victim impact statements was used almost verbatim by Chambers $\mathrm{J}$ in $R v$ Burns. ${ }^{6}$ A year later, in $R v$ Schofield, Chambers $\mathrm{J}$ applied the same purpose again, noting that neither counsel "attempted to argue that [his] decision was wrong as to the principles stated or as to the application of those principles" and indeed "each used Burns as the starting point for their submissions.", Notwithstanding the lack of argument on the purpose of victim impact statements, Chambers $\mathrm{J}$ offered the following clarification of the law: ${ }^{8}$

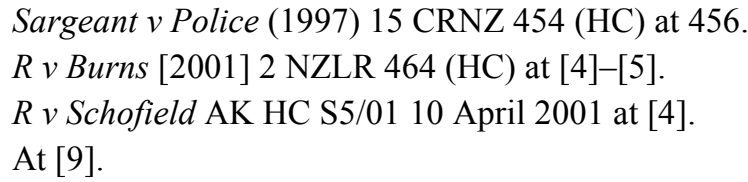


... Hammond $\mathrm{J}$ referred to victim impact statements as serving at least four purposes. The third of those purposes was to give the victim input into the administration of justice. The act of completing a victim impact statement was, his Honour said, a form of catharsis and may aid in the healing process. This is indeed an important feature of the victim impact statement process. But the principal purpose of a victim impact statement is not to provide an outlet to the victim's anguish but rather is to assist the sentencing judge in his or her task by providing information. That was the first purpose in Hammond J's list and it is the most important.

In this version, Chambers $\mathrm{J}$ usefully made it clear that it is the process of completing a victim impact statement (with its opportunity for victims to express their feelings about the offending) that may be cathartic, rather than having input into the administration of justice, as the wording in Sargeant suggested. However, Chambers J left out the reference to giving the victim input into the administration of justice. He also left out Hammond J's point that victim impact statements "assist the Court in seeing things through the victim's eyes". He focused instead on catharsis, overlooking the possibility that a victim impact statement could both provide relevant information and allow victims to express themselves.

Since Schofield, the provision of information relevant to sentencing has been accepted as a primary purpose of victim impact statements. ${ }^{9}$ There is little trace of the ideas from the early conceptualisation of the purpose of victim impact statements, such as empowerment, assistance with recovery or showing victims they are cared about. Remnants are still to be found of the ideas that victim impact statements should provide an opportunity for victims to express how they were affected by the offending and to have some input into sentencing. The courts have been adamant, however, that these purposes are secondary to the provision of (only) the information required by the court. This has led the courts to impose restrictions on the permissible content of victim impact statements, an issue I discuss next.

Sargeant, Burns and Schofield were all decided when the governing statute for victim impact statements was the Victims of Offences Act 1987, since replaced by the Victims' Rights Act 2002. The purpose of victim impact statements did not change with the introduction of the Victims' Rights Act, and since Schofield, the provision of information relevant to sentencing has been the primary purpose of victim impact statements. 


\section{$B$ Restrictions on the Permissible Content of Victim Impact Statements}

Section 17(1) of the Victims' Rights Act reads as follows:

(1) The prosecutor must make all reasonable efforts to ensure that information is ascertained from the victim, for submission under section 21 to the judicial officer sentencing the offender, about the following matters:

a) Any physical injury or emotional harm suffered by the victim through, or by means of, the offence; and

b) Any loss of, or damage to, property suffered by the victim through, or by means of, the offence; and

c) Any other effects of the offence on the victim.

The main way in which sentencing judges use the information provided in victim impact statements is to assess the seriousness of the offence, which determines the starting point for the sentence. The degree of harm suffered by the victim is one factor affecting how serious the offending is judged to be. ${ }^{10}$ Despite the broad language of s 17(1), the courts have imposed restrictions on the permissible content of victim impact statements, purporting to ensure that only information relevant to the assessment of offence seriousness is included. The rationales for the relevance-based restrictions were articulated in $R v$ Haddon as prevention of unfairness to the offender and promotion of efficiency. The restrictions lessen the extent to which sentencing judges have to filter out irrelevant information when reading or listening to victim impact statements. ${ }^{11}$

In this section, I outline the restrictions the courts have imposed on the permissible content of victim impact statements. They fall into four categories. These are the facts of the offending and other alleged offences or misconduct; consequential loss or harm; emotive language; and the victim's views on the sentence the offender should receive. I argue that the extent to which the first three categories of restrictions are justified is unclear. The courts have not engaged in any discussion about the appropriate role of harm suffered by the victim in the assessment of offence seriousness. This is a complex issue, on which no legislative guidance has been provided. ${ }^{12}$ As I illustrate, some of the restrictions imposed by the courts may actually prevent victims from providing information relevant to the assessment of seriousness. The fourth category of restriction,

$10 \quad$ Michael Cavadino The Law of Gravity: Offence Seriousness and Criminal Justice (Joint Unit for Social Services Research, Sheffield, 1997) at 29-35.

$11 \quad R v$ Haddon (1990) 6 CRNZ 508 (CA) at 510-511.

12 Section $8(\mathrm{f})$ of the Sentencing Act states that the court "must take into account any information provided to the court concerning the effect of the offending on the victim", but how it should be taken into account is not explained. 
the victim's views on sentence, is slightly different to the other three. The victim's views on the sentence the offender should receive are not relevant to the assessment of how serious the offence is. However, as I argue fully in Part C of this chapter, completely excluding the victim's views limits the extent to which victim impact statements can protect the victim's interests. This increases the likelihood of the victim suffering further harm. I discuss each category of restriction in turn.

1 Victims should not discuss the facts of the offending or allege other offending or misconduct by the offender

An example of this restriction can be found in Haddon, where the Court of Appeal criticised victim impact statements that alleged criminal offending other than that for which Mr Haddon was being sentenced, and that included allegations of other misconduct. ${ }^{13}$ This restriction on the content of victim impact statements is unsurprising, as it is a basic principle that only offences for which convictions have been entered should be taken into account at sentencing. ${ }^{14}$ However, in $R v$ Proctor the Court narrowed the permissible content of victim impact statements further. ${ }^{15}$ It held that they should not contain details of the offending for which sentence is being passed. Chambers J for the Court held: ${ }^{16}$

Victim impact statements should not contain the victim's account of the actual offending. In cases where the offender has pleaded guilty, details of the offending come before the court either in an agreed statement of facts or by way of a disputed facts hearing. Victim impact statements are to inform the sentencing judge of the effects of the offending, not the details of the offending.

The decision that victims cannot describe what they experienced during the offending itself (as opposed to its after-effects) is quite a strict interpretation of s 17. Part of the impact of the offending is the victim's experience of it at the time it occurs, and limiting the permissible content of victim impact statements to the after-effects of the offending is artificial. Sentencing should proceed on the basis of facts admitted by the offender or proved at a defended hearing or trial (if the case is defended) or in a disputed facts hearing (if there is a guilty plea but an aspect of the summary of facts is challenged). Victim impact statements should not be the source of information about the facts of the

\footnotetext{
Rv Haddon, above $\mathrm{n} 11$, at 515.

14 Ian Edwards "The Evidential Quality of Victim Personal Statements and Family Impact Statements" (2009) 13 Int'l J Evidence \& Proof 293 at 310-315.

$15 \quad R$ v Proctor [2007] NZCA 289.

16 At [19].
} 
offending. ${ }^{17}$ However, they can provide information about the victim's subjective experience of the offending, which is part of the harm, and therefore relevant to the assessment of the seriousness of the offence. Relevance does not provide an adequate justification for stopping victims from referring to or describing the offending itself in their victim impact statements.

2 Victims should not include effects of the offending which are "too remote" from the criminal conduct

In two cases, Burns and Schofield, the Court held that particular effects of an offence should not have been included in victim impact statements. These were cases where the effects in question were caused by the offence (in the sense that they would not have occurred but for the offence), but resulted from events that took place after the completion of the offence and that involved third parties. The effects in question were considered irrelevant to the assessment of the seriousness of the offending in these cases.

It is useful to consider first a Court of Appeal judgment in which relevance appears to have been drawn quite widely. In $R v$ Barrett, Thomas $\mathrm{J}$ (writing for the Court) dismissed the appellant's argument that it was improper for the victim impact statement to have included the effects on the victim of her family's rejection of her following her disclosure of the offending. ${ }^{18}$ This rejection was a result of the defendant's denial of the offending when the family asked him about it. Thomas $\mathrm{J}$ said: ${ }^{19}$

... it is artificial to separate the impact of the offence per se from Mr Barrett's subsequent denial of it when assessing the impact on the victim. It is part of the consequences of the offending, and for that reason is relevant to sentencing.

Furthermore, failing to have due regard to these consequences is contrary to the objective of the Victims of Offences Act 1987. Parliament passed that Act with the intention of making better provision for the treatment of victims of criminal offences by, among other things, ensuring in s 8 that appropriate arrangements are made to ensure that the sentencing Judge is informed about any physical or emotional harm suffered by the victim "through or by means of the offence" and "any other effects of the offence" on the victim. The wording does not suggest that the impact is restricted to the physical and emotional harm suffered as a direct result of the offence per se.

\footnotetext{
$\overline{17}$ For a discussion of the requirement of a factual basis for sentencing, see Edwards, above $\mathrm{n} \mathrm{14}$, at 299 and Hall, above $n$ 2, at 144-147.

$18 \quad R v$ Barrett [1999] 1 NZLR $146(\mathrm{CA})$ at 149-150.

19 At 150.
} 
However, in Schofield and Burns, Chambers J took a narrower approach to relevance, possibly limiting permissible content to the harm suffered as a direct result of the offence itself. In Schofield, Chambers J ordered the removal of a section of the victim impact statement written by the deceased's mother that described "an unfortunate episode involving a television crew" that occurred in the aftermath of the offence, and which formed part of its impact on her. Chambers $\mathrm{J}$ stated that as Mr Schofield was not responsible for this incident, it had no relevance to sentencing, and so should not have been included in the victim impact statement. ${ }^{20}$ Similarly, in Burns, he held that comments about the conduct of defence counsel at the trial should not have been included in a victim impact statement because they were irrelevant and unjustified: ${ }^{21}$

They reveal a misunderstanding of the role of defence counsel, albeit a misunderstanding that is shared by many of the community. There was nothing improper about the way defence counsel acted in this case. Mr Hart and his team vigorously upheld Mr Burns's rights throughout the trial. They probed the Crown case, as they were entitled and indeed required to do. There is nothing in this criticism and it was irrelevant.

Rather than characterising the victim's comments as criticism of defence counsel, they could have been understood as a description of the emotional harm suffered by the deceased's family during the trial. This is part of the harm caused by the offence. For the victims, it may not have mattered that defence counsel were "entitled and indeed required" to behave as they did, because their behaviour caused the victims further harm. In sexual violence cases in particular, there is evidence that robust cross-examination can be harmful to victims. ${ }^{22}$ While this type of harm may not be an inevitable result of the criminal conduct, it flows from the offending and the accused's decision to defend the charges.

It appears that in these cases the judge wanted to limit the harms resulting from the offence for which offenders can be held responsible. This is consonant with a retributive justification for sentencing, which is concerned with the blameworthiness of the criminal conduct. Von Hirsch argued that the sentence imposed conveys censure, and so it is important that it is proportionate to the degree of blameworthiness. A disproportionate

\footnotetext{
$20 \quad R v$ Schofield, above $\mathrm{n}$ 7, at [20].

$21 \quad R v$ Burns, above n 6, at [24].

22 Venezia Kingi and others Pathways to Recovery: Responding to Sexual Violence (Ministry of Women's Affairs, Wellington, 2009) at 31.
} 
sentence conveys an inaccurate moral message ${ }^{23}$ and offends commonsense notions of fairness. ${ }^{24}$ Under a retributive approach, taking into account harm for which the offender is not directly blameworthy is problematic because it may lead to the imposition of a disproportionately severe sentence and therefore an inappropriate degree of censure. However, deciding whether or not the offender is blameworthy for the harm in question is not a simple matter. There is debate in the academic literature about whether the harm caused in individual cases should be taken into account at all in assessing the seriousness of the offending, and if so to what extent. ${ }^{25}$ In New Zealand, the Sentencing Act 2002 requires judges to take into account any information about the effects of the offending on the victim, but does not provide any guidance on how to do so. ${ }^{26}$

Burns and Schofield do not provide any analysis that can assist in deciding which effects are relevant to the assessment of the seriousness of the offending. There may be a justifiable distinction between the type of harm in Barrett (which was considered relevant) and the harm in Burns and Schofield (which was not). However, the distinction has not been articulated in the case law. What is the difference between denying the offending when confronted by the victim's family (Barrett) and defending the charge (Burns)? Why were the actions of the victim's family in Barrett relevant, but the actions of the television crew in Schofield not? It seems that the decisions were value judgments about what it is fair to hold the offender accountable for. This is similar to the way in which tort law uses the concept of remoteness to limit liability for harm causally connected with a wrongful action. ${ }^{27}$ Lord Nicholls framed the remoteness inquiry as: ${ }^{28}$

... whether the plaintiff's harm or loss should be within the scope of the defendant's liability, given the reasons why the law has recognised the cause of action in

\footnotetext{
$23 \quad$ Andrew von Hirsch Censure and Sanctions (Clarendon Press, Oxford, 1993) at 14-15.

24 Andrew von Hirsch "Doing Justice: The Principle of Commensurate Deserts" in Hyman Gross and Andrew von Hirsch (eds) Sentencing (Oxford University Press, New York, 1981) 243 at 244-245.

25 For differing views, see Andrew Ashworth "Victim Impact Statements and Sentencing" [1993] Crim LR 498 at 503; Cavadino, above n 10; Andrew von Hirsch and Nils Jareborg "Gauging Criminal Harm: A Living Standard Analysis" (1991) 11 OJLS 1; Marvin Wolfgang "Basic Concepts in Victimological Theory: Individualisation of the Victim" in Hans Joachim Schneider (ed) The Victim in International Perspective (de Gruyter, Berlin, 1982) 47 at 47-57; Lynne Henderson “The Wrongs of Victim’s Rights" (1985) 37 Stan L Rev 937 at 999-1001.

26 Section $8(\mathrm{f})$.

27 For a discussion of remoteness in tort law see Geoff McLay and David Neild "Torts" in Peter Blanchard and others (eds) Civil Remedies in New Zealand ( $2^{\text {nd }}$ ed, Brookers Ltd, Wellington, 2011) 87 at 100-101 and 119-121.

28 Kuwait Airways Corp v Iraqi Airways Co [2002] UKHL 19, [2002] 2 AC 883 at [70].
} 
question. The law has to set a limit to the causally connected losses for which a defendant is to be held responsible.

If this inquiry was applied to sentencing, the task would be to identify the harm at which criminalisation of the conduct in question is directed. If a particular effect of the offending falls outside the scope of the harm the offence responds to, it may not be a relevant factor in the assessment of the seriousness of the offence. Phrased another way, if the effect in question was not a result risked by the offender when he or she engaged in that conduct, perhaps it should not be taken into account. This is because of the importance of blameworthiness in criminal law. However, this sort of analysis has not been undertaken. As a result, there is no clear, principled basis for restrictions on the inclusion of consequential loss or harm in victim impact statements. There is only a vague sense that some harms are too remote to be included.

\section{Victims should not use emotive language}

The courts have also sought to limit the emotional content of victim impact statements, again on the grounds of relevance. Chambers $\mathrm{J}$ explained this at the beginning of his judgment in Schofield: ${ }^{29}$

Every judge on sentencing must be on his or her guard to ensure that the sentencing process is not improperly swayed by sympathy for the victims of crime. The effect of the crime on a victim or victims is always an important aspect of sentencing. But it is only one aspect. The sentencing judge is enjoined by law to consider a range of factors when sentencing. It would be inappropriate for victims of crime or the police to try to sway the judge emotionally by unduly sensational or emotive victim impact statements.

There is a concern that the inclusion of emotional content in victim impact statements can make it more difficult for judges to make decisions, by distracting them from legally relevant information or requiring them to expend effort to extract specific facts about the effects of the offending. These ideas can be seen in a passage from Burns, in which Chambers J said: ${ }^{30}$

There needs to be some control by the police and the Crown over the content of these statements. In $R v$ Haddon (1990) 6 CRNZ 508, the sentencing judge was presented with statements which were couched in strongly emotional terms. The Court of Appeal in that case emphasised that victim impact statements "must be

\footnotetext{
$29 \quad R v$ Schofield, above $\mathrm{n} 7$, at [8]

$30 \quad R v$ Burns, above $\mathrm{n} 6$, at [20].
} 
factual and relevant. Otherwise they are likely to hinder rather than help the sentencing judge in his task."

In the cases the judges have drawn a sharp distinction between content that is "factual and relevant" (and therefore permissible in a victim impact statement) and content that is "emotive" (and should therefore be excluded). However, this approach may prevent victim impact statements from conveying information about emotional harm, thereby depriving the court of information necessary to assess the seriousness of the offence. A preferable approach can be found in the more recent case of $R v$ Ofakineiafu, in which the Court of Appeal said: ${ }^{31}$

Criticisms of victim impact statements must be assessed with a sense of realism. If such statements are stripped of all emotive language, there is a risk they will not authentically express the views and feelings of victims. Further, there is more than one way in which information about the matters provided for in s 17 of the Victims Rights Act 2002 can be conveyed to the Court. For instance, anger on the part of a victim can be seen as being amongst the "effects of the offence on the victim". That a victim is angry can be conveyed directly (by the victim saying that he or she is angry) or indirectly (by the victim expressing that anger in what is said). As well, a sentencing Judge can be expected to pick up from a victim impact statement what is relevant and to discard the balance.

In some of the earlier cases, information about emotional harm conveyed indirectly seems not to have been recognised as effects of the offence on the victim. For example, in Schofield, Chambers J stated that the mother of the deceased could describe "the horror she experienced as she watched her son die" but that this did not "necessitate" information about his medical treatment and what was happening to his body (as relayed to her by the doctors). ${ }^{32}$ Again, by including this information she was describing her own experience immediately after the offence occurred and her subsequent experience of thinking about her son's suffering. In both these cases, the passages in question described the emotional impact of the offending on the victim, and were therefore relevant considerations for the sentencing judge.

As the Court of Appeal pointed out in Ofakineiafu, sanitised, detached descriptions cannot fully convey the emotional impact of offending, particularly in serious cases. ${ }^{33}$ The courts in the earlier cases, however, seem to be asking for objectivity from victims in

\footnotetext{
31 $\quad R$ Ofakineiafu CA301/04, 8 December 2004 at [10].

$32 \quad R v$ Schofield, above $\mathrm{n} 7$, at [20].

$33 \quad R v$ Ofakineiafu, above n 31, at [10].
} 
their victim impact statements, in line with ideas about the requirements of procedural fairness. The inherently subjective nature of emotional harm makes this unrealistic. ${ }^{34}$ Requiring victims to use non-emotive language limits the information which can be provided to the court, affecting the ability of the court to assess the seriousness of the offence in order to impose a proportionate sentence.

\section{Victims should not include their views on the sentence that should be imposed}

Finally, the courts have held that victims should not include in their victim impact statements any views on the sentence that should be imposed on the offender. In Burns, Chambers $J$ stated that it is "well established that victim impact statements should not contain opinions as to penalty." 35 His discussion was limited to the citation of two passages in support of his conclusion, the first of which was from $R v B .^{36}$ The judge in that case held that: ${ }^{37}$

$\ldots$ it is ...quite inappropriate for the victim to be asked to suggest the punishment to be imposed and for that suggestion to be placed before the Court. The one exception to that is where the victim volunteers a plea of clemency or compassion.

Unfortunately neither judge discussed the difference between a plea of clemency and any other sort of plea. It is likely that implicit in their decisions was the well-established principle of penal parsimony, which states that "the least restrictive sanction necessary to achieve defined social purposes should be imposed." ${ }^{38}$

The second passage Chambers J quoted in support of his statement in Burns was from $R v$ Hopkirk $^{39}$. The Judge in Hopkirk noted that the victim impact statement in that case breached the Victims of Offences Act 1987: ${ }^{40}$

... by tendering advice to the sentencer in emotive language as to the correct attitude of the Court to the imposition of penalties for sexual offending. The purpose of such a report is to inform the sentencer of the impact of the particular offence or offences for which sentence must be imposed on the particular victim, and it is important that the nature of the reporter's role be recognised. Edna Erez "Who's Afraid of the Big Bad Victim? Victim Impact Statements as Victim Empowerment and Enhancement of Justice" [1999] Crim L Rev 545 at 554-555.

$35 \quad R v$ Burns, above $\mathrm{n}$ 6, at [21].

$R v B$ HC Dunedin S8/89, 14 June 1989.

$R v$ Burns, above $\mathrm{n} 6$, at [21].

Norval Morris The Future of Imprisonment (University of Chicago Press, Chicago, 1974) at 59. This principle is reflected in s 8(g) of the Sentencing Act 2002.

$R$ v Hopkirk (1994) 12 CRNZ 216 (CA).

$R v$ Hopkirk, above n 39, at 219.
} 
Chambers J's decision in Burns is consistent with the wording of s 8 of the Victims of Offences Act (in force at the time) and the identical wording of s 17 of the Victims' Rights Act. There is nothing in the legislative language suggesting that victim impact statements were intended to convey victims' views on sentence to the court. Indeed, the Select Committee considering the Victims' Rights Bill 1999 decided against allowing victims to include their views on sentence in their victim impact statements, despite the arguments put forward by some parties that this should be permissible. ${ }^{41}$

In New Zealand, it is reasonably clear that the victim's views on sentence are not to be taken into account when assessing the seriousness of the offence. $R v$ Taueki (the guideline judgment for serious violence) explicitly stated that a victim's plea for leniency is not relevant to the seriousness of the offence. ${ }^{42}$ Presumably this also applies to a victim's request for a harsh sentence. The concern is with the wrongfulness of the offender's conduct, rather than the victim's views on the appropriate sentence, because of the public interest involved in criminal cases. ${ }^{43}$ This approach is not universal, however. In his article about the place of victims' views on the sentence in England and Wales, Edwards summarised a series of cases in which the courts held that an expression of forgiveness or an unwillingness to proceed with prosecution could be taken into account as evidence that the harm to the victim was less than would normally be expected, and could therefore mitigate the sentence. ${ }^{44}$ However, Edwards' criticised an approach which equates an expression of forgiveness with evidence of limited suffering: ${ }^{45}$

The link between forgiveness and lack of harm is to some extent a fallacious one. It seems to imply that those who find themselves able to feel and express forgiveness must necessarily be suffering less than those who do not. It implies that those who do not express forgiveness must be suffering more. This reasoning fails to address deeper complexities. By equating forgiveness with a lack of harm the Court of Appeal has tried to accommodate the difficult issue of forgiveness within a sentencing framework guided by proportionality. This reasoning provides no guidance to courts on how to deal with situations in which the victim feels able to forgive, but has suffered, and continues to suffer, physical and psychological injuries as a result.

\footnotetext{
41 Victims' Rights Bill 1999 (331-2) (select committee report) at 20 and 33-34.

$42 \quad R v$ Taueki [2005] 3 NZLR 372 (CA) at [33].

43 Ian Edwards "The Place of Victims' Preferences in the Sentencing of "Their" Offenders" [2002] Crim LR 689 at 671.

$44 \quad$ At $697-701$.

$45 \quad$ At $698-699$.
} 
The approach in that series of cases also overlooks the multitude of reasons a victim may not wish to proceed with a prosecution that are independent of the level of harm suffered. In New Zealand, however, it seems relatively settled that a victim's views on sentence are not relevant to the assessment of the seriousness of the harm. I support this approach, for the reasons Edwards set out.

The courts' exclusion of the victim's views on sentence from the permissible content of victim impact statements would therefore be unproblematic if victim impact statements were only to provide information relevant to the assessment of offence seriousness. However, the restriction may not be as easily justified if protection of the interests of the victim is treated as a purpose of victim impact statements. I argue in Part $\mathrm{C}$ that victims should have the opportunity to include their views on sentence, where they are relevant to their interests in reparation, the prevention of further harm from the offender and prevention of further harm to the victim from the sentence imposed on the offender.

\section{Summary}

In accordance with their decision that the primary purpose of victim impact statements is to provide relevant information, the courts have imposed a number of restrictions on the permissible content of victim impact statements. Victims may not include in their victim impact statements information about the facts of the offending or other alleged offences or misconduct by the offender; some types of consequential loss or harm; unduly emotive language; or their views on the sentence that should be imposed. The justification for these restrictions is that these types of information are not relevant to the assessment of the seriousness of the offending. However, uncertainty about the precise role of harm suffered by the victim in the assessment of offence seriousness means that the justification for the first three categories of restrictions is unclear. The fourth category of restriction, views on sentence, is justified on the basis of irrelevance to the assessment of offence seriousness. However, the victim's views on sentence are relevant to other enquiries which should be made at sentencing, but which the courts have not yet given due attention.

The current conceptualisation of the purpose of victim impact statements, and the restrictions on permissible content flowing from it, mean that making a victim impact statement is of little benefit to victims and can cause them further harm. I turn now to a discussion of these problems in depth. 


\section{The Limits of the Current Approach in Meeting Victims' Needs and Protecting their Interests}

The current approach to victim impact statements limits the extent to which they can meet victims' needs and protect their interests. The needs which victim impact statements could meet, but currently do not, are recognition, acknowledgement and assistance with recovery. The interests which victim impact statements could protect more effectively are reparation and prevention of further harm from the offender and from the sentence imposed on the offender. The failure to meet victims' needs and protect their interests can leave them feeling as if justice has not been done, and result in further physical, emotional, and material harm.

The current restrictions on content can prevent victims from describing what may be a highly significant experience in a way that is meaningful to them. This is illustrated by the quotes from victims in the media, discussed in the introduction to this dissertation. This means that the wrongfulness of the offending, from the victim's perspective, may not be fully recognised by the court in a formal way. Moreover, the harm suffered by the victim may not be formally acknowledged by the court. The result of failing to meet victims' needs for recognition and acknowledgement is that victims may be left feeling as if justice has not been done. Further, the restrictions limit the extent to which making a victim impact statement can promote victims' recovery. As I argue fully in Chapter III, recovery (from serious offending such as sexual violence, at least) involves making sense of the experience. When victims have to leave out key aspects of their experience, or are unable to discuss it in their own way, making a victim impact statement is unlikely to meet victims' needs for assistance with recovery.

In this section, I discuss ways in which the current approach limits the potential of victim impact statements to protect victims' interests. First, the restrictions on the permissible content of victim impact statements can prevent information about the harm and loss suffered by victims from being submitted to the sentencing judge. This means that victims may miss out on reparation for certain types of harm or loss. Secondly, the restrictions can prevent information about the ongoing risk posed by the offender from being submitted. As a result, the sentencing judge may not impose a sentence providing enough protection of the victim from further harm from the offender. Thirdly, the restrictions on content prevent the victim's views on sentence from being included in the victim impact statement. This increases the likelihood that the sentence imposed on the offender will cause further emotional and material harm to the victim. Other avenues currently exist for all of this information to be provided to the sentencing judge. 
However, in some cases victim impact statements may be the best vehicle for its submission to the sentencing judge. Preventing victims from including it jeopardises the ability of the court to protect their interests.

\section{The victim's interest in reparation}

One of the purposes for which a sentence may be imposed is to provide reparation to the victim. ${ }^{46}$ There is a statutory presumption that reparation will be awarded unless it would cause undue hardship to the offender. ${ }^{47}$ The court may order a reparation report to be prepared, covering the loss or harm suffered and the offender's means to pay. ${ }^{48}$ This information may also be provided in other ways, including through a victim impact statement. However, the current restrictions on content (discussed in Part B above) limit the extent to which victim impact statements can provide information relevant to the assessment of reparation. First, the restrictions on emotive language may prevent the sentencing judge from being informed of the full extent of the emotional harm suffered by victims as a result of the offending. Secondly, the remoteness limits may prevent judges from being informed of loss or harm consequential on physical or emotional harm or property loss or damage, for which reparation may also be awarded. ${ }^{49}$

While some information about emotional harm and consequential harm and loss may be provided by a reparation report, the current process does not ensure that it is. Reparation reports are not prepared in every case and they are not necessarily prepared by a person whose role it is to ensure that the victim's interests are properly represented. Victim impact statements are therefore important because they can provide information which may otherwise be missed. The current restrictions on content limit their effectiveness in assisting the judge to assess reparation.

\section{The victim's interest in prevention of further harm from the offender}

Protection of the community from the offender is another purpose for which the sentence may be imposed. ${ }^{50}$ Information victims have about the level of risk posed by the offender to the victim or to others may therefore be relevant to the sentencing decision. Most obviously, this information is relevant to the sentencing judge's decision whether or not to make a protection order when there was a domestic relationship between the victim

\footnotetext{
$46 \quad$ Sentencing Act, s 7(1)(d).

$47 \quad$ Sentencing Act, s12.

$48 \quad$ Sentencing Act, ss 33 and 34.

49 Sentencing Act, s 32(1)(c).

$50 \quad$ Sentencing Act, s $7(1)(\mathrm{g})$.
} 
and the offender, and the offence was one of domestic violence. ${ }^{51}$ Further, the victim's information could also assist the judge to determine appropriate conditions of sentence if a non-custodial or a short-term custodial sentence is imposed. ${ }^{52}$ It could also affect the decision whether to impose a custodial or non-custodial sentence, ${ }^{53}$ the length of a custodial sentence and whether a minimum period of imprisonment is imposed. ${ }^{54}$ Finally, it could influence whether preventive detention is sought by the Crown when the offender has been convicted of a qualifying offence. ${ }^{55}$

If victims have information about the risk posed by the offender, it will usually be in circumstances when a relationship between them existed prior to the offending. As victims are not usually interviewed for pre-sentence reports (which are the primary way in which information about risk is submitted to the court), there is no mechanism for ensuring that judges are informed of any concerns. If the information is submitted to the court at all, it is by the prosecutor. However there is currently no way of ensuring that prosecutors ask victims for their views or submit any information the victim has provided. Victim impact statements are another way in which victims could inform the court of any concerns they have about their own or others' safety from the offender. However, the current restrictions on content may prevent victims from informing the judge of any concerns they have. In particular, the restrictions on referring to other alleged offences and alleged misconduct by the offender may prevent this from occurring.

Some victims may not wish to provide this information in their victim impact statements for fear of reprisal from the offender or associates. In addition, allowing this sort of information to be included in a victim impact statement raises concerns about fairness to the offender. On the other hand, the victim may be the person most at risk from the offender in the future, and may have the most information about the risk posed to others by the offender. Any concerns the victim has should be considered by the court, because they are relevant when the protection of the community is a purpose of sentencing. However, there is currently no robust process for ensuring this occurs, limiting the extent to which the court can protect the victim's interest in safety from the offender and promote the safety of the wider community.

\footnotetext{
Sentencing Act, ss $123 \mathrm{~A}-123 \mathrm{G}$.

52 Sentencing Act, ss 49, 50 and 52; 80C, 80D, 80O and 80P; and 93.

53 Sentencing Act, s 16.

$54 \quad$ Sentencing Act, s 86.

$55 \quad$ Sentencing Act, s 87.
} 
3 The victim's interest in prevention of further harm from the sentence imposed on the offender

Victims are affected by the sentence imposed on the offender, particularly when a relationship existed between them prior to the offending. The sentence may affect the victim emotionally and, especially when there is a continuing relationship, have social and material implications for the victim and the victim's dependents. Despite the potential impact of the sentence on the victim, victims are currently prohibited from including any views on the sentence to be imposed on the offender in their victim impact statements, as discussed in Part B.

This position does not mean that the courts never take into account a victim's views on the sentence. Indeed, the Court of Appeal has held that sentencing judges are required to take into account any views on sentence expressed by victims, at least when the victim makes a request for leniency. ${ }^{56}$ However, rather than submitting their views to the court through their victim impact statements, victims must rely on either the prosecutor or defence counsel to convey their views to the sentencing judge. There is no mechanism to ensure that victims' views are routinely sought by the prosecutor, so many victims may be unaware that their views can be taken into account. Further, as prosecutors represent the state and defence counsel represent their clients, neither may be in a position to fully represent the victim's interests at sentencing. Having defence counsel submit victims' requests for leniency poses a particular risk to victims, as it may be difficult to ascertain whether the requests are genuine or the result of pressure from the offender or others. Defence counsel cannot protect the interests of both the victim and the offender in this situation. Victims' interests therefore remain unrepresented at sentencing. The current approach to victim impact statements leaves victims without an effective way of conveying their views on sentence to the court, so their interests may not be taken into account.

Even when the victim's views on sentence are submitted to the court, they may not be taken into account in a way that actually protects the victim's interests. There is no case law suggesting that a request for a severe sentence can be taken into account. However, two (conflicting) approaches to requests for leniency can be found. Requests for leniency tend to be made in cases where there is an ongoing relationship between the victim and the offender, particularly when they have children together. I describe the two

56 $R v$ Hadland CA 204/01, 25 September 2001 at [12]; $R v H$ CA248/02, 24 October 2002 at [16]; $R v$ Iona CA416/02, 27 March 2003 at [23]-[24]; $R v W$ CA352/05, 5 December 2005 at [22]; $R v$ Taueki, above n 42, at [33]. 
approaches below, and explain why neither provides adequate protection for the victim's interest.

In the first approach, a small reduction in the sentence may be made in accordance with a victim's request for leniency, as long as the sentence is still long enough to achieve accountability, denunciation and deterrence. The first in the line of cases constituting this approach was Hadland, a sexual violation case. The Court of Appeal held: ${ }^{57}$

Although a victim's views are not necessarily persuasive and may not even be taken into account, the views expressed by the complainant in this case deserve respect. The Court has, in the past, taken into account a victim's wishes and also the interests of an offender's family in reducing an otherwise appropriate sentence. This is for the purpose of avoiding further victimisation of the victim and other innocent members of an offender's family.

In a second sexual violation case, $H$, the Court of Appeal stated that the sentencing purposes of holding the offender accountable, denunciation, and deterrence must be weighed against a victim's request for leniency. ${ }^{58}$ In Iona the Court of Appeal emphasised that the victim's views are one of a number of factors to be taken into account. It cited s 8 of the Sentencing Act, which sets out the principles of sentencing, to emphasise this point. ${ }^{59}$ Consistent with Hadland, $H$ and Iona, Taueki (the guideline judgment for serious violence issued by the Court of Appeal in 2005) is authority for the rule that a request for leniency can be taken into account but does not outweigh the public interest. ${ }^{60}$ Finally in this line of cases, $R v W$, another sexual violation case, confirmed the approach, but framed the ability of the sentencing judge to consider a victim's request for leniency as a requirement: ${ }^{61}$

It is correct that a sentencing Judge is required to consider a complainant's forgiveness, and the impact of a sentencing upon that person. However, this Court has consistently held that a complainant's views do not outweigh the public interest in holding an appellant accountable, denouncing his conduct, and deterring others.

While judges are allowed or required to consider a request for leniency under this approach, there is no guarantee that it will be given any weight or enough weight to make any real difference to the victim. Additionally, this approach offers no assistance to

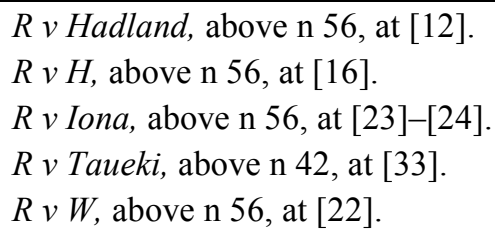


victims who believe they would be harmed by the imposition of a more lenient sentence than they would like.

An alternative approach to requests for leniency can be found in $R v A M$, the guideline judgment for sexual violation issued by the Court of Appeal in $2010 .^{62}$ The Court here seems to have taken a less permissive approach to the consideration of a request for leniency than the case law up to that point. ${ }^{63}$ The Court listed reasons why such requests are problematic: ${ }^{64}$

Where sexual offending occurs within a family or social group, victims are frequently under pressure either not to involve the criminal justice system or to withdraw from it. Defying this pressure can have adverse consequences in terms of family or social rifts and resulting ostracism. The circumstances of the present case... in which $\mathrm{C}$ has suffered as a result of the fracturing of the wider family, are not untypical. Unsurprisingly, judges often treat victims' calls for leniency with caution, seeing them as likely to be the result of illegitimate family or social pressure. Giving effect to such calls may lead to increased pressure on other victims. Judges are required to treat like cases alike.

Sentencing Judges could interpret this passage as signalling the need to exercise extra caution about requests for leniency. It may have the effect of making it unlikely that a request will ever be given weight. ${ }^{65}$ The problem with it is that the views of victims who are not subject to pressure may be dismissed, either on the grounds that they might be the result of pressure or that considering them creates an incentive for pressure to be placed on other victims. The interests of victims who willingly make a request for leniency on the grounds that a more severe sentence would cause them further harm will not be protected under the $A M$ approach. Accordingly, neither approach to requests for leniency ensures that the victim's interest in the prevention of further harm from the sentence imposed on the offender will be protected.

62 RvAM(CA27/2009) [2010] 2 NZLR 750.

63 This approach is consistent with changes under the Evidence Act 2006, in particular the removal of spousal immunity and the ability to rely on the complainant's previous out-of-court statements. Prosecutions can now continue where they would previously have been dropped because the complainant was unwilling to give evidence. See the discussion in Singh $v R$ [2010] NZSC 161, [2011] 2 NZLR 322 at [21]-[23].

64 At [63].

65 However, see $B v R(C A 65 / 11)$ [2011] NZCA 173 at [23]-[26], in which the Court of Appeal cited the passage in question but gave the views of the victim as one reason for reducing the sentence on appeal. 
In addition to increasing the likelihood of poor outcomes for victims, the current approach to victim impact statements is problematic for victims from a procedural perspective. I turn to this now.

\section{Procedural Problems with the Current Approach}

There are two quite serious problems with the current processes for the preparation, submission and consideration of victim impact statements. First, the lack of a robust process for considering victims' views relevant to their interests in the sentence is disrespectful and unfair to victims. Secondly, the lack of information victims are given when writing their victim impact statements, and the presentation of making a victim impact statement as compulsory, can cause victims further distress. As well as causing victims further harm, these two problems can contribute to victims' sense of alienation from the criminal justice process. I discuss each of them in turn.

1 The lack of a robust process for consideration of victims' views relevant to their interests in the sentence

The current approach to the consideration of victims' views on sentence can leave victims feeling that the sentencing process is unfair to them and that they have not been treated with respect and consideration. The case of $K M v$ Police illustrates this. ${ }^{66}$ It was an appeal to the High Court against the sentence imposed for violence committed by the offender against his partner and two sixteen year old daughters. The Judge noted: ${ }^{67}$

[Defence counsel] told me that the victims (who were present in Court when KM was sentenced and in this Court on appeal) felt a sense of grievance at the way in which the District Court Judge had, in their minds, been dismissive of their views. They want the family reunited and do not see merit in KM's continued detention in custody. They felt their views had not been given any weight notwithstanding their distress at the possibility of losing a partner and a father (respectively) for some time.

The Judge went on to explain that this was not a failing on the part of the sentencing Judge, but a reality of District Court practice:

[33] I am very reluctant to criticise a District Court Judge for the way in which such issues are addressed in Court. In a perfect world District Court Judges would be able to take time to consider the views of victims in a more measured fashion and, if they

\footnotetext{
K6 KM volice HC Auckland CRI 2004-404-440, 8 December 2004. $67 \quad$ At [32].
} 
had doubts as to the genuineness of views expressed, would interact with the victims, through counsel or the Victims' Adviser, to ascertain the true position. Regrettably, most District Court Judges are required to work in busy Courts in which time for reflection and a measured approach is at a minimum. Those comments are not intended as excuses for standards falling below what ought to be expected, but they do provide some explanation of why that sometimes occurs, particularly from the perspective of a victim.

[34] I make these points for the benefits of the victims who have expressed concerns to me through [defence counsel]. Nothing I have said amounts to a criticism of Judge Harvey for the way in which he conducted himself on this particular occasion.

It would be understandable if this explanation provided little solace for the victims. The sentencing decision was likely to have been very important to them, as the sentence affected their daily lives for a considerable period and impacted on the family as a whole. Given the extent to which the interests of some victims are affected by the sentence imposed on the offender, there should be a process for ensuring that victims' views are given due consideration. As far as possible, this process should also ensure that victims feel that their views have been treated seriously. While the outcome in $K M$ may have been the same even if the victims' views had been considered fully, their sense of grievance at the dismissal of their views may have been reduced. ${ }^{68}$

Requests for leniency made by victims of offending occurring within families or intimate relationships raise very difficult issues. As noted earlier, judges must ensure that these requests are not the result of improper pressure on victims. Additionally there is a concern that considering them at all will lead to pressuring of other victims. ${ }^{69}$ Sentencing judges must also consider the need to keep the victim and others safe from the offender, and the need to denounce the conduct and deter the offender and others. ${ }^{70}$ Finally, acting in the public interest could require the courts to consider the costs to the collective welfare that may result from allowing relationships containing violence to continue. These costs include increased use of health services by the victim, police time if there are further incidents, and the long-term impact on any children witnessing the violence. These are all important considerations, and they should not be treated any less seriously than they currently are. However, the current approach does not take seriously enough

\footnotetext{
68 For further discussion of the importance of process as well as outcome, see Laura Hickman and Sally Simpson "Fair Treatment or Preferred Outcome? The Impact of Police Behavior on Victim Reports of Domestic Violence Incidents" (2003) 37 Law and Society Review 607.

$69 \quad R \vee A M$, above $\mathrm{n}$ 62, at [63].

$70 \quad$ Sentencing Act, s 7(1)(e)-(g).
} 
the impact on the victim of the imposition of a sentence which is contrary to the victim's wishes and which the victim believes will cause him or her further harm.

While a paternalistic approach may sometimes be justified, this should not be a decision made lightly or without hearing the victim's perspective in full. $H$ provides an illustration of a case where the sentencing judge took a paternalistic approach, substituting her own view of the relationship (based on the evidence in the case) for the victim's. The Court of Appeal summarised the victim's views as follows: ${ }^{71}$

At the time of sentencing the complainant wrote a letter to the Judge in which she explained that she and the appellant had been through a lot, that together they had a wonderful daughter who had a very strong and close bond with the appellant, that their daughter was wondering why she has not seen her father, and that she had been greatly upset by his absence. The complainant also told the Judge that her son, the appellant's step-son, was also very close to the appellant and was missing him dearly. She said that although the relationship had been through a lot of "ups and downs" their love for each other was still there and she would stand by the appellant "the whole way". She felt that she had been backed into a corner and pressured by the police to give evidence. The complainant said that she held herself " $50 \%$ to blame" for what had happened and indicated that whatever punishment "you give us we will face together with our children until he can come home and we can rebuild our life and our family."

However, the sentencing Judge took a different view of the relationship between the victim and the offender: ${ }^{72}$

Despite the complainant's expressions of love for the appellant, the sentencing Judge's analysis was that the appellant always expected to have his way without regard to the complainant's wishes and that whenever the complainant was less than compliant she suffered physically. It was the Judge's view that what the appellant said and did during the night in question demonstrated an attitude of arrogance and contempt towards the complainant and that in some ways this had been confirmed by the probation officer's report. The Judge noted that the appellant had four previous convictions for violence, the most recent having involved the complainant, and that the offending had involved violence additional to that in the act of rape in the sense that the appellant had been prevented from leaving the house.

\footnotetext{
71 $R v H$, above n 56, at [11].

72 At [12].
} 
As noted in the passage quoted, the sentencing Judge's view was formed on the basis of the evidence in the case and the pre-sentence report. While certainly an outside perspective can be valuable, it is questionable whether the Judge had enough information about the relationship to assume that her understanding of it was more reliable than the victim's. If a victim's request for leniency is given little weight because the judge sees a need to protect the victim from further violence, the judge is effectively saying that he or she knows better than the victim what is in the victim's best interests. There may be situations where this is justified. However, before acting paternalistically, the judge should be satisfied that the potential harm to the victim from the offender is more serious than the other types of harm the victim might suffer from a more severe sentence.

Accordingly, careful consideration of the circumstances of each case is required. This was the approach advocated by the High Court in $K M:^{73}$

What a Judge, sentencing on domestic violence charges, must guard against is the assumption that every positive comment (in every case) by a victim in favour of an offender should be discounted because of the possibility of inappropriate influence by the offender. Each case requires careful consideration of its own circumstances.

Failing to take the time to consider the circumstances of each case means that victims are treated unfairly and disrespectfully, increasing their sense of exclusion and alienation from the process.

\section{Risks of further harm from the current process for the preparation and submission of victim impact statements}

There is no clear process for informing victims of the purpose of victim impact statements, their likely effect on the sentence, or their permissible content. This means that when writing their victim impact statements, people may include material they should not. When victims wish to read their victim impact statements at the sentencing hearing, any inclusion of impermissible content is addressed by giving the victim a "censored" copy to read out. As illustrated by the quotes at the beginning of this dissertation, the insensitivity of this process and the lack of explanation for it can cause victims further distress. An additional concern, often cited in the academic literature, is that asking victims to make victim impact statements can raise their expectations about the effect they will have on the sentence. If these expectations are not fulfilled, victims

73 KM Police, above $\mathrm{n} 66$, at [35]. 
may be hurt and disappointed. ${ }^{74}$ As victims are likely already to be vulnerable from the impact of the offending and their earlier involvement in the process, all these concerns need to be taken seriously.

Also of concern is victims' lack of choice about whether to submit a victim impact statement for sentencing. Section 17 of the Victims' Rights Act requires "prosecutors to make all reasonable efforts to ensure that information is ascertained from the victim" about the impact of the offending. However, victims may prefer not to provide this information to the court. Feeling or being told they are obliged to do so may cause further harm and have an adverse impact on their recovery. ${ }^{75}$

In Chapter III, I discuss principles for the design and implementation of victim impact statements which minimise the likelihood that making a victim impact statement could cause victims further harm. Information about the purpose, use and permissible content of victim impact statements, support and guidance when preparing them, and having a genuine choice whether to make a victim impact statement are three of these principles. I turn now to a discussion of the second procedural problem with the current approach to victim impact statements, the way in which courts take into account the victim's views on sentence.

\section{E The Necessity of Fundamental Reform of Victim Impact Statements}

So far in this chapter, I have discussed how the courts' decisions that the primary purpose of victim impact statements is to provide information relevant to sentencing led them to impose restrictions on the permissible content of victim impact statements. I have argued that these restrictions limit the extent to which victim impact statements can meet victims' needs for recognition, acknowledgement, and assistance with recovery. I have argued that they also limit the extent to which victim impact statements can protect victims' interests in reparation and prevention of further harm from the offender and the sentence imposed on the offender. The very limited extent to which victim impact statements can meet victims' needs and protect their interests can leave victims feeling that justice has not been done, and cause them further physical, emotional and material harm. Finally, I have argued that the lack of robust processes around the preparation and submission of victim impact statements and the consideration of the victim's views on

\footnotetext{
74 See for example Andrew Ashworth "Victims' Rights, Defendants' Rights and Criminal Procedure" in Adam Crawford and Jo Goodey (eds) Integrating a Victim Perspective within Criminal Justice: International debates (Dartmouth Publishing, Aldershot, 2000) 185 at 198.

75 This argument will be made in more depth in relation to sexual violence victims in Chapter III.
} 
sentence is disrespectful and unfair to victims, and can cause them further distress. The need for reform of victim impact statements is clear.

Some suggestions for reform have already been made in the New Zealand context. In Section 1, I discuss the provisions relating to victim impact statements in the Victims of Crime Reform Bill, which is currently before the Justice and Electoral Select Committee. The Bill does not address the fundamental problems with the current approach to victim impact statements. Victim impact statements remain an instrument in the case between the state and the offender and the Bill does not increase in any significant way the extent to which they can meet victims' needs or protect their interests. In Section 2, I discuss an earlier academic article by Peter Sankoff. He suggested that increasing victim satisfaction should become the purpose of victim impact statements. I argue that while increased satisfaction is a desirable result of changing victim impact statements, it should not be the value underpinning changes or the measure of their effectiveness. Accordingly, an adequate alternative to the current approach to victim impact statements has yet to be advanced.

\section{The Victims of Crime Reform Bill}

When the Bill was introduced, the Minister of Justice claimed that it would empower victims and make the criminal justice process more responsive to their needs, ${ }^{76}$ and protect them from secondary victimisation. ${ }^{77}$ However, the proposals in relation to victim impact statements achieve none of these goals. They do not address effectively any of the issues with the current approach to victim impact statements I have raised in this chapter.

The purpose of victim impact statements set out in the Bill is largely a re-statement of the current purpose, with its focus on provision of information about the effects of the offending. The only significant difference is that the proposed purpose has left out any reference to aiding victims' healing. It reads as follows: ${ }^{78}$

\footnotetext{
76 Andrea Vance "Children's drawings to be allowed in court" (Wellington, 16 August 2011) $<$ http://www.stuff.co.nz/national/crime/5453267/Childrens-drawings-to-be-allowed-in-court>.

77 Andrea Vance "Reforms to give victims greater freedom in court" (Wellington, 20 April 2011) $<$ http://www.stuff.co.nz/national/politics/4911146/Reforms-to-give-victims-greater-freedom-incourt>; "Sophie's dad says victim impact statement censored" (Wellington, 13 November 2009) $<$ http://www.stuff.co.nz/national/crime/3059154/Sophies-dad-says-victim-impact-statementcensored $>$.

78 Victims of Crime Reform Bill 2011 (319-2), cl 11.
} 
The purpose of a victim impact statement is to -

(a) enable the victim to provide information to the court about the effects of the offending; and

(b) assist the court in understanding the victim's views about the offending; and

(c) inform the offender about the impact of the offending from the victim's perspective.

Assisting the court to understand "the victim's views about the offending" could possibly widen the purpose slightly. ${ }^{79}$ However, the vagueness of the phrase and the lack of direction that the courts should take the victim's views into account in the sentencing decision make it unlikely that this section will effect any real change to the use or permissible content of victim impact statements.

Despite the Minister's assertions to the contrary, it is not clear that the Bill will make more content permissible in victim impact statements. ${ }^{80}$ The current s 17 of the Victims' Rights Act states that victim impact statements should inform the judge of any physical injury, emotional harm, loss of or damage to property, and any other effects of the offence. The Bill adds to s 17 "any other matter consistent with the purpose of victim impact statements set out in section 17AB." 81 However, as the Bill does not appear to change the purpose of victim impact statements, it is unlikely that this addition will have any significant effects on the permissible content.

Under the Bill, victim impact statements would still be limited in the extent to which they can meet victims' needs for recognition, acknowledgement and assistance with recovery. The Bill enacts a presumption that victims of specified offences will have the opportunity to read their victim impact statements at sentencing hearings. ${ }^{82}$ For some victims, reading their victim impact statement at the hearing could allow them to feel that their experience has been recognised and acknowledged, and it could assist with their recovery. However, increasing the likelihood that some victims will have the opportunity to read their victim impact statements at the hearing is likely to be of limited effectiveness in meeting victims' needs. Victims will still be subject to quite severe restrictions on the permissible content of victim impact statements. Further, no process has been introduced to avoid "censorship" of victim impact statements. The Bill

\footnotetext{
79 This was a concern raised by the Chief High Court and District Court Judges in their submission on the Bill. See The Hon Justice Winkelmann and Her Honour Judge Doogue "Victims of Crime Reform Bill" at 1.

80 Simon Power "Unanimous support for bill to enhance victims' rights" (press release, 4 October 2011) <http://beehive.govt.nz/release/unanimous-support-bill-enhance-victims039-rights $>$.

$81 \quad$ Clause 12.

$82 \quad$ Clause 15.
} 
therefore does little to prevent further distress being caused to those who wish to read their victim impact statements at the hearing. Finally, there are no changes in the Bill which would allow victim impact statements to better protect victims' interests in the sentence, or which enact a fairer and more respectful process for considering victims' views relevant to their interests.

\section{Academic literature on options for reform}

A suggestion for a change in the purpose of victim impact statements was made in an article by Peter Sankoff in 2007. ${ }^{83}$ Citing the political rhetoric around the introduction of the Victims' Rights Act and the Sentencing Act, Sankoff argued that Parliament intended victim impact statements to give victims a more satisfying experience in the criminal justice process. He believed that the courts frustrated this intention when they adopted information provision as the primary purpose of victim impact statements. ${ }^{84}$

Drawing on work by Edna Erez, Sankoff explained victim satisfaction as a combination of procedural and therapeutic goals: ${ }^{85}$

... victim satisfaction is about providing victims with the ability to "engage in the criminal justice process" and "reduce the power imbalance they felt with the defendant, resolve the emotional aspects of the [crime], achieve emotional recovery, or achieve formal closure."

Sankoff's idea that victim impact statements could increase victims' satisfaction should be approached with caution. Increased satisfaction might be one result of making changes to victim impact statements, but it should not in itself be the justification for changes or the measure of their effectiveness. Changes to the processes around preparation and submission of victim impact statements and the consideration of victims' views on sentence could make victims feel more satisfied that they have been treated with respect and consideration, and that their interests have been taken into account. Victims' satisfaction with the sentencing outcome itself might also be increased if their interests in the sentence are given due consideration.

Increasing victims' satisfaction should not be the reason for making changes to victim impact statements. Rather, changes should be made because they are necessary to

\footnotetext{
$83 \quad$ Peter Sankoff "Is Three Really a Crowd? Evaluating the Use of Victim Impact Statements under New Zealand's Revamped Sentencing Regime" [2007] NZ L Rev 459.

84 At $472-479$.

85 At 476, citing Edna Erez, above n 34, at 552.
} 
achieve justice for victims. This is a much more principled basis for reform than simply increasing satisfaction, and it allows for more effective weighing of competing values and interests. ${ }^{86}$ Further, whether victims in fact feel satisfied with their experience of making a victim impact statement will vary depending on the circumstances of each individual. A more objective way to evaluate the effectiveness of victim impact statements is to assess whether they are meeting specified needs of victims and protecting specified interests. Additionally, it is important to be clear that changing victim impact statements is not intended to increase victims' satisfaction with the criminal justice process as a whole. There are many problems with the way victims are treated at each stage of the process, and these problems should be addressed directly. ${ }^{87}$ Victim impact statements can only meet the needs and protect the interests of victims which arise at the sentencing stage.

Finally, satisfaction is not the most useful concept to apply to the potential therapeutic benefits of victim impact statements. Therapeutic benefits obtained from making a victim impact statement are not measured by satisfaction, but by the extent to which making a victim impact statement aids recovery from the offending. ${ }^{88}$ Victims may feel more satisfied with the experience of making a victim impact statement if it has helped with their recovery, but this is not necessarily the case. Rather, the therapeutic goals of victim impact statements should be selected by reference to a theory of recovery, and effectiveness evaluated against those goals.

In the rest of this dissertation, I develop a proposal for the fundamental reform of victim impact statements. I discuss how they can be changed in order to meet victims' needs for recognition, acknowledgement and assistance with recovery. I also discuss how victim impact statements can better protect victims' interests in reparation and prevention of further harm from the offender and the sentence imposed on the offender. I suggest processes for the preparation, submission, and consideration of victim impact statements which are fair and respectful to victims and which minimise the risk of further harm to

\footnotetext{
86 See the discussion in Ian Edwards "An Ambiguous Participant: The Crime Victim and Criminal Justice Decision Making” (2004) 44 Brit J Criminol 967 at 968-972.

87 For a discussion of the issues currently faced by complainants in sexual violence cases, and a range of options for addressing these issues, see Elisabeth McDonald and Yvette Tinsley (eds) From "Real Rape" to Real Justice: Prosecuting Rape in New Zealand (Victoria University Press, Wellington, 2011).

88 Antony Pemberton and Sandra Reynaers "The Controversial Nature of Victim Participation: Therapeutic Benefits in Victim Impact Statements" in Edna Erez, Michael Kilchling and Jo-Anne Wemmers (eds) Therapeutic Jurisprudence and Victim Participation in Justice: International Perspectives (Carolina Academic Press, North Carolina, 2011) 229 at 238.
} 
them. Finally, I offer a solution to the issues with the proper role of harm in the assessment of offence seriousness raised in Part B of this chapter. Under my proposal, the role of victim impact statements will change. They will no longer be a tool in the case between the state and the offender, but rather will be for the benefit of victims themselves. 


\section{A New Role for Victim Impact Statements}

Only if we find new ways for women to tell their stories, and, crucially, be heard, will we transcend their "states of injury" and allow the rape trial to become an always risky - space for recovery rather than continued victimisation. ${ }^{1}$

In this chapter, I propose a new role for victim impact statements that would help turn Nicola Lacey's vision, encapsulated in the quote above, into reality, albeit at sentencing rather than at the trial stage. I argue that victim impact statements should be reformed so that they can more effectively meet victims' needs for recognition, acknowledgement, and assistance with recovery, and protect victims' interests in the sentence. This would be a step towards providing justice for victims. Reconceptualising victim impact statements in this way would help to make the criminal justice process a genuine space for recovery rather than further victimisation.

My proposal is consistent with an international trend away from the conventional model of criminal justice, in which a criminal case is between the state and the offender, and the victim's role is limited to the provision of the information required for prosecution. ${ }^{2}$ There is now increasing recognition of victims as individuals with needs arising from the offending against them, and as persons affected by the prosecution process and the outcome of the case. ${ }^{3}$ This recognition is reflected in s 7 of the Victims' Rights Act, which sets out general principles for the treatment of victims by criminal justice professionals. It reads as follows:

Any person who deals with a victim (for example, a judicial officer, lawyer, member of court staff, Police employee, or other official) should-

(a) treat the victim with courtesy and compassion; and

(b) respect the victim's dignity and privacy.

The reforms to victim impact statements I propose would implement in concrete ways the values set out in $\mathrm{s} 7$.

\footnotetext{
$1 \quad$ Nicola Lacey "Unspeakable Subjects, Impossible Rights: Sexuality, Integrity and Criminal Law" in Nicola Lacey (ed) Unspeakable Subjects: Feminist Essays in Legal and Social Theory (Hart Publishing, Oxford, 1998) 104 at 123.

2 For further discussion of this trend in relation to the victim's role in sentencing, see Jonathan Doak, Ralph Henham and Barry Mitchell "Victims and the Sentencing Process: Developing Participatory Rights?” (2009) 29 Legal Stud 651.

3 See generally Jonathan Doak Victims' Rights, Human Rights and Criminal Justice: Reconceiving the Role of Third Parties (Hart Publishing, Oxford, 2008).
} 
My argument that victim impact statements should assist with recovery perhaps goes beyond the values in $\mathrm{s} 7$. It reflects my view that the role of the criminal justice process in society should be to secure the conditions that allow individuals and communities to flourish. Punishment of offenders (with its censuring, preventive, and reintegrative aims) is one way in which the criminal justice process attempts to do this. Assisting victims with recovery (to an extent that is feasible and compatible with its other tasks) is another way it could do so. In this respect, the criminal justice process is one of a number of social institutions with a role to play in the achievement of social justice. The ideal towards which these institutions should be working (captured in this quote about the purpose of social work) is: ${ }^{4}$

... to release human power in individuals for personal fulfilment and social good, and to release social power for the kinds of society, social institutions, and social policy which make self-realization most possible for all [people]. Two values which are primary in such purposes are respect for the worth and dignity of every individual and concern that [she] have the opportunity to realize [her] potential as an individually-fulfilled, socially contributive person.

Reforming victim impact statements to make them more helpful and less harmful to victims is one way in which the criminal justice process can move towards fulfilling this social role.

Two perspectives in particular inform my view of the role the criminal justice process should play and my proposal for reform of victim impact statements: feminism and the strengths perspective. The idea that the criminal justice process should be responsive to the needs of sexual violence victims and refrain from causing them further harm has its origins in feminist activism and scholarship. ${ }^{5}$ My proposal for the reform of victim impact statements is a contribution to the body of work dedicated to achieving these goals. Some of the core ideas of feminism are reflected in the emphasis I place on empowerment and on the importance of understanding the social context within which sexual violence occurs and recovery takes place. ${ }^{6}$ In my discussion of how victim impact statements can promote recovery from sexual violence, I draw on core concepts of the

RE Smalley Theory for Social Work Practice (Columbia University Press, New York, 1967) at 1. For examples, see Elaine Mossman and others Responding to Sexual Violence: A Review of Literature on Good Practice (Ministry of Women's Affairs, Wellington, 2009) at 63-96.

For a summary of these ideas, see Meg Bond and Anne Mulvey "A History of Women and Feminist Perspectives in Community Psychology" (2000) 28 American Journal of Community Psychology 599 at 600-601 and Margaret Thornton "The Development of Feminist Jurisprudence" (1998) 9 Legal Educ Rev 171 at 171-173. 
strengths perspective. The strengths perspective is an approach to helping individuals, families and communities. It emphasises resilience, capacity for growth, the importance of people making their own choices, and the value of community. It is an empowering and holistic approach. ${ }^{7}$

In Part A of this chapter, I argue that victim impact statements should allow victims to tell their stories to the court and the offender. This would give the court an opportunity to recognise the wrongfulness of the offending and to acknowledge the harm caused to the victim in a more effective way than is currently possible. It would also recognise the relationship that exists between the victim and the offender as a result of the crime, by giving the victim an opportunity to address the offender. In Part B I argue that victim impact statements should provide an opportunity for victims to have direct input into the sentencing decision. In this way, victim impact statements could protect the victim's interests in reparation and prevention of further harm from the offender and from the sentence imposed on the offender. In Part C, I discuss how victim impact statements could promote the victim's recovery. In each of these parts I discuss how the victim's interests interact with other aspects of the public interest and with the offender's interests. I also highlight some of the risks for victims in making a victim impact statement, and suggest ways that these risks could be minimised. I outline some general principles for the design and implementation of victim impact statements in Part D. These principles are essential if victim impact statements are to achieve the aims set out in Parts A, B and $\mathrm{C}$. They are also necessary to minimise the risk that making a victim impact statement will cause further harm to victims.

\section{A Recognition and Acknowledgement}

Victim impact statements could provide an opportunity for the court to meet the victim's needs for recognition of the wrongfulness of the offending and acknowledgement of the harm caused. Victim impact statements could also provide an opportunity to recognise the relationship existing between the offender and the victim as a result of the offending. Victims may need this recognition and acknowledgement in order to feel that justice has been done.

See generally Ann Weick and others "A Strengths Perspective for Social Work Practice" (1989) 34 Social Work 350; Marlys Staudt, Matthew Howard and Brett Drake "The Operationalization, Implementation, and Effectiveness of the Strengths Perspective" (2001) 27 Journal of Social Service Research 1; and Dennis Saleebey "The Strengths Perspective in Social Work Practice: Extensions and Cautions" (1996) 41 Social Work 296. 


\section{Formal recognition of the wrong and acknowledgement of the harm}

In sexual violence cases, victims are often left feeling as if they have not had the opportunity to tell their story in their own way, even in cases in which the accused is convicted. ${ }^{8}$ Their experience of the offending, what they consider made it wrongful, and the harm they suffered as a result may not have been formally acknowledged by the court. A number of factors might contribute to this. Definitions of sexual offences do not fully capture the wrongfulness of sexual violence and the ways in which it harms victims. ${ }^{9}$ These definitions shape the evidence presented in the case, whether through a summary of facts (if there is a guilty plea) or at trial (if the case is defended). At trial, evidence is presented in question and answer format, with counsel rather than the complainant determining relevance. Even if further reforms were made to the trial process to allow victims to give their best evidence (such as more use of alternative ways of giving evidence and decreasing the use of distressing cross-examination techniques), the evidence would still be directed at the elements of the offence. As a result, even when complainants have given evidence, they may feel that their experience of the offending has not been heard.

It is important that the victim's perspective becomes part of the formal record, not necessarily because it is information required by the court, but because recognition and acknowledgement are parts of a just response to offending. ${ }^{10}$ The court should formally recognise, as a core part of the sentencing hearing, that the offending violated the victim's interests and acknowledge the harm that this caused. Recognition and acknowledgement may be necessary for victims to feel that justice has been done. Judith Herman interviewed people who had been victims of violent crime, and asked about their perceptions of justice. She found that: ${ }^{11}$

Elisabeth McDonald and Yvette Tinsley "Evidence issues" in Elisabeth McDonald and Yvette Tinsley (eds) From "Real Rape" to Real Justice: Prosecuting Rape in New Zealand (Victoria University Press, Wellington, 2011) 279 at 322-324.

9 Stephen Schulhofer "Taking Sexual Autonomy Seriously: Rape Law and Beyond" (1992) 11 Law and Philosophy 35 at 68-71; Mary Childs "Sexual Autonomy and Law" (2001) 64 MLR 309 at 311 and Lacey, above $\mathrm{n}$ 1, at 104-107.

10 The idea of justice as recognition was a principle underpinning South Africa's Truth and Reconciliation Commission. For a full discussion, see Andre du Toit "The Moral Foundations of the South African TRC: Truth as Acknowledgement and Justice as Recognition" in Robert Rotberg and Dennis Thompson (eds) Truth v Justice: The Morality of Truth Commissions (Princeton University Press, Princeton, 2000) 122 at 135-139.

11 Judith Lewis Herman "Justice from the Victim's Perspective" (2005) 11 Violence Against Women 571 at 585. See also Amanda Konradi and Tina Burger "Having the Last Word: An Examination of Rape Survivors' Participation in Sentencing" (2000) 6 Violence Against Women 351 at 367368. 
Whether the informants sought resolution through the legal system or through informal means, their most important object was to gain validation from the community. This required an acknowledgement of the basic facts of the crime and an acknowledgement of harm... For survivors who had been ostracized by their immediate families, what generally mattered most was validation from those closest to them. For others, the most meaningful validation came from representatives of the wider community or the formal legal authorities.

The imposition of a sentence on its own does not fulfil this function of formal recognition and acknowledgement. Something more is needed. ${ }^{12}$ There is some evidence that victims of sexual violence see obtaining recognition and acknowledgement as a purpose of making a victim impact statement:

When I did mine I thought they can't just look at me like someone who doesn't exist. I'm here and I have feelings and I want to tell the court about them. ${ }^{13}$

The judge and my family now they know what was done, what was wrong, why I was the way I was, why I did that, why I did this, you know... They got to see the pain, they were able to see me, the real me, not the character I put on. They got to see the hurt. The judge would know the truth, sort of, without my statement, but he wouldn't know the way he knew it because of what I did, I think it was better that he heard my voice and saw the pain and honesty. ${ }^{14}$

It is particularly important that the court recognises that the offending was wrong and acknowledges the harm it caused in cases involving an "expressive wrong"15 or "moral injury." 16 This is offending where the perpetrator's conduct conveyed that the victim's rights and wishes are unimportant and that he or she is worth less than the perpetrator, as occurs in sexual violence. Formal recognition and acknowledgement of the victim's

\footnotetext{
$12 \quad$ Clare McGlynn "Feminism, Rape and the Search for Justice" (2011) 31 OJLS 826 at 836-839.

13 Leslie Walberg-Hegan "Voices of Victims: The Experience of Preparing a Victim Impact Statement for Use in Court, as Described by Adolescent Sexual Abuse Survivors" (PhD Dissertation, University of Toronto, 1997) at 83 (Melanie).

$14 \quad$ At 88 (Elanor).

15 Tarunabh Khaitan "Dignity as an expressive norm: Neither vacuous nor a panacea" (2012) 32 OJLS 1 at 4.

16 Jean Hampton “Correcting Harms versus Righting Wrongs: The Goal of Retribution” (1992) 39 UCLA L Rev 1659 at 1666.
} 
experience could assist with the restoration of the victim's dignity in these cases, by conveying respect for the victim as a rights-holder and an individual. ${ }^{17}$

To allow the court to recognise wrongdoing and acknowledge harm, the current restrictions on the content of victim impact statements would need to be relaxed. As discussed in Chapter II, the primacy of the information purpose of victim impact statements under the current approach prevents victims from fully describing their experience. In order for the court to recognise the wrong effectively, the victim must have the opportunity to discuss the offending as he or she understands it. For the court to acknowledge the harm, the victim must have an opportunity to describe in full the consequences of the offending in his or her own way. ${ }^{18}$ In order for these needs to be met, more content would need to be permissible in victim impact statements. I discuss necessary changes to the permissible content in Chapter IV.

\section{Recognition of the relationship between victim and offender}

If the victim and the offender were strangers before the offending, it created a relationship between them. If they knew each other, the offending is likely to have changed their relationship or arisen from an already unsafe one. ${ }^{19}$ This relationship can create a legitimate desire on the part of the victim to address, either orally or in writing, the person who harmed them. Victims may feel that justice will not be done between themselves and the offender unless they have an opportunity to say something to the offender. Being denied the opportunity to do so could be frustrating and disempowering. Some victims might feel that until they have had that opportunity, they cannot undertake the rest of the work required for recovery.

Additionally, for some victims addressing the offender could be a way to reclaim their sense of self and their dignity, which were damaged by the offender's actions. ${ }^{20}$ People might do this in different ways. Some might want the offender to see the consequences of

\footnotetext{
$17 \quad$ Jonathan Allen "Balancing Justice and Social Unity: Political Theory and the Idea of a Truth and Reconciliation Commission" (1999) 49 U Toronto LJ 315 at 328-332.

18 For discussions of differences between victims' experience of offending and the legal definitions of it, see Lacey, above n 1, at 116 and Rebecca Saunders "Lost in Translation: Expressions of Human Suffering, the Language of Human Rights, and the South African Truth and Reconciliation Commission" (2008) 9 SUR Int'l J on Hum Rts 51.

19 Rupert Ross "Victims and Criminal Justice: Exploring the Disconnect" [2002] 46 Crim LQ 483 at 483; Mary Margaret Giannini "Equal Rights for Equal Rites?: Victim Allocution, Defendant Allocution, and the Crime Victims' Rights Act” (2008) 26 Yale L \& Pol'y Rev 431 at 451-452.

20 Giannini at 452; Richard Bierschbach "Allocution and the Purposes of Victim Participation under the CVRA" (2006) 19 Federal Sentencing Reporter 44 at 46.
} 
his or her actions, in the hope that the offender will recognise the victim as a real person who has been hurt, and feel remorse. ${ }^{21}$ For example, one young woman said: ${ }^{22}$

When I was writing I really wanted... him to know that he ruined my life and I'm not the same as I was before... It's hard to have to face the accused, but I wanted him to hear what I had to say and know it was wrong and how it affected me.

Others might wish to express anger, forgiveness, or their hope that the offender will turn his or her life around. Some might wish to show the offender that they are not afraid of him and that they are carrying on with their lives despite his actions: ${ }^{23}$

I felt like I wanted to confront him, that I wanted the last word with this guy, and he was sitting in the courtroom, and that's what I wanted, I wanted the chance, even though I was addressing the court, I wanted him to see that um, he couldn't intimidate me, I mean he had intimidated me but that he wasn't getting the last word, I wanted the last word.

Restricting the content of victim impact statements to the effects of the offending and limiting which effects victims can include and how they can discuss them can prevent victims from addressing the offender in the way they might wish to. Victims may then be left feeling that justice has not been done, increasing their sense of exclusion and alienation from the criminal justice process and slowing their recovery. In making the argument that victim impact statements should recognise the relationship between victims

and offenders, I am not advocating giving victims free reign to criticise or berate offenders. The permissible content of victim impact statements should be limited by the need to respect the dignity of the offender. I discuss what my argument means for the permissible content of victim impact statements in more concrete terms in Chapter IV.

\section{$B$ Input into Sentence}

The second purpose of victim impact statements should be to provide an opportunity for victims to have direct input into the sentencing decision. I briefly outline how victim impact statements could be changed in order to provide information relevant to reparation and to the assessment of ongoing risk to the victim from the offender. I then discuss in more detail how victim impact statements could provide information to the court about

\footnotetext{
Konradi and Burger, above n 11, at 371.

22 Walberg-Hegan, above n 13, at 82 (Melanie).

$23 \quad$ Konradi and Burger, above n 11, at 370.
} 
the effect of the proposed sentence on the victim, and how this information should be used by the sentencing judge.

\section{Assessing reparation}

Victim impact statements should become the primary way in which victims who seek reparation provide information about the harm, loss or damage suffered as a result of the offending. This would ensure that victims provide the information only once, and would allow them to be assisted by a person whose role it is to ensure that the victim's interests are fully represented. A victims' advisor would probably be the most appropriate person for this role, because of their knowledge about the impact of offending and their skills in supporting victims. This person could ensure that information about all harm, loss or damage suffered for which reparation may be payable (and for which the victim would like reparation to be granted) has been provided to the court.

\section{Assessing risk}

Victims should have the opportunity to include in their victim impact statements any concerns they have about their own or others' safety from the offender. They should be asked to state the reasons for their concern.

Allowing the victim's opinion and unproven allegations to be included in a victim impact statement and possibly taken into account at sentencing raises concerns about fairness to the defendant. For this reason, the defence should have the option to cross-examine victims on these aspects of their victim impact statements. While this may not be ideal from the victim's perspective, as it could add further stress, it is necessary from a fairness perspective.

Some victims who have concerns about safety may not wish to include them in their victim impact statement. This may be because they fear reprisal or because they do not wish to be subject to cross-examination. In this case, there should be an option for a report to be prepared by a person who has expertise in the areas of family and sexual violence. This report would be in addition to a pre-sentence report, and would put forward the victim's concerns and comment on them in the context of what is known about the dynamics of abusive relationships. That expert would then be subject to crossexamination on the contents of the report. ${ }^{24}$

24 This was the approach recommended in Hadar Dancig-Rosenberg and Dana Pugach "Pain, Love, and Voice: The Role of Domestic Violence Victims in Sentencing” (2012) 18 Mich J Gender \& L 423 at $472-482$. 


\section{The impact of the proposed sentence}

The length of a term of imprisonment imposed on an offender can cause the victim in the case distress. This distress may be grief or guilt at the severity of the sentence, or anger and disappointment at its leniency. The distress may have a number of sources, including the impact on the victim of the offending and his or her involvement in the criminal justice process, the nature of the relationship between the victim and the offender and the victim's moral, political and spiritual beliefs. ${ }^{25}$ The victim's response to the length of the sentence is, of course, subjective. An acceptable sentence to one victim may be entirely unacceptable to another. Any distress caused to a victim by the length of a term of imprisonment should be taken into account as a relevant factor at sentencing. This is for the purpose of preventing further harm to the victim through the sentence imposed on the offender.

Prosecutors should have a duty to inform the victim of the proposed sentence in advance of the hearing, so that victims can include their response to that proposal in their victim impact statements if they wish to. A victims' advisor should be available to discuss the matter with victims, and to answer any questions the victim may have. One issue the victims' advisor could raise with the victim is the possibility that he or she may feel differently about the sentence in the future. It would be useful for victims deciding whether to include views on the sentence in their victim impact statements to have considered this possibility.

My argument departs from the conventional approach to criminal justice, in which the case is solely between the state and the offender. Applying the conventional model of criminal justice to sentencing, Ashworth argued that victims have a legitimate interest in reparation from the offender or compensation from the state, but that their victimisation gives them no further interest in the sentence: ${ }^{26}$

It would be wrong to suggest that the victim has no legitimate interest in the disposition of the offender in his or her case, but the victim's interest is surely no greater than yours or mine. The victim's interest is as a citizen, as one of many citizens who make up the community or the state... Just because a person commits an offence against me, however, that does not privilege my voice above that of the

\footnotetext{
25 See the discussion in Ian Edwards "The Place of Victims' Preferences in the Sentencing of "Their" Offenders" [2002] Crim LR 689 at 694-696.

26 Andrew Ashworth "Responsibilities, Rights and Restorative Justice" (2002) 42 Brit J Criminol 578 at 585 .
} 
court (acting 'in the general public interest') in the matter of the offender's punishment.

Ashworth's view does not reflect the reality for victims, which is that they are affected by the offending, the prosecution process, and the outcome of the case to a much greater extent than most other citizens. This greater interest should be recognised when the sentencing decision is made. The Sentencing Act already includes provision for the interests of the victim as one purpose for which a sentence may be imposed (s 7(1)(c)). However, the nature of the victim's interest has not been defined in that context. As reparation and protection of the community (which includes the victim) are already covered by other provisions in s 7(1), I suggest that s 7(1)(c) be interpreted as meaning the victim's interest in prevention of further harm to the victim from the sentence imposed on the offender. Adopting this suggestion would make s 7(1)(c) into a meaningful provision.

The greatest issue with taking victims' views on sentence into account is the threat this could pose to proportionality and consistency. Increasing or decreasing a sentence on the basis of the victim's views rather than the seriousness of the offending threatens proportionality and consistency, which are fundamental principles of sentencing. ${ }^{27}$ However, judges routinely depart from strictly proportionate sentences to achieve deterrence, incapacitation, rehabilitation or reintegration of the offender. ${ }^{28}$ My argument is that preventing further harm to the victim is also a justified reason to depart from a strictly proportionate sentence. Doing so would increase inconsistency and uncertainty in sentencing. However, it is justified to impinge in a limited way on consistency and certainty in order to protect victims from further distress. This argument is consistent with modified desert theory, which Von Hirsch explained as follows: ${ }^{29}$

... ordinal proportionality does require equal punishment for equally reprehensible conduct - that unequal punishment sacrifices equity. The extent of that sacrifice, however, depends on how great the inequality is. Why not, then, allow preventive considerations to override ordinal desert, but only within specified limits? Variations in the punishment for a given offense would be countenanced, provided the specified limits were not exceeded. The idea is to enhance crime prevention without imposing "too much" unfairness.

$27 \quad$ Sentencing Act, s 8 .

28 Sentencing Act, s 7(1).

29 Andrew von Hirsch "Hybrid Principles in Allocating Sanctions: A Response to Professor Robinson" (1988) 82 NWUL Rev 64 at 67. 
The advantages of preventing further harm to victims by taking their views into account outweigh the disadvantages of increasing inconsistency and uncertainty. The small adjustment argued for would prevent further harm to the victim without creating "too much" unfairness to offenders.

Current sentencing methodology would need to be revised slightly in order to accommodate the consideration of the victim's views. Taueki, the guideline judgment for serious violence, set out a structured methodology for determining sentence. ${ }^{30}$ This methodology is now the standard approach, and has been used in other guideline judgments, including $R v A M$ (sexual violation). ${ }^{31}$ Under the Taueki methodology, desert determines the starting point for the sentence, which is the first step in the sentencing exercise. $^{32}$ The second step involves consideration of factors personal to the offender which may justify a departure from the starting point in order to fulfil either retributive or non-retributive purposes of sentencing. The non-retributive purposes are deterrence, protection of the community from the offender, rehabilitation and reintegration of the offender. $^{33}$ The third step in the sentencing exercise is to apply an overall discount of up to 25 per cent in order to reflect a guilty plea and any assistance to the authorities. ${ }^{34}$

Under my proposal, the victim's interest in prevention of further harm from the sentence imposed on the offender should be one factor justifying a departure from the starting point. A 10 or 15 per cent adjustment upwards or downwards could be made. This is the same degree of adjustment suggested by von Hirsch for the purpose of preventing further offending. ${ }^{35}$ The adjustment could be made between the second and third stages in the Taueki methodology. It would be best for the degree of adjustment to be a standard amount that is applied in every case when the distress is significant enough for the victim to have included it in a victim impact statement. It should only be made, however, when there are no compelling public interest reasons for not applying an adjustment. The most

\footnotetext{
30 Rv Taueki [2005] 3 NZLR 372 (CA).

$31 \quad R v A M(C A 27 / 2009)$ [2010] 2 NZLR 750. For further discussion, see $R v$ Clifford [2011] NZCA 360 at [45]-[60].

$32 \quad R v$ Taueki, above $\mathrm{n} 30$, at [26]-[30]. See further the discussion of this step in Chapter II.

33 Sentencing Act, s 7(1)(f)-(h). The same factor may be relevant to both retributive and nonretributive purposes of sentencing, sometimes in conflicting ways. For example, an offender's mental disorder may decrease culpability, but increase risk of re-offending, pointing towards the need for incapacitation and rehabilitation. For further discussion, see Bruce Robertson (ed) Adams on Criminal Law - Sentencing (online looseleaf ed, Brookers) at SAC3.

$34 \quad$ Hessell $v$ R [2010] NZSC 135 at [72]-[77].

35 Andrew von Hirsch "Proportionate Sentences: a Desert Perspective" in Andrew von Hirsch, Andrew Ashworth and Julian Roberts (eds) Principled Sentencing: Readings on Theory and Policy ( $3^{\text {rd }}$ ed, Hart Publishing, Oxford, 2009) 115 at 121-122.
} 
likely reason would be the need for incapacitation based on the level of risk to the victim or to others, making a downward adjustment inappropriate. Applying a standard adjustment would avoid the need for judges to evaluate the significance of the distress caused to the victim in the particular case, or to have to decide whether the victim's reason for feeling distressed at the proposed sentence is a "good" one. The purpose of having this type of adjustment is to recognise the victim's subjective response to the sentence, and making these sorts of evaluations would defeat that purpose.

A 10 or 15 per cent adjustment is small. If the victim is grieving the loss of the offender to prison, it is not likely to make a very large difference to the victim's distress. Equally, if the victim feels that justice would not be done unless a much longer sentence than usual was imposed, a 10 to 15 per cent adjustment may not do much to assuage the victim's anger and disappointment. However, it may be questioned whether any degree of adjustment could be of substantial help to victims in these sorts of situations. Even allowing victims to choose the sentence to be imposed (which would present an unacceptable threat to proportionality and consistency) would not remove the need for them to address their grief or anger as part of their recovery. Making a small adjustment is a way to avoid causing further distress by ignoring the victim's wishes, without creating too much unfairness to offenders.

The effectiveness of making an adjustment in order to prevent further harm to victims is, however, an important question when modifed desert theory is used. Von Hirsch highlighted the need for concern with the effectiveness of departures from proportionate sentences aimed at non-retributive purposes of sentencing. He noted: ${ }^{36}$

The model has its own problems, however. Within the stated limits it would allow inequalities in punishment so long as any preventive benefit resulted. Those preventive benefits, however, may be small... If ordinal proportionality is a demand of fairness, even limited deviations from it should be justified only by strong countervailing reasons. Small preventive benefits should not be deemed reason enough for overriding desert constraints.

Following this reasoning, the effectiveness of small adjustments in preventing distress caused by ignoring victim's wishes would need to be evaluated. If the benefits of making

36 Andrew von Hirsch, above n 29, at 67. 
adjustments are only small, it may not justify the departure from proportionality. This question cannot yet be answered empirically, as the model I propose is new. ${ }^{37}$

A more radical approach would be to consider imposing a non-custodial sentence when it is the fact of a custodial sentence, rather than its length, that causes the victim distress. Currently there is a presumption that a custodial sentence will be imposed for sexual violation. ${ }^{38}$ Where there are no aggravating features present to any significant degree, the starting point for sexual violation by rape is six to eight years, ${ }^{39}$ and for sexual violation by unlawful sexual connection, two to five years. ${ }^{40}$ These starting points may be reduced to take into account circumstances of the offending that warrant a lower starting point and mitigating factors personal to the offender. The sentence can be reduced by up to 25 per cent for a guilty plea. ${ }^{41}$ In a case of unlawful sexual connection, in particular, the end sentence may be under or close to the two-year custody threshold. In cases such as these, when a victim believes that he or she would be further harmed by the imposition of a custodial sentence on the offender, a non-custodial sentence should be considered.

The safety of the community (including the victim and the victim's dependents) should be the overriding concern when considering imposing a non-custodial sentence. Before imposing a non-custodial sentence, the court should be satisfied that adequate monitoring of the offender is available in the community in order to contain any risk of re-offending. Treatment, whether for the problematic sexual behaviour or for factors contributing to it (such as alcohol and drug problems), could decrease the risk of re-offending. The lack of community-based treatment programmes for those who commit sexual offences against adults means that in many cases a non-custodial sentence may not be appropriate. ${ }^{42}$ However, if the risk of re-offending is low or can be reduced with supervision and treatment for factors contributing to the offending, a non-custodial sentence may be imposed in order to prevent further harm to the victim through a sentence that causes additional distress. Reducing a sentence may have a negative effect on its deterrent potential, or be seen as reducing its denunciatory power. However, the risks of concrete

\footnotetext{
$37 \quad$ However, in England and Wales a sentence may be decreased on appeal if it aggravates the victim's distress. See the summaries of this line of cases in Ian Edwards "Sentencing Councils and Victims" (2012) 73 MLR 324 at 343-345 and Ian Edwards, above n 25, at 693-697.

Crimes Act 1961, s 128B.

$R \vee A M$, above $\mathrm{n} 31$, at [93].

At [114].

Hessell $v$ R, above $\mathrm{n}$ 34, at [75].

Elisabeth McDonald and Yvette Tinsley "Rejecting "one size fits all": Recommending a range of responses" in Elisabeth McDonald and Yvette Tinsley (eds) From "Real Rape" to Real Justice: Prosecuting Rape in New Zealand (Victoria University Press, Wellington, 2011) 377 at 388-391.
} 
and direct harm to individual victims from failing to take their views into account outweigh the risk of potential harm resulting from the community perception of the sentence.

I turn now to the third proposed purpose of victim impact statements, assisting victims with recovery from the offending against them.

\section{Recovery}

I begin this section with a discussion of the harm caused by sexual violence, as background to my arguments about how victim impact statements can assist with recovery. I then move on to discuss recovery, and set out a theory of how making a victim impact statement could assist. I draw on empirical research on sexual violence and more general grief and trauma literature, most of which has not been applied to victim impact statements before. Where possible I have used New Zealand research, however most of the research that has been done in this area is North American. I have selected studies with a diverse range of participants and which are sensitive to ethnicity and socio-economic status as factors affecting the impact of sexual violence and the process of recovery. However, the applicability of these studies to a New Zealand population is a question which may require further investigation.

\section{A framework for the harm caused by sexual violence}

Any discussion of how making a victim impact statement could assist sexual violence victims with recovery should be grounded in a comprehensive understanding of the impact of sexual violence on victims. Without this understanding, it is not possible to develop a meaningful conception of recovery, let alone a theory of how making a victim impact statement could help victims achieve it. However, there is no comprehensive discussion of the impact of sexual violence on victims in the existing literature on victim impact statements. Rather, most of the literature on the potential therapeutic benefits of victim impact statements treats crime victims as a generic class. ${ }^{43}$ This is of limited usefulness, as different types of offending have different effects on victims.

43 See for example Edna Erez "Who's Afraid of the Big Bad Victim? Victim Impact Statements as Victim Empowerment and Enhancement of Justice" [1999] Crim L Rev 545 at 551-552; Carolyn Hoyle and others Evaluation of the 'One Stop Shop' and Victim Statement Pilot Projects (Home Office, London, 1998) at 30; Andrew Sanders and others "Victim Impact Statements: Don't Work Can't Work" [2001] Crim L Rev 447 at 450-451; James Chalmers, Peter Duff and Fiona Leverick "Victim Impact Statements: Can Work, Do Work (For Those Who Bother to Make Them)" [2007] Crim L Rev 360 at 371-372; Bas van Stokkom "Victims' Needs, Well-Being and 'Closure': Is Revenge Therapeutic?" in in Edna Erez, Michael Kilchling and Jo-Anne Wemmers (eds) Therapeutic Jurisprudence and Victim Participation in Justice: International Perspectives 
An exception is an article by Lynne Henderson which advanced a theory of the impact of violent crime on victims, with a particular focus on sexual violence. Henderson's theory was structured around the existential issues victims of violence are forced to face. She emphasised the fear and sense of isolation that confrontation with these existential issues could create for victims. In Henderson's theory, the struggle to make sense of the experience is at the core of the recovery process. ${ }^{44}$ As a great deal of research on the impact of sexual violence has been done since Henderson's article was published, it is worth re-examining the impact of sexual violence on victims. In particular, much more is known about how the victim's personal and social context contributes to differences between victims in the types and degree of harm suffered. Accordingly, I draw on this more recent research, rather than Henderson's theory.

The framework for my discussion of the harm caused by sexual violence is based on the living-standard analysis von Hirsch and Jareborg developed for assessing offence seriousness. Their aim was to compare the seriousness of different types of crimes (for example, murder compared with burglary). They argued that the gravity of the offence was determined by the extent to which it interfered with the victim's quality of life. The term "living standard" refers to "the means or capabilities which would ordinarily help one achieve a good life." life". What it means to each person to live a good life will depend on his or her particular goals and values. ${ }^{46}$ Accordingly, the interests that I argue sexual violence interferes with are means or capabilities which ordinarily help people to live as they choose.

This framework for discussing the harm done by sexual violence is a different approach to the one used in much of the social science literature on the effects of sexual violence.

(Carolina Academic Press, North Carolina, 2011) at 207; Antony Pemberton and Sandra Reynaers "The Controversial Nature of Victim Participation: Therapeutic Benefits in Victim Impact Statements" in Edna Erez, Michael Kilchling and Jo-Anne Wemmers (eds) Therapeutic Jurisprudence and Victim Participation in Justice: International Perspectives (Carolina Academic Press, North Carolina, 2011) 229; Carolyn Hoyle "Empowerment through Emotion: The Use and Abuse of Victim Impact Evidence" in in Edna Erez, Michael Kilchling and Jo-Anne Wemmers (eds) Therapeutic Jurisprudence and Victim Participation in Justice: International Perspectives (Carolina Academic Press, North Carolina, 2011) at 249; Matthew Hall "A narrative-based model of victim-centredness in criminal trials" in Victims of Crime: Policy and Practice in Criminal Justice (Willan Publishing, Devon, 2009) 95 at 106-109.

44 Lynne Henderson “The Wrongs of Victim's Rights” (1985) 37 Stan L Rev 937 at 956-964.

45 Andrew von Hirsch and Nils Jareborg "Gauging criminal harm: A living-standard analysis" (1991) 11 OJLS 1 at 10.

46 At $10-11$. 
The framework which is most commonly used is post-traumatic stress disorder (PTSD). ${ }^{47}$ PTSD is a mental disorder characterised by increased physiological arousal (usually experienced as fear or anxiety), intrusive thoughts related to the traumatic event (such as nightmares, vivid memories, and being unable to stop thinking about it), and avoidance of reminders of the event. It is highly distressing and interferes with day-to-day functioning. ${ }^{48}$ I devote the remainder of this section to a discussion of my reasons for taking an interests-based approach instead of adopting PTSD as the framework.

The first reason for adopting an interests-based approach is that the PTSD framework has been criticised for its limited conceptualisation of the harm done by sexual violence and of the sources of this harm. Qualitative research that has asked victims about their experience has revealed that the effects included in the PTSD diagnosis are only a fraction of the harm done by sexual violence. ${ }^{49}$ Further, the PTSD framework treats the traumatic event as the only source of harm. However, research examining the experience of sexual violence victims emphasises that contextual factors also need to be taken into account because they can compound the harm caused by the offending itself. ${ }^{50}$ I draw mainly on this qualitative research, and emphasise the role of contextual factors such as previous experience of violence, social disadvantage, the responses of formal and informal support systems, and the impact of the criminal justice process in either aggravating the harm done by the offending or assisting the victim to heal from it. ${ }^{51}$ The response of the criminal justice process in particular is, of course, a central concern of this dissertation.

A second reason for structuring the discussion of harm around interests interfered with is that it affirms the importance of a public response to sexual violence through the criminal justice process. The PTSD framework, on the other hand, has been criticised for making the harm done by sexual violence a private, individual matter. It has been argued that

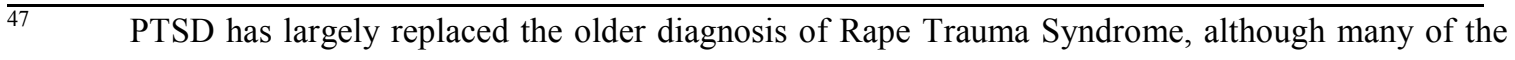
arguments in this section apply to both. For further discussion of Rape Trauma Syndrome, see Louise Ellison "Closing the Credibility Gap: The Prosecutorial Use of Expert Witness Testimony in Sexual Assault Cases” (2005) 9 Int'1 J Evidence \& Proof 239 at 251-256. Diagnostic and Statistical Manual of Mental Disorders ( $4^{\text {th }}$ ed, text revision, American Psychiatric Association, Washington DC, 2000). experiences of sexual assault” (2003) 4 Trauma, Violence \& Abuse 309 at 313-314.

$50 \quad$ At $315-316$.

51 For an example of a mental disorder framework that treats sexual violence as a social problem and illustrates the role of contextual factors, see Rebecca Campbell, Emily Dworkin and Giannina Cabral "An Ecological Model of the Impact of Sexual Assault on Women's Mental Health" (2009) 10 Trauma, Violence and Abuse 225.
} 
conceptualising the impact of sexual violence as a mental disorder, rather than as a legitimate response to a serious social problem, undermines efforts directed at denouncing sexual violence and changing the social conditions that foster it. ${ }^{52}$ Framing victims' responses to sexual violence as a mental disorder suggests that the proper course of action is therapy and reliance on informal support networks. While these resources can certainly be helpful to victims, the criminal justice process should acknowledge the harm done and assist victims with recovery to the extent that this is feasible within the process and desired by the victim. I frame the harm done by sexual violence in terms of the interests interfered with in order to reinforce the responsibility of the criminal law and the criminal justice process to secure the conditions necessary for individuals and communities to flourish.

A third reason for avoiding the PTSD framework in this discussion is its limited ability to recognise individuals' strengths and resources and the very narrow vision of recovery to which it gives rise. Using a mental disorder framework tends to conceptualise recovery as the relief of symptoms, occurring as the result of treatment. The efforts made by victims themselves are side-lined under some clinical and research approaches to the treatment of PTSD. Learning and development as a result of these efforts are not highlighted as potential outcomes of recovery, and the connection between individual and social change is overlooked. ${ }^{53}$ At its worst, the application of the PTSD framework to sexual violence stigmatizes those who have experienced it. Diagnostic labels can have the effect of reducing a person (in their own view or in others') from a whole person with a range of experiences, ideas, strengths and weaknesses to a set of problems to be treated. This can cause distress in itself, and impede recovery by making the person's strengths and resources less visible and undermining hope that change is possible. ${ }^{54}$ The conceptualisation of recovery $\mathrm{I}$ use in this dissertation emphasises learning and development as a result of confronting the experience of victimisation. It highlights the possibility of victims going on to use skills and insight gained as a result of the recovery process in creative ways for their own and others' benefit. I turn now to a discussion of the harm done by sexual violence.

\footnotetext{
$52 \quad$ Mary Gilfus "The Price of the Ticket: A Survivor-Centered Appraisal of Trauma Theory" (1999) 5 Violence Against Women 1238 at 1241-1244.

53 Suzanne McKenzie-Mohr "Out From and Beyond Trauma: Women's Experiences of the Process from Rape to Living Well” (PhD Dissertation, Memorial University of Newfoundland, 2008) at 910.

$54 \quad$ Julia Hutchinson and Juan Carlos Lema "Ordinary and Extraordinary Narratives of Heroism and Resistance: Uncovering Resilience, Competence and Growth" (2009) 24 Counselling Psychology Review 9 at 10.
} 


\section{The interests interfered with by sexual violence}

Drawing on the available empirical literature about the impact of sexual violence on victims, I argue in this section that any instance of sexual violence can interfere with a number of the victim's interests. ${ }^{55}$ These interests fall into two categories. Interference with the interests in the first category is inherent in any instance of sexual violence. These interests are sexual autonomy, dignity, integrity, and safety. Interference with the interests in the second category may occur as a result of any instance of sexual violence, but is not inherent. These interests are the capacity for intimacy, sense of belonging, and ability to contribute to the community. The extent to which interests in either category are interfered with by a particular instance of sexual violence varies. Accordingly, the impact of an offence on any individual victim is best understood using an ecological model. ${ }^{56}$ Ecological models illustrate how the kinds and degree of harm to an individual are a product of the interaction between features of the offending itself and the victim's personal and social context. I highlight this interaction throughout my discussion.

A third category comprises interests which may be interfered with by sexual violence, depending on the circumstances of the offending. One example is freedom from physical injury (beyond the injury inherent in the offence), including sexually transmitted diseases and complications arising from pregnancy as a result of rape (particularly for very young women). Another example is the privacy and security of the home, if the offending occurs in the victim's residence. Violation of these interests can increase the harm to the victim, and are properly treated as aggravating features of the offending or (where applicable) as offences in their own right. In this discussion, I focus on the interests in categories one and two, as violation of them may arise in any case of sexual violence.

\section{a) Sexual autonomy}

At the core of sexual violence is the violation of the victim's sexual autonomy. The perpetrator acts as if the victim's wishes and feelings do not matter, by taking away the victim's choice whether or not to engage in sexual activity. ${ }^{57}$ The nature of the intrusion into autonomy in sexual violence is particularly damaging, because it "involves what is deeply personal, taking without consent what an individual should be able to choose to

\footnotetext{
$55 \quad$ My discussion covers a broader range of interests than that discussed by von Hirsch and Jareborg in their analysis of the interests interfered with by rape. They confined themselves to bodily safety and freedom from humiliation (in the case of "forcible rape"), and freedom from humiliation (in the case of "date rape"). See von Hirsch and Jareborg, above n 45, at 26.

56 For examples, see Mary Harvey "An Ecological View of Psychological Trauma and Trauma Recovery" (1996) 9 Journal of Traumatic Stress 3 and Campbell, Dworkin and Cabral, above n 51. Schulhofer, above n 9, at 68-71.
} 
share consensually." 58 The violation of sexual autonomy is the keystone to the other interests interfered with by sexual violence: dignity, integrity, safety, capacity for intimacy, sense of belonging, and the ability to contribute to the community. In the following sections, I describe how the violation of sexual autonomy interferes with each of these interests, and discuss the consequences of this interference for victims.

\section{b) Dignity}

Through the display of contempt for the victim's sexual autonomy, the perpetrator undermines the victim's dignity. ${ }^{59}$ Kant conceived of dignity as arising from the capacity for free will and rationality. It requires people to "treat humanity, both in your person and in the person of each other individual, always at the same time as an end, never as a mere means." ${ }^{60}$ By acting as if the victim's lack of consent to sexual activity is unimportant, the perpetrator treats the victim as a means to an end, thereby undermining the victim's dignity. As von Hirsch and Jareborg argued: ${ }^{61}$

We hardly need belabour that forced sex is about the most demeaning imposition that can be imagined - far more humiliating than a beating. Because of the strength, in our culture, of the norm that sexual favours may be granted only with consent, forced sexual intercourse is an extreme form of being subjected to another's dominion.

Using people as a means to an end is a way of "treating them as though they were somehow worth less than oneself, or simply worthless." 62 This violates dignity because it is an assertion of the offender's superiority over the victim, rather than respecting the intrinsic worth that each person has in equal measure, which is the core of the idea of dignity. ${ }^{63}$ In instances where the perpetrator is male and the victim female, the behaviour also displays disrespect for women as a group and demonstrates the attitude (whether or not it is explicitly held by the particular perpetrator) that men are entitled to exercise power over women and to use them for their own pleasure, and indeed that that is what

\footnotetext{
$58 \quad$ McDonald and Tinsley, above $\mathrm{n}$ 42, at 418.

$59 \quad$ Khaitan, above n 15 , at 14.

60 Immanuel Kant Grounding for the metaphysics of morals $\left(2^{\text {nd }} \mathrm{ed}\right.$, translated by James Ellington, Hackett Publishing Company, Indianapolis, 1983) at 44.

61 von Hirsch and Jareborg, above n 45, at 26.

62 John Murphy "The nature and domain of aggravated damages" (2010) 69 Cambridge Law Journal 353 at 361. At 361; Khaitan, above n 15, at 14.
} 
women are for. ${ }^{64}$ The violation of dignity can leave the victim feeling humiliated and disgraced: ${ }^{65}$

Rape is humiliating even when unaccompanied by further affronts, because the sheer use of a person, and in that sense the objectification of a person, is a denial of their personhood. It is literally dehumanizing.

These feelings can be exacerbated if the perpetrator engaged in conduct intended to degrade the victim further. In addition, having to recount the events for the purposes of investigation and prosecution, and in particular being cross-examined on them, can also be humiliating, despite the protections currently available to make this process less distressing for complainants. ${ }^{66}$

c) Integrity

The violation of sexual autonomy interferes with the victim's interest in integrity. The most obvious sense in which it does so is through the interference with bodily integrity. The physical intrusiveness of sexual violence is a violation of bodily integrity. A forensic medical examination can exacerbate the violation. There are also two other, less obvious, ways in which the interest in integrity is interfered with. I discuss each of these in turn.

Lacey conceptualised integrity as the state of having physical, mental and emotional experiences integrated, which is necessary for feeling like "a whole being, worthy of respect and capable of self-esteem."67 Integrity is a state which we are not normally conscious of. We tend only to become aware of it when it is violated. Integrity is violated during sexual assault because victims are physically engaged in sexual activity, but it is against their will and (if they are conscious) usually accompanied by feelings such as fear, anger, disgust, humiliation or numbness.

The violation of integrity has painful consequences. First, the splitting of physical from mental and emotional experience can persist after the sexual assault, leaving victims feeling as if their body is alien to them, rather than belonging to them and feeling like a

$64 \quad$ Jean Hampton "Punishment, Feminism, and Political Identity: A Case Study in the Expressive Meaning of the Law" (1998) 11 Can J L \& Jurisprudence 23 at 31.

65 John Gardner and Stephen Shute "The wrongness of rape" in Jeremy Horder (ed) Oxford Essays in Jurisprudence (4 ${ }^{\text {th }}$ ed, Oxford University Press, Oxford, 2000) 193 at 205.

66 Venezia Kingi and others Responding to Sexual Violence: Pathways to Recovery (Ministry of Women's Affairs, Wellington, 2009) at 174.

$67 \quad$ Nicola Lacey, above n 1, at 118. 
part of themselves. ${ }^{68}$ This sense of depersonalisation or separation from the body may contribute to the use of self-harm, substance abuse and risk-taking by some victims in the aftermath of sexual assault. This is because the physical sensations resulting from these activities may help them feel less numb and so restore some sense of connection with the body. ${ }^{69}$ Secondly, the violation of integrity may make people feel exposed, and their body may become a source of disgust or hatred. The anxiety provoked by the feeling of exposure may cause people to withdraw socially. The desire to change their physical appearance in order to hide from unwanted attention and to protect themselves from further harm may contribute to the elevated rates of disordered eating among victims of sexual violence. ${ }^{70}$ Thirdly, the violation of sexual integrity can make it difficult for people to feel as if they have a choice over who has access to their body and to protect themselves from unwanted sexual contact. They may engage in sexual activity to which they consent, but that is undesired or lacking in intimacy and pleasure, exacerbating the harm already done by the sexual assault. ${ }^{71}$ They may also fail to take steps to protect themselves from further assaults in ways they otherwise would have, increasing their vulnerability to further harm. ${ }^{72}$

In addition to interfering with victims' ability to integrate the physical, mental, and emotional aspects of experience, sexual violence interferes with integrity in a broader way: the ability to integrate experiences into their sense of self. Like the ability to integrate different aspects of a particular experience, integrating experiences into the sense of self is important for feeling like a whole person, and allows people to experience a sense of continuity over time. ${ }^{73}$ Sexual violation is a particularly difficult experience to integrate, because its consequences can be overwhelming and very difficult to describe or

$68 \quad$ See the examples in Rupert Ross, above n 19, at 486.

69 For evidence of increased rates of self-harm, substance abuse and risk-taking amongst sexual violence victims, see Campbell, Dworkin and Cabral, above n 51, at 226; Helen Neville and Mary Heppner "Contextualizing Rape: Reviewing Sequelae and Proposing a Culturally Inclusive Ecological Model of Sexual Assault Recovery" (1999) 8 Applied and Preventive Psychology 41 at 45; Rebecca Campbell, Tracy Sefl and Courtney Ahrens “The Impact of Rape on Women's Sexual Health Risk Behaviors" (2004) 23 Health Psychology 67.

Bonnie Dansky and others "The National Women's Study: Relationship of Victimization and Posttraumatic Stress Disorder to Bulimia Nervosa" (1997) 21 International Journal of Eating Disorders 213 at 219-227; Diann Ackard and Dianne Neumark-Sztainer "Date violence and date rape among adolescents: associations with disordered eating behaviors and psychological health" (2002) 26 Child Abuse \& Neglect 455 at 463 at 468-470.

$71 \quad$ McKenzie-Mohr, above n 53, at 89.

72 Campbell, Sefl and Ahrens, above n 69, at 67.

73 Michele Crossley "Narrative Psychology, Trauma and the Study of Self/Identity" (2000) 10 Theory and Psychology 527 at 541. 
understand. People may lack language for what they are experiencing, ${ }^{74}$ and their thoughts, feelings, and behaviour may differ so much from what they are accustomed to that they struggle to make sense of them. ${ }^{75}$ Understanding the experience may be particularly difficult if their thoughts, feelings, and behaviour conflict with their values or with others' expectations of how the victim should respond to the sexual violence. ${ }^{76}$ Not being able to make sense of experiences can create a great deal of distress and anxiety, particularly if victims attribute this to their own incompetence or instability. ${ }^{77}$ Making sense of difficult experiences requires much cognitive and emotional effort, so is particularly challenging when victims' resources are already taxed by the effort of coping with the impact of the sexual assault. ${ }^{78}$

Pregnancy resulting from rape presents a particular challenge to each of these three types of integrity. While it should not be assumed that pregnancy resulting from rape will always be experienced by victims as a type of harm, it is likely that it will always take some effort to integrate. For some women, the circumstances of conception make the pregnancy a particularly insidious violation of bodily integrity. Medical procedures because of the pregnancy can exacerbate the violation of bodily integrity, and are likely to be particularly difficult for a person who is already in a vulnerable state because of the rape. Pregnancy resulting from rape can also add to the violation of the second type of integrity, the experience of having physical, mental, and emotional experiences integrated. This is because women who do not experience the pregnancy as a violation of bodily integrity, but instead as something which in itself feels right, might struggle to integrate those feelings with their thoughts and emotions about the rape. Additionally, internal conflict about the decision whether to continue the pregnancy and, if so, who will parent the child when he or she is born, can also violate this sense of having mental and emotional experiences integrated. Finally, the third type of integrity, the sense of continuity over time from having experiences integrated into the sense of self, can be violated by pregnancy resulting from rape. Regardless of the decision the woman makes,

\footnotetext{
M4 Menzie-Mohr, above n 53, at 88-90.

75 Robert Neimeyer, Olga Herrero and Luis Botella "Chaos to Coherence: Psychotherapeutic Integration of Traumatic Loss” (2006) 19 Journal of Constructivist Psychology 127 at 131.

76 Susan Roth and Leslie Lebowitz "The experience of sexual trauma" (1988) 1 Journal of Traumatic Stress 79 at 97-98.

77 Robert Neimeyer and Alan Stewart "Trauma, Healing, and the Narrative Emplotment of Loss" (1996) 77 Families in Society 360 at 371; Emma Dunmore, David Clark and Anke Ehlers "A Prospective Investigation of the Role of Cognitive Factors in Persistent Post-Traumatic Stress Disorder (PTSD) after Physical or Sexual Assault" (2001) 39 Behaviour Research and Therapy 1063 at 1068.

78 Neimeyer, Herrero and Botella, above n 75, at 131.
} 
pregnancy can change the course of her life. If she does not continue the pregnancy or decides on adoption, she may live with grief and a preoccupation with what might have been. If she chooses to raise the child herself or to have close contact with the child, this will be a permanent change to her life course and likely to her sense of self.

d) Safety

The violation of sexual autonomy threatens victims' physical safety. Victims often experience high levels of fear and anxiety, during the offending and in the long-term. This can occur whether the victim was threatened, physically overpowered, or his or her incapacitation caused or taken advantage of by the perpetrator. ${ }^{79}$ Fear may be heightened if the offending involved a betrayal of trust or if the identity of the assailant is unknown, because the victim may feel as if almost anybody is a potential assailant. Fear may also be heightened if the offending occurred in a place where the victim previously felt safe. ${ }^{80}$ For some people, sexual assault brings them face to face with their own vulnerability, in a way they may not have experienced before, leaving them feeling shocked and betrayed. For others, sexual assault confirms their previous experience of the world as unsafe and others as untrustworthy, leaving them feeling more alone and embattled. ${ }^{81}$ Some lose faith in their own judgement and the trustworthiness of their perceptions. ${ }^{82}$ In order to soothe fear and anxiety, some people may engage in self-harm, substance abuse, disordered eating and risk-taking. ${ }^{83}$ However, aside from being harmful in themselves, these behaviours may increase fear and anxiety if they believe that engaging in them is evidence of their own lack of ability to cope or if it exposes them to further harm. ${ }^{84}$ At the extreme end of the risk to safety come ongoing threats from the offender or the offender's associates, and the risk of self-harm resulting in death or suicide.

e) Intimacy, sense of belonging and capacity to contribute The violation of sexual autonomy and the resulting interference with dignity, integrity, and safety, can leave victims feeling powerless, worthless, and ashamed. These feelings are highly distressing in themselves. They also have the potential to be very destructive

\footnotetext{
$79 \quad$ Roth and Lebowitz, above n 76, at 131-132.

80 At $131-132$.

81 Claire Burke Draucker "Learning the Harsh Realities of Life: Sexual Violence, Disillusionment, and Meaning" (2001) 22 Health Care for Women International 67; Wasco, above n 49, at 312313 .

82 Judith Daylen, Wendy van Tongeren Harvey and Dennis O'Toole Trauma, Trials, and Transformation: Guiding Sexual Assault Victims through the Legal System and Beyond (Irwin Law, Toronto, 2006) at 54-55.

83 For examples, see Kingi and others, above n 66, at 132-134; McKenzie-Mohr, above n 53, at 7279.

84 Dunmore, Clark and Ehlers, above n 77, at 1068
} 
because they can interfere with the victim's capacity for intimacy, sense of belonging, and ability to contribute to the community. I briefly discuss how offence and postoffence factors can contribute to victims' sense of powerlessness, worthlessness and shame. I then discuss how these feelings interfere with the capacity for intimacy, sense of belonging, and ability to contribute to the community.

Feelings of worthlessness and shame tend to be stronger if victims are assaulted by an acquaintance rather than a stranger. ${ }^{85}$ This may be because they are more likely to be blamed or blame themselves, have a more difficult experience if they report the assault and if it is prosecuted, and are less likely to receive empathy and validation of their experience from those to whom they turn for support. ${ }^{86}$ These feelings may also be stronger in people for whom the assault confirmed negative beliefs they already held about themselves, such as believing they do not deserve to be treated well by others, or that they do not have the strength to cope with difficult experiences. These sorts of beliefs often develop out of previous experiences of abuse and neglect, and as a result of membership of marginalised populations. ${ }^{87}$ If victims believe (or perceive others as believing) that their responses are pathological, inappropriate, or signs of weakness, or if their emotions feel overwhelming or uncontrollable, they may feel more powerless, worthless, and ashamed. ${ }^{88}$ Post-offence factors can exacerbate victims' feelings of powerlessness, worthlessness and shame. These feelings can be exacerbated if the victim is not treated with respect and consideration in the criminal justice process and other institutions with which he or she has contact. ${ }^{89}$ Feelings of powerlessness, worthlessness and shame can also be exacerbated if those to whom the victim turns for support and understanding do not respond with empathy and compassion ${ }^{90}$ or if their attempts to care for the victim further undermine the victim's feeling of control and agency. ${ }^{91}$

Sexual violence can interfere with victims' capacity for intimacy. Sexual intimacy becomes dangerous or undesirable for a person feeling powerless, worthless and

85 R Felson and P Pare "The Reporting of Domestic Violence and Sexual Assault by Nonstrangers to the Police" (2005) 67 Journal of Marriage and Family 597.

86 Maria Elena Vidal and Jenny Petrak "Shame and Adult Sexual Assault: A Study with a Group of Female Survivors Recruited from an East London Population" (2007) 22 Sexual and Relationship Therapy 159 at 168. Vulnerabilities in Sexually Assaulted Women" (1999) 27 Clinical Social Work Journal 171 at 173; Vidal and Petrak. above n 86, at 168-169.

88 Roth and Lebowitz, above n 76, at 91 and 100.

$89 \quad$ At 93.

$90 \quad$ Wasco, above $\mathrm{n} 49$, at 318.

$91 \quad$ Roth and Lebowitz, above n 76, at 96. 
ashamed. The person might need to avoid or end sexual relationships to regain a sense of safety and control. ${ }^{92}$ This may be a need to avoid reminders of the assault, to protect their physical boundaries, or because they find the emotional vulnerability associated with sexual intimacy overwhelming. ${ }^{93}$ Sexual intimacy may be difficult if they feel damaged or tainted by the assault, ${ }^{94}$ or because they struggle to believe that they are valued or to value themselves for anything other than their body. ${ }^{95}$ Feelings of powerlessness, worthlessness and shame can also interfere with emotional intimacy. They make people believe that parts of themselves or their experience are unacceptable to others and have to be hidden, ${ }^{96}$ that they do not deserve love and respect, or that they are a burden and have nothing to contribute to the relationship. ${ }^{97}$ These difficulties are exacerbated by the betrayal of trust inherent in any sexual assault (regardless of whether there was a previous relationship between the perpetrator and the victim, but strongest if there was a close relationship or significant power imbalance), and if others have ended relationships or withdrawn from the victim because of the impact of the assault. ${ }^{98}$ The result is that victims may be less willing to invest in relationships, less able to trust others, and less likely to rely on others for support, all of which are necessary for emotional intimacy. ${ }^{99}$

Sexual violence can also interfere with victims' sense of belonging to a community. High levels of distress and the need for safety may cause them to withdraw socially. Changing residence or leaving work, study or leisure activities as a result of the assault can cause a sense of dislocation. When sexual violence occurs within families, the ramifications are particularly likely to lead to a loss of community for victims. ${ }^{100}$ In a psychological sense, victims of sexual violence often feel very alone with their experience and as if they are damaged and inferior to those around them, despite the frequency with which sexual violence occurs and the high probability that they know somebody else who has experienced it. ${ }^{101}$ Feelings of powerlessness, worthlessness and shame can stop people from reaching out to others who might understand and relate to

\footnotetext{
Kingi and others, above n 66, at 101-132.

Roth and Lebowitz, above n 76, at 100.

Kingi and others, above n 66, at 101-132.

Janet Foliano "Listening to the Voices of Survivors: The Effects of Rape on Self-Esteem and SelfBlame" (PhD Dissertation, Indiana University of Pennsylvania, 1995) at 48-49; McKenzie-Mohr, above n 53, at 88 .

Roth and Lebowitz, above n 76, at 97-98.

Mark Thelen, Michelle Sherman and Tiffany Borst "Fear of Intimacy and Attachment among Rape Survivors" (1998) 22 Behavior Modification 108 at 109-112.

See generally Thelen, Sherman and Borst.

At 109-112.

Kingi and others, above n 66, at 134; Roth and Lebowitz, above n 76, at 97-98.

Kingi and others at 134; Roth and Lebowitz at 97-98.
} 
their experience, or to those who have not experienced anything similar themselves but are able to empathise with, accept and support them. Others' judgments about the assault or the victim's response to it, or their uncertainty about how to help, may make the victim feel more alone.

Finally, being the victim of sexual violence can interfere with people's capacity to contribute to their communities, because of the impact of psychological distress and feelings of powerlessness, worthlessness and shame on their ability to work, care for others, and pursue creative endeavours. ${ }^{102}$ People's capacity to contribute will be particularly inhibited if they suffer depression as a result of the sexual violence, a common outcome which is characterised by a pervasive sense of isolation, worthlessness and powerlessness to make changes. ${ }^{103}$ Women who have been the victims of sexual violence often have trouble sleeping. ${ }^{104}$ Physical health problems are also very common after sexual assault, even if the person was not physically injured during the assault, and can also interfere with victims' ability to contribute to their communities. ${ }^{105}$

Having outlined the types of harm caused by sexual violence, the next step is to select the therapeutic goals of victim impact statements. This is the subject of Section 3.

\section{Theoretical underpinnings of the proposed therapeutic goals of victim impact statements}

There is a small body of literature discussing the potential therapeutic benefits of making a victim impact statement. ${ }^{106}$ However, it contains no well-developed theory about how making a victim impact statement could assist victims with recovery from the offending against them. In Section 4, I advance a theory of how making a victim impact statement could assist sexual violence victims to recover. In this section I discuss the theoretical

\footnotetext{
$102 \quad$ Kingi and others, above n 66, at 132; Jeannine Monnier, Heidi Resnick and Dean Kilpatrick "The Relationship between Distress and Resource Loss Following Rape" (2002) 17 Violence and Victims 85.

Campbell, Dworkin and Cabral, above n 51, at 225.

Jill Astbury, Dorothy Bruck and Deborah Loxton "Forced Sex: A Critical Factor in the Sleep Diffiulties of Young Australian Women" (2011) 26 Violence and Victims 53 at 59-69.

Jacquelyn Campbell and Karen Soeken "Forced Sex and Intimate Partner Violence: Effects on Women's Risk and Women's Health" (1999) 5 Violence Against Women 1017 at 1019-1020 and 1026-1032; Rebecca Campbell, Tracy Sefl and Courtney Ahrens "The Physical Health Consequences of Rape: Assessing Survivors' Somatic Symptoms in a Racially Diverse Population" (2003) 31 Women's Studies Quarterly 90.

Konradi and Burger, above n 11; Walberg-Hegan, above n 13; Giannini, above n 19; Erez, above n 43; Sanders, above n 43; Chalmers, Duff and Leverick, above n 43; Pemberton and Reynaers, above n 43; Hall, above n 43; Henderson, above $n 44$.
} 
underpinnings of that theory. There are five principles which my theory will follow. I illustrate the importance of these principles using examples from the existing literature on victim impact statements where other approaches have been taken. I discuss each principle in turn.

First, the therapeutic goals of victim impact statements should be clearly defined. A weakness of some of the literature on victim impact statements is its use of poorlydefined therapeutic goals, such as "feeling better."107 Selecting clearer goals would allow victim impact statements to be designed and implemented in a way that maximises their potential to promote victims' recovery. Clearly defined goals would also allow for meaningful evaluation of the effectiveness of victim impact statements in promoting recovery. ${ }^{108}$ I argue that victim impact statements could assist victims with three processes which are part of recovery: developing insight, negotiating vulnerability, and grief and growth.

Secondly, the therapeutic goals should come from an understanding of the harm done by sexual violence and the range of needs of individual victims. The importance of this is illustrated by some recent work by Antony Pemberton and Sandra Reynears. ${ }^{109}$ Writing about the impact of crime in general, rather than sexual violence specifically, they argued that the reduction of anger and anxiety should be the goal of victim impact statements. In their view, anger and anxiety are "the two most important emotional reactions to victimisation". ${ }^{110}$ However, as illustrated in Section 2, anger and anxiety are two of many possible emotional responses to sexual violence. Which emotional state is most distressing or disruptive will vary between individuals. The significance of a particular emotional response may also change over time for each individual, as recovery progresses. This indicates the need for goals which encompass the full range of needs that victims of sexual violence victims may have. Selecting broader goals would allow victims to use their victim impact statements in ways that are appropriate for their needs.

Thirdly, the therapeutic goals should reflect the nature of recovery and be based on realistic expectations of what victim impact statements could achieve. A weakness of some of the existing literature on victim impact statements is its use of "closure" as a

\footnotetext{
107 Hoyle and others, above n 43, at 30; Chalmers, Duff and Leverick, above n 43, at 371-372.

108 For a discussion of the problems with the ongoing debate about the effectiveness of victim impact statements in promoting recovery, see Pemberton and Reynaer, above n 43, at 235-238.

109 Pemberton and Reynaers, above $\mathrm{n} 43$.

110 At 236-237.
} 
therapeutic goal. ${ }^{111}$ I assume the term is used to mean achieving a sense of resolution of the experience and "moving on" from it. Closure is an entirely unrealistic goal of victim impact statements for sexual violence victims, and does not reflect the nature of recovery from sexual violence. As illustrated in Section 2, the physical, psychological, social and material ramifications for the victim are extensive and severe. As a result, recovery is a long process. The image of a spiral is often used to emphasise the non-linear nature of the recovery process and the repeated revision of earlier stages that is required. ${ }^{112}$ Different aspects of the experience become salient at different times, and the meaning of the experience may change throughout the person's life. ${ }^{113}$ Additionally, as mentioned in Section 1, common outcomes of efforts towards recovery are growth and an ability to put what has been learnt from the experience to good use. This means that the experience remains part of the person's daily life in some form, even if he or she has for the most part overcome its negative effects. For these two reasons, I do not use the concept of closure in my discussion of how victim impact statements could assist with recovery. Instead, I discuss recovery in terms of processes, rather than outcomes, in order to reflect the lack of a clear end-point for recovery. Instead of resolution, I focus on coping with the effects of sexual violence, integration of the experience into the sense of self, and awareness of growth and development as a result of efforts made towards recovery.

Fourthly, the therapeutic goals should situate recovery within the individual's ongoing development. The goals should not be confined to a return to the level of functioning experienced by the individual before the offending, or (in the case of ongoing abuse) to the attainment of the level of functioning that the individual may have experienced if the abuse had not occurred. Confinement is one of the problems with Pemberton and Raynaers' selection of the reduction of anger and anxiety as the therapeutic goals of victim impact statements. The therapeutic goals should allow for the possibility of the recovery process advancing the individual's development. Individuals gain knowledge and skills from confronting the adverse effects of sexual violence. The processes of recovery I propose as therapeutic goals of victim impact statements are aimed at assisting victims to recognise the knowledge and skills they have gained. This is so they can apply

\footnotetext{
111 See the discussion in Pemberton and Reynaers, above n 43, at 234-236. See also van Stokkom, above n 43 and Susan Bandes "Victims, "Closure," and the Sociology of Emotion" (2009) 72 Law \& Contemp Probs 1 at 9-13.

112 Marilyn Smith and Lillian Kelly "The Journey of Recovery After a Rape Experience" (2001) 22 Issues in Mental Health Nursing 337 at 343-344; Sharon Murphy, Mary Moynihan and Victoria Banyard "Moving Within the Spiral: The Process of Surviving" (2009) 24 Affilia 152.

113 Sexual Abuse and Mental Injury: Practice Guidelines for Aotearoa New Zealand (Accident Compensation Corporation, 2008) at 21 and $31 .$.
} 
them when faced with challenging situations in the future. It is also so they can use them creatively in ways that are personally fulfilling and allow them to make valuable contributions to their communities. In this way, recovery becomes part of the person's ongoing development. ${ }^{114}$

Fifthly, the therapeutic goals of victim impact statements should be grounded in an understanding of the social context of sexual violence. Sexual violence reflects and contributes to social inequality. While I have used gender-neutral language throughout this dissertation, this choice was not intended to disguise the gendered nature of sexual violence. The New Zealand National Survey of Crime Victims 2001 estimated the lifetime prevalence rates of sexual victimisation at 19.3 per cent for women and 4.9 per cent for men. ${ }^{115}$ Others factors which increase vulnerability to sexual violence are age (women aged under 24 are most at risk), ethnicity (Maori women are much more at risk than non-Maori women), disability, and previous victimisation. ${ }^{116}$ Many victims of sexual violence have experienced more than one incident of sexual violence as well as other types of victimisation and deprivation. ${ }^{117}$ Pemberton and Reynears' argument that reduction of anxiety and anger should be the therapeutic goals of victim impact statements requires examination in this context. I address their arguments about anxiety and anger in turn.

The straightforward reduction of anxiety should not be a therapeutic goal of victim impact statements. The lack of safety which is a reality for many women makes this goal inappropriate. No therapeutic intervention should aim to make people feel safe in unsafe situations. Further, the fear and anxiety suffered by those who have experienced sexual violence can often serve a protective function. As part of recovery, victims may need to find new ways to take care of themselves and they may need to make changes to increase their physical and emotional safety. They may also need to learn how to live with the knowledge of their vulnerability to further harm. ${ }^{118}$ In combination with making any required changes, techniques to reduce or manage PTSD symptoms may help to ensure

\footnotetext{
$114 \quad$ For further discussion of the strengths perspective, which underlies this goal, see Staudt, Howard and Drake, above n 7; Saleebey, above n 7; Weick and others, above n 7.

115 Allison Morris and James Reilly New Zealand National Survey of Crime Victims 2001 (Ministry of Justice, Wellington, 2003) at 166.

Restoring Soul: Effective Interventions for Adult Victim/Survivors of Sexual Violence (Ministry of Women's Affairs, Wellington, 2009) at 12.

The New Zealand Crime and Safety Survey 2009 found that six per cent of people suffered 54 per cent of all crime in the previous year. See Multiple Victimisation in New Zealand: Findings from the 2009 New Zealand Crime and Safety Survey (Ministry of Justice, Wellington, 2011) at 1-6. Draucker, above n 81at 72-75; McKenzie-Mohr, above n 53, at 147-153.
} 
that victims' daily lives are not unduly constrained by fear and anxiety. For these reasons, reduction of anxiety alone is not an adequate therapeutic goal. However, the goals of developing insight and negotiating vulnerability I propose could assist victims to address fear and anxiety in a way that takes account of the social reality of sexual violence.

Similarly, the reduction of anger should not be a therapeutic goal of victim impact statements. Sexual violence violates the victim's rights and has a devastating impact. It is not surprising that many victims feel angry as a result. Victims' anger may be directed at the event, at the perpetrator, at people who failed to protect the victim or to respond supportively, at social conditions that feed sexual violence and at institutions that condone sexual violence or have failed to develop an adequate response to it. These are all legitimate sources of anger. The more appropriate goals, therefore, are to ensure that victims are not hurting themselves or anybody else as a result of any anger they are feeling, and to assist them to use their feelings in constructive ways. The former goal is incorporated within the first process of recovery I discuss, developing insight into the effects of the offending. The latter goal is part of the third process, grief and growth.

I turn now to a full discussion of how making a victim impact statement could assist victims with recovery from sexual violence.

\section{How making a victim impact statement can promote recovery from sexual violence}

In this section, I discuss in detail three ways in which making a victim impact statement may be helpful to victims in their recovery from sexual violence. First, writing a victim impact statement may help the person develop insight into the effects of the offending and the strengths and resources he or she has for coping with them. Secondly, making a victim impact statement may help the person negotiate the vulnerability arising from fear of exposure and uncertainty about the future. Thirdly, making a victim impact statement could facilitate grief and growth, processes of recovery for some people.

Most of the benefits I discuss in this section will come from writing a victim impact statement. Under my proposal, victims may then choose to keep their victim impact statements for themselves rather than submitting them for sentencing. For some victims, however, additional benefits may come from submitting the victim impact statement and possibly reading it aloud at the hearing. Any of these options would be acceptable under my proposal. Where information and support would maximise the benefits victims could gain from making a victim impact statement, I indicate that in my discussion. 
a) Developing insight

Writing a victim impact statement is an opportunity for the victim to reflect on and articulate the effects of the sexual violence and to identify the resources he or she has for coping with these effects and any assistance that may be needed. Developing this insight could promote recovery by making the effects of the sexual violence feel more manageable and by highlighting practical steps the person can take to deal with them. There is some empirical evidence that victim impact statements can serve this function. Two of the young women interviewed by Walberg-Hegan described the benefits of writing their victim impact statements in the following ways:

You start sitting there looking at your victim impact statement and you know what was wrong. You look at it and you say, "well I know how to fix it now." You look at it and say, "well I can go back to school, I know how to fix that, I feel confident, I can do this, I can do that", that's what you really feel. You get the help you need. $^{119}$

Putting together a victim impact statement helped me figure out how everything felt to me... Reading your victim impact statement to yourself can help you to let you know it wasn't your fault and that it affected your life. It's a big thing but you can move on and have a good life. ${ }^{120}$

There have been no studies directly assessing whether writing a victim impact statement can promote recovery by helping the person develop insight. Below is a discussion of relevant theory and empirical evidence from other contexts supporting my argument that the opportunity to articulate the effects of the sexual violence and identify resources available for coping with them could promote victims' recovery.

i) Articulating the effects of the incident of sexual violence As discussed in Section 2, the physical, psychological, social and material consequences of sexual violence can cause significant loss and disruption, and people need a way to start making sense of their experience. Writing a victim impact statement may help the person translate images, sensations and emotions into words. Writing may also assist the person to link feelings with thoughts and behaviours and attribute them to specific causes (for example, their fear of being killed during the assault, the loss of their relationship with the perpetrator, or their involvement with the criminal justice process). Establishing a coherent narrative of what is happening and why is likely to reduce victims' distress and

\footnotetext{
$119 \quad$ Walberg-Hegan, above n 13, at 90 (Elanor)

$120 \quad$ At 82 (Melanie).
} 
help them feel that the impact of the sexual violence is more manageable. ${ }^{121}$ In addition, it facilitates confiding in others, so the person can receive support. ${ }^{122}$ It may also be helpful for the victim to note in their victim impact statement other stressors they are experiencing, as these can add to the difficulty of coping with the impact of sexual violence. Being aware of this could help them reduce stress in other areas of their life, so they have more energy for addressing the impact of the sexual violence. ${ }^{123}$

As discussed in Chapter II, the current restrictions on the content of victim impact statements allow the person to link effects only with event factors (consequences that can be attributed directly to the perpetrator). This inhibits the possible effectiveness of victim impact statements in helping the person develop insight into the impact of the sexual violence and its interaction with other stressors. Victim impact statements would be more helpful if the current restrictions on content were relaxed, in order to allow people to describe the full impact of the sexual violence on them, and to make the cause and effect connections that the restrictions currently prevent. ${ }^{124}$

It could be helpful to provide information to victims about common effects of sexual violence for them to refer to when writing their victim impact statement. This would be particularly useful for people who are not accustomed to talking about their thoughts and feelings and who do not have high levels of self-awareness. It might also be helpful for those who are struggling with concentration and information processing because of the psychological effects of the sexual violence. Accessible information could reduce the cognitive effort required to write a victim impact statement. It would be important for any information provided to make clear that there is a wide range of possible responses to sexual violence, and that the list is a starting point. It should emphasise that the person may experience effects that are not on the list and they may not experience every effect listed. This is to ensure that the information does not make victims worry that their response is not "normal".

\footnotetext{
$121 \quad$ For evidence that writing about difficult experiences helps with cognitive processing and reduces distress, see James Pennebaker and Janel Seagal "Forming a Story: The Health Benefits of Narrative" (1999) 55 Journal of Clinical Psychology 1243; Scott Hemenover "The Good, the Bad, and the Healthy: Impacts of Emotional Disclosure of Trauma on Resilient Self-Concept and Psychological Distress" (2003) 29 Pers Soc Psychol Bull 1236.

122 John Harvey and others "Coping with Sexual Assault: The Roles of Account-Making and Confiding" (1991) 4 Journal of Traumatic Stress 515 at 520.

123 Daylen, van Tongeren Harvey and O’Toole, above n 82, at 41-42.

124 I will return to this in Chapter IV.
} 
A possible concern about providing information of this sort to victims for the purpose of assisting them to write their victim impact statements is that it could be leading. It could increase the likelihood of victims including effects which they are not experiencing or change the way victims phrase their victim impact statement. However, the reminder to consider carefully whether particular effects apply to them could alleviate this concern. Another option would be to ensure that victims are given the information earlier in the process, as part of the general support that is offered to them, rather than specifically for writing their victim impact statement. This might help them start thinking about how they have been affected by the sexual violence, but because it is not given to them specifically for the purpose of writing a victim impact statement, might raise less of a concern about it being leading.

ii) Identifying the resources available to cope with the impact of the sexual violence

Writing a victim impact statement could help the person identify resources he or she has for coping with the adverse effects of the sexual violence. This is important because asking only about adverse effects without also asking about strengths and resources could leave people "drowning" in them. ${ }^{125}$ Ecological models of sexual violence emphasise that the resources available for recovery will vary between individuals. They might include personal characteristics, knowledge, and skills that can help the person manage their distress and take steps towards reducing it. The person may have parts of their life that are going well, providing some protection for their self-esteem, a sense of purpose, and distraction from the parts that have been more severely affected by the sexual violence. ${ }^{126}$ Support from others is another resource for recovery, and may include both informal support (provided by friends, family, and other members of communities to which the person belongs) and formal support (provided by community organisations such as Rape Crisis, medical and mental health services, and social welfare support). ${ }^{127}$ Lynch and colleagues summarised their findings from research on resilience in women who had experienced interpersonal violence as follows: ${ }^{128}$

\footnotetext{
125 Ncazelo Ncube "The Journey of Healing: Using Narrative Therapy and Map-Making to Respond to Child Abuse in South Africa" (2010) 1 International Journal of Narrative Therapy and Community Work 3 at $4-5$. Harvey, above $\mathrm{n} \mathrm{56}$, at 21-22. For further discussion of self-care strategies used by people recovering from sexual violence see Vanja Stenius and Bonita Veysey “"'It's the Little Things": Women, Trauma and Strategies for Healing" (2005) 10 Journal of Interpersonal Violence 1155. Campbell, Dworkin and Cabral, above n 51, at 233-234. 75 at $83-84$.
} 
First, we noted their ability to make and sustain positive connections with other individuals and as members of a group, in essence to trust others even after experiencing interpersonal violence. Next, they clearly demonstrated the capacity to utilize opportunities to be successful and in that action, to recognize their skills and competencies even though many struggled with negative feelings about themselves. Finally, they all seemed to describe a process of self change that included developing and maintaining multiple, active coping strategies, a shift in the attribution of responsibility for the violence, a current focus on making different life choices, and holding onto hope through difficult times.

People may not always be aware of the resources they have that can help them in recovery. Writing a victim impact statement could prompt them to think about how they have been managing the impact of the sexual violence so far, highlighting strengths they have, good decisions they have made, and people who care about them. This is important to protect the person's sense of self-worth, give them hope that they will recover in time, and reinforce positive steps they have taken towards recovery. ${ }^{129}$ The information people are given should include suggestions of strengths and resources they may be drawing on to cope with the impact of the sexual violence. Asking about sources of resilience may also prompt people to think about further steps they could take or assistance that they need. Information about further help available in their communities should also be given to victims.

Some people may wish to write about only the negative impact of the sexual violence in order to emphasise the severity of the harm they have suffered. Others may wish to describe in detail only the ways in which they are responding to the impact and working to overcome it. Some people may cover both negative effects and responses to them, but be quite selective about what they include, in order to protect their own or others' privacy. Victim impact statements can best promote recovery when individuals have freedom of choice about what to include. This is one of the reasons why I argue in Chapter IV that the content of victim impact statements should not be used to assess the seriousness of the offence.

b) Negotiating vulnerability

One of the key tasks of recovery is negotiating vulnerability. Vulnerability has two aspects: the fear of exposure of our flaws and uncertainty about the future. These two concerns are particularly salient for victims of sexual violence, because of the feelings of

$129 \quad$ Ncube, above $\mathrm{n} 125$, at 4-5. 
powerlessness, worthlessness and shame which can arise from the experience. I address each of them in turn.

\section{i) Fear of exposure}

As discussed in Section 2, victims of sexual violence may feel damaged as a result of the experience, may believe that the impact on them reflects their own weakness or incompetence, and may feel judged or rejected by others' responses. As a result, they may feel shame. Shame is a feeling of exposure, defined as "[a]n intensely painful feeling or experience of believing we are flawed and therefore unworthy of acceptance and belonging." $" 130$ It is important to find ways to reduce this feeling, because it is so painful, and because it cuts people off from intimacy and belonging, and can prevent them from seeking support. In this section I discuss the long-term process of negotiating the fear of exposure component of vulnerability, and suggest some ways in which making a victim impact statement can assist with this process.

As I understand it, there are two steps to the process of negotiating the fear of exposure for sexual violence victims. The first step is for them to acknowledge that they were hurt by the sexual violence, and to become aware of all the ways it has affected them. The second step is to come to understand that the experience is not evidence of weakness and does not mean that they are damaged. Rather, they must accept the experience as part of themselves and believe that they are still worthy of acceptance and belonging. This means understanding that there is nothing wrong with them as a person because they were hurt and because they are struggling with the consequences of that. Both these things are part of being human and if they are flaws, they are ones we all have. As such, negotiating vulnerability is not about making something positive out of a negative experience. It is about learning to live with having had that experience. This is necessary for victims to reconnect with others, whether in intimate relationships or with their wider communities. Acceptance of personal vulnerability is also where empathy and compassion come from, valuable resources in relationships and for many types of contribution to the community.

Writing a victim impact statement could help victims negotiate the fear of exposure in relation to their experience of sexual violence. This is because it provides an opportunity for them to talk about it with somebody trustworthy, whether that is a victims' advisor, a counsellor, or someone with whom the victim has a personal relationship. What is

$130 \quad$ Brene Brown "Shame Resilience Theory: A Grounded Theory Study on Women and Shame" (2006) 87 Families in Society 43 at 45. 
crucial for helping victims to negotiate the fear of exposure is this person's response to what the victim shares about their experience. Empathy, compassion, information and alternative perspectives are the key ingredients of a response that can lessen victims' feelings of shame.

Responding with empathy means communicating understanding of the victim's experience without judgment. ${ }^{131}$ Responding with compassion means being willing to listen to the painful parts of the victim's experience, without being afraid of it, withdrawing from the victim, or trying to fix it. An empathic and compassionate response can help victims feel less alone. It can also show them that their experience is understandable to others and that there are people who can cope with knowing about it. Providing information about common effects of sexual violence and answering any questions the victim has can help to normalise the victim's experience. ${ }^{132}$ Providing alternative perspectives to shame-increasing beliefs the victim has about the meaning of sexual violence can help the victim reassess these beliefs. ${ }^{133}$ Information and alternative perspectives can provide a very good starting point for helping victims see that their experience does not indicate that there is something wrong with them as a person. Together, empathy, compassion, information and alternative perspectives can help victims to accept their experience of sexual violence as part of themselves and believe that they are still worthy of acceptance and belonging.

There is a risk that submitting a victim impact statement for sentencing, and even more so, reading it aloud at the hearing, will increase victims' feeling of exposure, making them feel more rather than less ashamed. In order to minimise this risk, it is important that victims know it is their decision what they disclose in a victim impact statement. They should be able to choose to include only what they feel relatively comfortable sharing with others. Their comfort may increase from having talked about it in a safe environment, but the more public nature of a victim impact statement means that extra care is required. Setting boundaries around disclosure is an important part of negotiating the fear of exposure. A successful experience of setting boundaries when making their victim impact statement might be useful for victims, as this is something they will probably need to do again in other contexts in the future. Secondly, it is important that the sentencing judge, counsel, court staff and other criminal justice professionals who are

\footnotetext{
$131 \quad$ At 47.

132 Rebecca Campbell and others ““"What Has It Been Like for You to Talk With Me Today?”: The Impact of Participating in Interview Research on Rape Survivors" (2010) 16 Violence Against Women 60 at $70-76$.

133 At $70-76$.
} 
present are careful with their responses to the victim impact statement. In order not to exacerbate feelings of shame, they should listen with respect and courtesy, and think carefully about the impact on the victim of any comments they make about the content of the victim impact statement.

\section{ii) Uncertainty}

As discussed in Section 2, traumatic experiences such as sexual violence can make victims much more aware of their own vulnerability to harm and loss, making the uncertainty of the future a more salient issue. Negotiating the uncertainty component of vulnerability is another task of recovery, important for addressing the effects of the sexual violence and for continuing with normative development. Recovery involves confronting difficult and painful questions, trying out new strategies, letting go of beliefs that are no longer useful, and relying on others for help and support. Parts of life that may be particularly difficult for somebody who has experienced trauma such as sexual violence include making plans with the knowledge that life can change suddenly and having relationships knowing they can lead to further pain and loss. ${ }^{134}$ All of these involve high levels of uncertainty. Negotiating the uncertainty component of vulnerability involves practising courage and trust, and developing faith in our own resilience. ${ }^{135}$

Making a victim impact statement, particularly if the person chooses to read it aloud at the sentencing hearing, could highlight for the victim his or her courage. Because the sentencing hearing is likely to be quite a memorable occasion, it has the potential to reinforce this message quite strongly. Some of the young women interviewed by Walberg-Hegan described the difficulty of making their victim impact statement, and how they felt having done it:

I got up there and I started shaking, my voice was shaking, I was slurring and I was stuttering, I started bawling my eyes out. It was hard, it was so hard, but I realized afterwards that it wasn't as hard as I thought it was, it was a lot easier because now that I'd gotten it all out it was a lot better for me. ${ }^{136}$

It's a great feeling knowing I got up there and I was strong enough to do that. You feel so strong like you can almost do anything and it makes you really happy, it doesn't drag you down. It doesn't make you feel like “I did this and now I'm going

\footnotetext{
$134 \quad$ McKenzie-Mohr, above n 53, at 126-207.

135 Judith Jordan "Valuing Vulnerability: New Definitions of Courage" (2008) 31 Women and Therapy 209.

136 Walberg-Hegan, above n 13, at 87.
} 
to cry about it now." Instead you feel "I did this, so I can do this, and this, and this too." It helps with your confidence especially when you're insecure about yourself. It gets you some security. You think, "hey, I'm not as bad as I thought I was." 137

I learned I was stronger than I thought I was by going through with delivering my statement. It's a good feeling because now I know I could do it again if I needed to. $^{138}$

Making a victim impact statement could also highlight for victims times when they have trusted others or themselves, and their other strengths and resources that contribute to their resilience. ${ }^{139}$

\section{c) Grief and growth}

Harvey and colleagues defined a major loss event as "an event that initially diminishes self. Such as event may reduce one's dignity, will, or resources, including close others." 140 As illustrated by the discussion in Section 2, being the victim of sexual violence is certainly a major loss event by this definition. Some people consider themselves recovered from this sort of loss when it no longer inhibits their day to day functioning or causes them high levels of distress. Keeping going despite the loss is a successful outcome. ${ }^{141}$ For others, however, recovery involves a further stage of grief and often growth. In this section I discuss how victim impact statements can assist with this process, for those who are at a point in their recovery where this is relevant. It is most likely to be helpful for those who have developed strategies to manage the impact of the sexual violence, and thus have the cognitive and emotional resources to engage in further exploration of the meaning of their experience. ${ }^{142}$

In this stage of recovery people explore the meaning of their experience, in terms of how they see themselves, others, and the world. Each person makes sense of their experience in their own way, influenced by their personal history, the circumstances of the assault, and their social and cultural context. When thinking about what they have lost as a result of the sexual violence, and what that experience means for their present and future,

\footnotetext{
$137 \quad$ At 90 .

$138 \quad$ At 83.

139 See the discussion in (a).

140 John Harvey and others "House of Pain and Hope: Accounts of Loss" (1992) 16 Death Studies 99 at 102 .

141 John Harvey, Katherine Barnett and Amanda Overstreet "Trauma Growth and Other Outcomes Attendant to Loss" (2004) 15 Psychological Inquiry 26 at 26-27.

142 Harvey and others, above n 140, at 103-104.
} 
people often experience grief. Grief often extends beyond their own experience, to include the suffering of others. When people are able to tolerate those feelings and use them to guide their exploration of the meaning of their experience, they are able to expand their understanding to accommodate the loss. It can be an extremely painful, deeply confusing process, the result of which is often a change in their sense of self. ${ }^{143}$ The sexual violence remains a profoundly negative experience, but it is one which the person understands and has been able to integrate into their life, as one part of it.

For some people, the struggle to make sense of their experience of sexual violence can lead to growth. ${ }^{144}$ Tedeschi and Calhoun defined post-traumatic growth as: ${ }^{145}$

the experience of individuals whose development, at least in some areas, has surpassed what was present before the struggle with crises occurred. The individual has not only survived, but has experienced changes that are viewed as important, and that go beyond what was the previous status quo. Posttraumatic growth is not simply a return to baseline - it is an experience of improvement that for some persons is deeply profound.

Positive changes associated with recovery from sexual violence that people have reported include a sense of becoming stronger as a person, ${ }^{146}$ liking themselves more, ${ }^{147}$ and learning to take better care of themselves. ${ }^{148}$ This may involve being more cautious about who they spend time with, and making sure that they only have relationships with people with whom they feel safe and respected. ${ }^{149}$ They have also talked about the experience bringing them closer to important people in their lives, and becoming more trusting of others as a result of talking with them about their experience. ${ }^{150}$ Some people spoke of the recovery process as being an opportunity to re-examine their beliefs and priorities and make changes in their lives, ${ }^{151}$ as increasing their political awareness, ${ }^{152}$ as deepening

\footnotetext{
$143 \quad$ At 102 .

144 Draucker, above n 81, at 79-80.

Richard Tedeschi and Lawrence Calhoun "Posttraumatic Growth: Conceptual Foundations and Empirical Evidence" (2004) 15 Psychological Inquiry 1 at 4. Draucker, above n 81, at 78; Kingi and others, above n 66, at 152.

Kingi and others at 152; Smith and Kelly, above n 112, at 347.

Draucker, above n 81, at 72-75; Kingi and others, above n 66, at 153.

Draucker at 74.

Smith and Kelly, above n 112, at 346.

Smith and Kelly at 346.

Foliano, above n 94, at 50; McKenzie-Mohr, above n 53, at 14-15.
} 
their spirituality ${ }^{153}$ and as heightening their gratitude. ${ }^{154}$ Some described how they are using what they have learnt from the experience to help themselves and others. ${ }^{155}$

It is not a coincidence that the types of positive changes commonly reported by those recovering from sexual violence tend to be in the areas threatened most severely by the experience. The person's awareness of the loss or damage to parts of themselves may push them to seek opportunities to repair and strengthen these areas. ${ }^{156}$ Further, the level of vulnerability after an incident of sexual violence means that relevant experiences (for example, achievements that affirm their self-worth or finding a trustworthy person to spend time with) may have more of an impact on the person than they would at other times, so there is increased potential for growth in the areas affected. ${ }^{157}$ Post-traumatic growth occurs when these positive experiences change the person's sense of self or beliefs about the world. The experience of sexual violence itself is not viewed as a positive event, but some of the changes as a result of their struggle with it are highly valued. ${ }^{158}$

Writing about difficult experiences can facilitate grieving and post-traumatic growth when the writer is engaged in both cognitive and emotional processing of the event. ${ }^{159}$ This means deliberately exploring what has been lost as result of the traumatic event, what has been learnt or the ways in which the person has grown as a result of their struggle with it, and how the person's life has changed as a result of the experience. Jennifer Pals called this type of thinking "exploratory narrative processing" and found that it is facilitated by activities in which the person puts their experience into words, for example writing, talking with others, and prayer. ${ }^{160}$ Change in the person's sense of self happens incrementally, through this process of putting the experience into words and developing it into a narrative of loss, change and growth. ${ }^{161}$

\footnotetext{
$153 \quad$ Smith and Kelly, above n 112, at 345-346.

$154 \quad$ Kingi and others, above n 66, at 152.

155 Draucker, above n 81, at 78-79; Kingi and others, above n 66, at 152.

156 Lynch and others, above n 128, at 84-91.

157 Kate McLean and Michael Pratt "Life's Little (and Big) Lessons: Identity Statuses and MeaningMaking in the Turning Point Narratives of Emerging Adults" (2006) 42 Developmental Psychology 714 at 715 . Posttraumatic Growth" (2004) 15 Psychological Inquiry 65 at 66.

See generally Hemenover, above n 121.

Jennifer Pals "Narrative Identity Processing of Difficult Life Experiences: Pathways of Personality Development and Positive Self-Transformation in Adulthood" (2006) 74 Journal of Personality 1079 at 1080.

Kate McLean, Monisha Pasupathi and Jennifer Pals "Selves Creating Stories Creating Selves: A Process Model of Self-Development" (2007) 11 Pers Soc Psychol Rev 262 at 264.
} 
Writing a victim impact statement could facilitate grieving and post-traumatic growth by helping people become aware of the loss or damage to parts of themselves caused by the incident(s) of sexual violence, highlighting positive changes in these areas as a result of the person's work at recovery, and helping the person develop the experience into a narrative which can be integrated into their life story and sense of self. These are sequential steps (although the recovery process is not linear because it involves revision of earlier stages ${ }^{162}$ ). Which step(s) writing a victim impact statement could facilitate for an individual will depend on how advanced the person's recovery is. Constructing a narrative of change and growth takes time, but the more opportunities the person has to share and develop their narrative, the better they will be able to incorporate it into their sense of self. ${ }^{163}$ The courtroom is not normally considered an appropriate venue for this kind of goal. However, the symbolic nature of the sentencing hearing and the authority of the court could offer people making a victim impact statement some validation of its content. This could help to cement positive changes in the person's view of themselves and the world. The importance of being able to include positive outcomes in a victim impact statement without risking an undesired effect on the sentence is another reason that I argue in Chapter IV that victim impact statements should not be used to assess the seriousness of the offence.

\section{General Principles for Victim Impact Statements}

In this section, I outline some general principles for the design and implementation of victim impact statements. These principles must be followed if victim impact statements are to achieve the aims set out in Parts A, B and C. They are also necessary to minimise the risk that making a victim impact statement will cause further harm to victims. The principles I discuss are safety, choice, empowerment, information, and support and guidance.

\section{Safety}

Making a victim impact statement could put the victim's safety at risk in three ways. First, it could expose victims to additional pressure from offenders or others. Secondly, it could increase their vulnerability to further harm from the offender or increase their feelings of intimidation. Thirdly, sentencing may be too early in some victims' recovery for them to begin thinking about the full extent of the harm they have suffered. Doing so could be overwhelming and unsafe for the victim. These are risks which must be 
managed if victim impact statements are not to do further harm to victims. As part of my discussion, I suggest some ways in which this could be done.

a) Pressure

Pressure on victims from offenders or others is of particular concern in sexual violence cases, and is relevant at every stage of the investigation and prosecution process. There are some particular concerns about pressure under my conceptualisation of victim impact statements. First, there may be pressure on victims not to make a victim impact statement. This pressure could be increased if victim impact statements are clearly represented as voluntary, as I am suggesting. Secondly, giving victims direct input into the sentence could increase pressure on victims to make particular representations or requests. For example, victims may be pressured to say that they do not feel at risk from the offender, that the length of the sentence proposed by the prosecutor is too severe or that a custodial sentence would have a negative impact on them. Victims who do not comply with demands may fear retaliation from the offender or the offender's associates, or may suffer further breakdown of family or community relationships.

Ensuring the safety of victims is a difficult task at any stage of the criminal justice process. The possibility of pressure is something for the police and victims' advisors to be aware of and to manage. As long as there is a robust process for responding to it, the risk of pressure being placed on victims does not outweigh the potential benefits of making victim impact statements genuinely voluntary and of allowing victims direct input into the sentence. The reason for these reforms is to prevent further harm to victims through the process of making a victim impact statement and the sentencing outcome. Pressure is a real concern, but not one that is answered by continuing to represent victim impact statements as a requirement or declining ever to take victims' views on sentence into account. $^{164}$

b) Increased vulnerability to intimidation

If the victim submits a victim impact statement for sentencing, the offender will have the opportunity to read it. If the victim reads it aloud in court, it will be in the presence of the offender and any of the offender's supporters who are there. This raises several safety concerns. First, giving offenders access to information about how the offending has affected the victim may increase the victim's vulnerability to harm from that person in

$164 \quad$ Under the current approach, pressure is also a possibility, as victims may be told to say that they have suffered minimal harm. Further, the lack of a robust process for the submission of victims' views on sentence means that, while the courts are aware that pressure is a concern, there is no processing enabling them to ascertain the genuineness of a request for leniency. 
the future. Secondly, the victim might feel intimidated by the thought of the offender reading the victim impact statement, or of reading it aloud in court in front of the offender and any of the offender's supporters. These are issues which victims may need to consider when deciding whether to make a victim impact statement. Those who do decide to make one may need to leave out certain aspects of their experience, and may prefer not to read it aloud themselves at the hearing.

The Victims' Rights Act includes some provisions which could reduce risks of vulnerability to further harm and intimidation. There are provisions to prevent offenders from keeping a copy of the victim impact statement ${ }^{165}$ and requiring that any copies held by the defence be returned at the end of the case. ${ }^{166}$ There is also provision for parts of the victim impact statement to be withheld from the offender to protect the victim's physical safety, ${ }^{167}$ but sentencing judges may not take any information that has been withheld into account in the sentencing decision. ${ }^{168}$ The sentencing judge may also make orders about copying and disclosure of all or parts of the victim impact statement in order to protect the physical safety, emotional welfare, and privacy of the victim. ${ }^{169}$ Victims who want their victim impact statement presented in court do not have to read it themselves. They have the option of nominating a representative to read it, or submitting it in an alternative way. The Victims' Rights Act gives audio or video tape as examples of alternative modes of presentation. ${ }^{170}$ Ensuring that victims are aware of these options and are consulted on whether the prosecutor should make an application would help to make these provisions more effective in protecting victims' safety.

c) Psychological distress

Most victims are likely to experience some distress when writing their victim impact statements, because of the nature of the material about which it requires them to think. Distress can become a safety issue if it leads to the escalation of psychological problems, reckless behaviour, self-harm and risk of suicide. ${ }^{171}$ This could occur if it is too early in the victim's recovery to undertake the kind of exploration a discussion of the impact of the offending involves. It could also occur if the person does not have sufficiently well

\begin{tabular}{ll}
\hline 165 & Section 23. \\
166 & Section 24. \\
167 & Section 25. \\
168 & Section 26. \\
169 & Section 27. \\
170 & Section 19. \\
171 & Sexual Abuse and Mental Injury, above n 113, at 21.
\end{tabular}


developed self-care skills (in particular distress tolerance, emotional regulation, and problem-solving) or if the person does not have enough support from others. ${ }^{172}$

It would be useful for victims' advisors or counsellors to discuss this issue with victims and offer guidance around it. In some cases, it may be better for the person to refrain from making a victim impact statement at that time. Alternatively, the person might wish to make one but need additional support to do so, whether from professionals or through their informal support networks. As part of this, victims could be offered resources including information about self-care and strategies for managing distress. The chapter entitled "A Psychological Tool Box" in the book Trauma, Trials and Transformation provides an example of this kind of information. ${ }^{173}$ The chapter is written specifically for survivors of sexual violence who are participating in the legal process. It explains a range of coping strategies that they might find valuable. A similar guide could be produced and given to complainants where appropriate, preferably early in the process, so they have it available as a resource for managing any distress they experience.

\section{Choice}

It is very important that victims are informed that making a victim impact statement is voluntary, and that if they do make one, it is their decision as to what to disclose. There are two reasons for this. First, the violation of autonomy inherent in sexual violence means that any situation which takes control away from the victim presents a risk of doing further harm. ${ }^{174}$ Secondly, the sense of exposure that many victims are likely to feel after the offending, the investigation and the prosecution could be exacerbated if they also felt required to include in their victim impact statements aspects of their experience they would prefer to keep private. Emphasising that the victim has a choice whether to make a victim impact statement and, if so, what to include, could help protect victims from further harm.

\footnotetext{
$172 \quad$ At 24.

173 Daylen, van Tongeren Harvey and O'Toole, above n 82, at 137-177.

174 See the discussion in Part A of this chapter.
} 


\section{Empowerment}

Cattaneo and Goodman described empowerment as made up of two core components: ${ }^{175}$

a psychological sense of power-an understanding of what one wants and needs and a feeling that one can reach those goals - and a real ability to effect change in important outcomes.

If making a victim impact statement is to be an empowering process for victims, it should include both these components.

The opportunity to have direct input into the sentence (through a request for reparation, informing the court of ongoing safety concerns, and informing the court of impact of the proposed sentence) could target both components of empowerment. Formulating their input could help victims reach a clearer understanding of their needs and wishes in relation to the outcome of the case. Having their input given serious consideration by the judge, and possibly seeing it reflected in the outcome, can show victims that they do have the ability to effect change. In cases where the sentencing outcome does not reflect the victim's wishes, the reasons for this should be explained to the victim, in order to minimise the risk that the experience will be disempowering.

Empowerment is a core part of recovery, because the experience of sexual violence and its aftermath leaves victims feeling powerless. Accordingly, empowerment is part of each of the processes of recovery with which I have argued making a victim impact statement could assist. Developing insight into the effects of the sexual violence and their resources for coping with it can increase victims' sense of psychological power. Having insight allows victims to take further steps to address the impact of the sexual violence, thereby giving them a real ability to effect change in their own lives. Secondly, in order to regain (or gain for the first time) a psychological sense of power, victims must come to terms with their vulnerability as revealed or reinforced by their experience of sexual violence. Being able to accept the experience as a legitimate part of themselves and developing a sense of resilience in order to face the uncertainty of the future increase victims' psychological sense of power. Finally, the learning and development that come out of the process of grief and growth increase both victims' psychological sense of power and their actual ability to make changes in their own lives and in the lives of others.

175 Lauren Bennett Cattaneo and Lisa Goodman "Through the Lens of Therapeutic Jurisprudence: The Relationship Between Empowerment in the Court System and Well-Being for Intimate Partner Violence Victims" (2010) 25 J Interpers Violence 481 at 483-484. 


\section{Information}

Victims should have clear information about the purposes of making a victim impact statement. This information should include an explanation of the role their views on sentence will play in the decision-making process. It should also include a clear statement about what content is permissible. An information booklet could accompany the victim impact statement form setting this information out clearly. The information could be reiterated by a victims' advisor if necessary, who could also answer any questions the victim has. This would allow victims to make an informed decision about whether to make a victim impact statement and, if so, what to include. It could avoid raising expectations about the influence of their victim impact statement on the sentence which will not be fulfilled. It would also mean that people will be able to write their victim impact statements in a way that is appropriate for their purpose, avoiding the need for "censorship" later on.

Providing information could also make it more likely that victims will benefit from making a victim impact statement, particularly in relation to recovery. If victims are to think about their victim impact statements as a tool for recovery (rather than only as a means to have direct input into the sentence or address the offender) they may need their attention drawn to the ways in which making a victim impact statement could assist with it. In addition, the form or information booklet could contain some questions or prompts, to help victims think about their experience. Victims could be invited to structure their victim impact statement around those questions, or to incorporate any of their answers into a narrative they have structured themselves. Ensuring that the questions or prompts are open-ended would avoid leading victims to particular answers.

As discussed earlier, information about the common effects of sexual violence and the kinds of strengths and resources that help people cope could be useful for people writing victim impact statements. More general resources such as feelings charts could also be helpful for people who are struggling to find the words to express themselves. It might be better for this sort of information to be provided by a victims' advisor on a discretionary basis, rather than automatically given to victims as part of an information pack. This is because of the need to ensure that the information people are given is appropriate to their needs. In particular, it is important to ensure that people are given only the type and amount of sexual violence-specific information that they can cope with 
at the time. ${ }^{176}$ They may also have questions about the information, so having the opportunity to discuss it with the person giving it to them could be beneficial.

\section{Support and guidance}

For making a victim impact statement to be safe and helpful for victims, it is important that support and guidance from a victims' advisor is available. The role of the victims' advisor needs to be carefully defined (for example, they are not counsellors or lawyers) and the question of confidentiality considered and explained to victims. This is very important because the question of appropriate boundaries may be especially salient for victims of sexual violence. The role should be filled by someone with appropriate experience, training and supervision, as these tasks are quite demanding.

As discussed earlier, information provision should be part of the role. A second part of the role should be to check the victim's safety and if there are concerns, to take appropriate steps. The ACC Practice Guidelines for Sexual Abuse Counselling recommend that safety in four areas be assessed: ${ }^{177}$

(a) risks to self (internal) such as suicidality, self-harm, medical and extended mental health needs;

(b) external risks to self such as substance abuse and unsafe sexual practices;

(c) risks from others, such as further sexual or physical abuse, witnessing domestic violence, and neglect;

(d) risks to others, including abuse or neglect of children.

A safety decision tree, setting out appropriate responses where there are safety concerns, is set out in the document. ${ }^{178}$ This decision tree could be followed by victims' advisors as well.

The quality of the interaction between victims' advisors and victims is important, if it is to be supportive and helpful for victims. Some general principles can be taken from a different context, also involving a short-term relationship with a specific purpose: research interviews with sexual violence victims. Community psychologists Rebecca Campbell and colleagues followed the following six principles when conducting their research: ${ }^{179}$

\footnotetext{
Sexual Abuse and Mental Injury, above n 113, at 30 and 39.

$177 \quad$ At 21.

$178 \quad$ At 57

179 Campbell and others, above n 132, at 65.
} 
First, the emotional well-being of the survivors was always our primary concern. If a survivor seemed particularly distressed, the interviewer should stop, offer comfort, and discuss with the participant whether she wanted to continue. Second, even though this was a structured interview, women should be given time to tell their stories in their own words, for however long that may take. Third, the interviewer needed to show patience and respect while the women's stories unfolded. It was important to affirm that it was always the survivors' choice what they chose to disclose or not disclose. Fourth, interviewers should encourage the participants to ask questions and be prepared to answer their questions and engage in dialogue with the participants. Fifth, interviewers should provide information to women that may help them understand or normalize their experiences. Finally, the emotional tenor of the interview should reflect warmth, compassion, and understanding.

The research participants identified these principles as helping them to feel comfortable in the interview and as providing some benefits of participating in the research. ${ }^{180}$ These are appropriate principles for victims' advisors to apply to their interaction with victims, whether it is a one-off meeting or involves some ongoing interaction.

\section{E Summary}

In this chapter, I set out a new role for victim impact statements. I discussed three ways in which they could be reformed in order to meet victims' needs and protect their interests more effectively. First, I argued that victim impact statements could provide an opportunity for the court to recognise the wrongfulness of the offending and acknowledge the harm done to the victim, and to recognise the relationship that exists between the victim and the offender as a result of the offending. Secondly, I argued that victim impact statements could protect victims' interests in the sentence. These interests are in reparation, prevention of further harm from the offender, and prevention of further harm to the victim from the sentence imposed on the offender. Thirdly, I argued that making a victim impact statement could assist victims to recover from the offending. I also set out some general principles for the design and implementation of victim impact statements. These principles must be followed to minimise the likelihood of victims suffering further harm from making a victim impact statement, and to maximise the likelihood that the experience will be helpful to them. In Chapter IV, I address the implications of this new role of victim impact statements. 


\section{Implications of the Proposed Role of Victim Impact Statements}

In Chapter II, I discussed the current restrictions on the permissible content of victim impact statements. The courts imposed those restrictions in accordance with their decision that the primary purpose of victim impact statements is to provide information about harm, to assist the judge to assess the seriousness of the offending. I argued that the extent to which these restrictions are justified on the basis of relevance to the assessment of seriousness is unclear, because the courts have not fully engaged with the question of the role harm should play in offence seriousness.

In Part A of this chapter, I return to the question of the proper role of harm in offence seriousness, in the context of sentencing for sexual violation. I argue that the harm caused to the victim should not be taken into account as an aggravating feature of the offending, as it currently is. Accordingly, victim impact statements should not be used to assess the seriousness of the offending. In Part B, I discuss what content should be permissible in victim impact statements, in light of the new purposes of victim impact statements I proposed in Chapter III and my argument that victim impact statements should not be used to assess the seriousness of the offending. I argue that the need to protect the dignity of the offender should be the justification for imposing restrictions on content. I specify some necessary restrictions and discuss a process for enforcing them that is respectful to victims. Finally, in Part C I consider the practical implications of the new role for victim impact statements proposed in this dissertation.

\section{A The Assessment of Offence Seriousness}

Victim impact statements should not be used to assess the seriousness of the offending in sexual violation cases. While the main reason for making this argument is that I consider this a more principled approach to sentencing, it may also increase the likelihood that making a victim impact statement is beneficial for victims. I discuss each argument in turn.

\section{Sentencing principles}

Assessment of the seriousness of the offending is the first step in sentencing for sexual violation. The Court of Appeal's guideline judgment, $R \vee A M$, sets out a number of

culpability assessment factors. ${ }^{1}$ The number of factors present in the case, and the extent to which they are present, determines which "band" the offending is placed into. For sexual violation by rape, there are four bands. Band one is 6-8 years, band two 7-13,

\footnotetext{
$R \vee A M(C A 27 / 2009)[2010] 2$ NZLR 750.
} 
band three 12-18 and band four 16-20 years. ${ }^{2}$ Sexual violation by unlawful sexual connection has three bands. Band one is $2-5$ years, band two is $4-10$ and band three is 9-18 years. $^{3}$ The judge then selects a starting point from within the appropriate band. Accordingly, the starting point reflects the seriousness of the offending.

Harm to the victim is one of the culpability assessment factors in $A M$. Sentencing judges are required to determine whether the harm in the particular case is serious enough that it is above the level of harm inherent in the offending. If it is, harm is taken into account as a factor increasing the offender's culpability. The relevant passage from $A M$ reads as follows: ${ }^{4}$

Harm is inherent in the offending. The more harmful the offending, the more serious it is. Section 9(1)(d) of the Sentencing Act applies. Physical harm, for example, cuts and bruising, are indications that the offending is more serious. Similarly, if the offending involves unprotected sex with the risk of pregnancy or infection or if it has those effects these factors indicate more serious offending. However, this is not to downplay the psychological and other non-physical harm, for example, escalation of psychological problems and restrictions on the ability to go about the victim's daily life. The impact on others, such as children, other family members or those providing care and support to the victim is also relevant.

One issue is that $A M$ provides sentencing judges with very little guidance about the level of harm, particularly non-physical harm, that could be considered inherent in sexual violation. ${ }^{5}$ As a result, there is no consistent way of assessing whether the harm in the particular case, as revealed by the victim impact statement, is above that level.

The issue I focus on here, however, is a more fundamental one. The starting point for the sentence should be commensurate with the blameworthiness of the offender. Taking harm into account as an aggravating feature in its own right disrupts commensurability in two ways. First, harm for which the offender is directly responsible is already taken into account in other ways. Including harm as an aggravating feature risks double-counting conduct constituting other aggravating features. Secondly, harm for which the offender is not directly responsible should not be taken into account. When harm is an aggravating feature in itself, there is an element of chance in the selection of the starting point, which

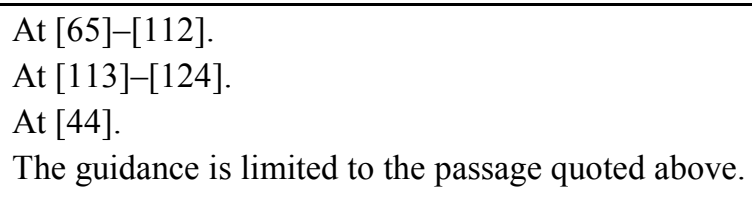


is improper because the starting point should be determined by blameworthiness. I discuss each argument in turn.

a) Harm which is attributable directly to the offender

The seriousness of the harm inherent in sexual violation has already been taken into account in setting the range of penalties. It is reflected in the 20 year maximum penalty and the legislative presumption in favour of imprisonment. ${ }^{6}$ The range of starting points for even the lowest level of seriousness (band one) is also quite high: 6-8 years for rape and 2-5 years for unlawful sexual connection. ${ }^{7}$ Aspects of the offender's conduct which are likely to increase the level of harm above that inherent in sexual violation are already taken into account as aggravating features (or culpability assessment factors, to use the language of $A M$ ). If serious physical injury or death results, the charges will reflect this. It is therefore unnecessary for harm also to be a culpability assessment factor in itself.

Conduct constituting aggravating features (or other offences) may increase the seriousness of the types of harm that are inherent in sexual violation, or it may cause other types of harm. In Chapter III, I suggested three categories of interests threatened by sexual violence. I argued that interference with the interests in category one (sexual autonomy, dignity, integrity, and safety) is inherent in any instance of sexual violence. Interference with the interests in category two (capacity for intimacy, sense of belonging, and the ability to contribute to the community) may result from any instance of sexual violence. Category three comprises interests which may be interfered with, depending on the circumstances of the offending (for example, freedom from physical injury beyond the injury inherent in sexual violation, security of one's home).

When a sexual offence involves interference with category three interests, often the conduct that caused this interference will already be counted as a separate aggravating factor or offence. For example, home invasion and additional violence are already taken into account as factors increasing culpability. ${ }^{8}$ Determining that the harm in the particular case was more serious because it included interference with the victim's interests in security of the home and freedom from physical injury would be counting the same conduct twice. Moreover, factors which are likely to increase the extent to which category one and two interests are interfered with by the offending can also be counted as separate factors increasing culpability under $A M$. Where the victim was particularly

Crimes Act 1961, s 128B.

$R v A M$, above $\mathrm{n} 1$, at [93]-[97] and [114]-[116].

At [38]-[41]. 
vulnerable (and the offender was aware of that vulnerability) ${ }^{9}$ or the victim was targeted because the offender believed he or she belonged to a particular group (making the offending a hate crime $)^{10}$, the seriousness of the offence is increased. A breach of trust ${ }^{11}$ and the involvement of multiple offenders ${ }^{12}$ are also factors increasing the seriousness of the offending. Further, the scale of the offending is relevant to seriousness. If it involved more than one incident, repeated violations, associated degradation and indignities, cruelty or callousness, it will be more serious. ${ }^{13}$ Similarly, if there was a high degree of violation, the offending will be more serious. ${ }^{14}$ The presence of any of these factors increases the culpability of the offender, because they increase the likelihood of harm to the victim. As a result, taking harm into account as a factor in its own right risks doublecounting.

b) Harm which is not directly attributable to the conduct of the offender

The second problem with taking harm into account as a factor in its own right is chance. The seriousness of the harm in a particular case does not necessarily correspond with the culpability of the offender as assessed using the aggravating features in $A M$. As discussed in Chapter III, the extent of the harm suffered is determined by the interaction between factors related to the offence and factors related to the victim's personal and social circumstances. In some cases, the harm suffered by the victim may be judged to be more serious than the level of harm inherent in the offending when no or few other factors increasing culpability are present.

It could be argued that by engaging in the criminal conduct in the first place, the offender assumed the risk of causing whatever harm resulted from it, and should be held accountable for that harm. However, using this approach means that two offenders committing identical offences against different victims could be punished differently. As the assessment of offence seriousness is made in order to determine the appropriate degree of censure, the blameworthiness of the offender is the primary consideration. Setting different starting points for the same conduct would be unjust. As Cavadino argued: ${ }^{15}$

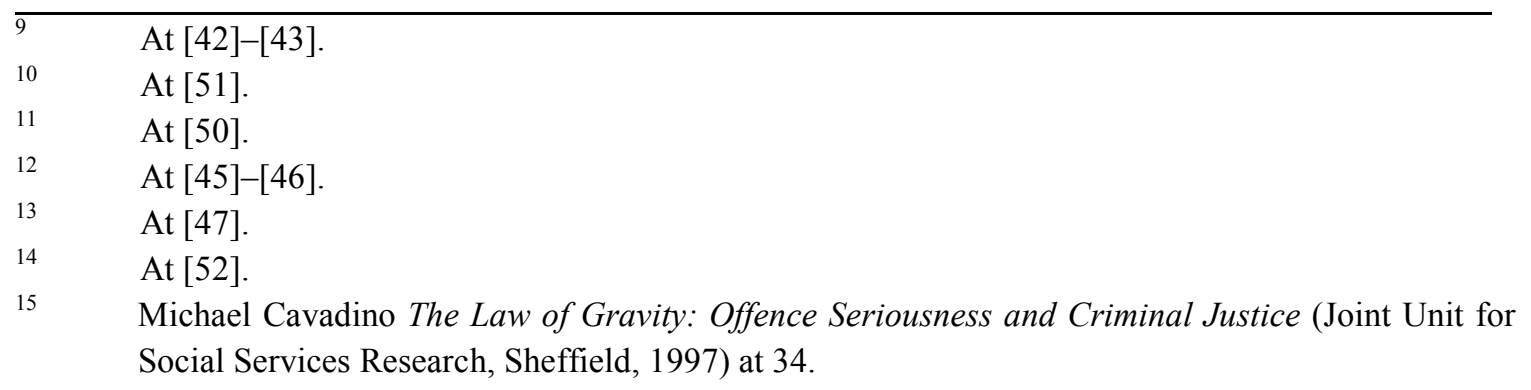


...it may be questioned whether a punitive sentence should in justice take account of the offence's actual consequences rather than of the results which the offender risked bringing about, since it is the latter which is relevant to blameworthiness. Would it be fair for an offender to get a heavier sentence because the victim or the victim's family turned out to be unexpectedly or unusually vulnerable? And if lack of sympathy for offenders leads us to hesitate over this question, what of its logical corollary: should the sentence be less if by similar chance the victims are unusually robust?

The harm which the offender risked bringing about is taken into account as the level of harm considered inherent in the offending (which sets the range for band one) and through the other culpability assessment factors. The harm actually caused should not also be taken into account as a factor in its own right. The proper measure of offence seriousness in this context is the offender's culpability (the harm risked by the offender when engaging in the criminal conduct) rather than the harm that may or may not have actually resulted from that conduct. ${ }^{16}$ Accordingly, information provided in victim impact statements about the actual harm suffered by the victim is not relevant to the assessment of offence seriousness. Information about conduct increasing the risk of harm (and therefore the offender's culpability) should be available from the evidence in the case, whether presented at trial, in the agreed summary of facts or in a disputed facts hearing.

There is a risk that the content of victim impact statements may influence sentencing judges' assessment of the seriousness of the offence, even if they believe they are not taking it into account. The emotional tone of the statement and the information provided in it about the offending itself and its effects on the victim may affect the judge's perception of whether aggravating features are present. Empirical research has demonstrated that judges, like everyone else, are susceptible to cognitive errors in decision-making. This includes being influenced by inadmissible evidence. ${ }^{17}$ If judges are mindful of their susceptibility to making these errors and are reflective about their decision-making process, this could help them manage the risk of improper influence. ${ }^{18}$ Judicial education is one way to encourage this awareness. Further, the structured

$16 \quad$ Cavadino at 34; Hyman Gross Crime and Punishment: A Concise Moral Critique (Oxford University Press, Oxford, 2012) at 56.

17 For a review of experimental studies, see Jennifer Robbennolt "Evaluating Juries by Comparison to Judges: A Benchmark for Judging?” (2005) 32 Florida State University Law Review 469 at 486-502.

18 Jeffrey Rachlinski and others "Does Unconscious Racial Bias Affect Trial Judges?" (2009) 84 Notre Dame L Rev 1195 at 1221. 
decision-making process of sentencing and the requirement to give reasons in writing ${ }^{19}$ can assist judges to ensure they are only taking relevant information into account. ${ }^{20}$ Accountability through appellate review is an additional safeguard. While it will not usually be apparent whether the judge was in fact unconsciously influenced by irrelevant material, the appellate court can at least review the evidence in the case and ensure that the sentence is not outside the appropriate range.

\section{Promotion of recovery}

It is important that victims are told, when deciding whether to make a victim impact statement, that what they say about the impact of the offending on them will not influence the sentence. They should be told that they could, however, influence the sentence if they include a request for reparation, concerns about their safety from the offender, or their response to the sentence proposed by the prosecutor. If victims want to have input into the sentence in this way, the other factors the judge must consider should also be explained to them, so victims are aware that their wishes may not be reflected in the outcome. Giving victims this information will avoid raising their expectations about the influence of victim impact statements on the sentence which may not be fulfilled. ${ }^{21}$ It also allows victims to make an informed decision about whether to make a victim impact statement and, if they do make one, what to include.

In Chapter III, I argued that one purpose of victim impact statements should be to promote the victim's recovery. In this section, I argue that the decision that victim impact statements should not be used to assess the seriousness of the offence means that they may be better able to promote recovery. This is because victims' decisions about whether to make a victim impact statement and, if so, which aspects of their experience they wish to include, are less likely to be influenced by their desire to affect the sentence.

\footnotetext{
$19 \quad$ Sentencing Act, s 31.

20 Vicki Waye "Judicial Fact-Finding: Trial by Judge Alone in Serious Criminal Cases" (2003) 27 Melb U L Rev 423 at 441; Jeremy Finn, Elisabeth McDonald and Yvette Tinsley "Identifying and qualifying the decision-maker: The case for specialisation" in Elisabeth McDonald and Yvette Tinsley (eds) From "Real Rape" to Real Justice: Prosecuting Rape in New Zealand (Victoria University Press, Wellington, 2011) 221 at 243-244.

21 For discussion of this concern, see Andrew Ashworth 'Victims' Rights, Defendants' Rights and Criminal Procedure" in Adam Crawford and Jo Goodey (eds) Integrating a Victim Perspective within Criminal Justice: International debates (Dartmouth Publishing, Aldershot, 2000) 185 at 198.
} 
Instead, victims can make a decision based on what is best for them in terms of their recovery. $^{22}$

In my discussion of how writing a victim impact statement could assist victims with recovery, I emphasised the importance of victims being able to include information about the strengths and resources they could draw on to help them cope with the adverse impact of the sexual violence. I also argued that it could be helpful to some victims to be able to include positive outcomes resulting from their efforts to address the impact of the sexual violence. If the harm suffered by the victim is taken into account as a factor increasing the seriousness of the offence, victims who want a more severe sentence for the offender may be reluctant to include information about strengths, resources and positive outcomes. This is because the inclusion of this kind of information could be taken as evidence that the harm was less serious, resulting in a lower starting point than if the information had not been included. However, if victims leave out information about strengths, resources and positive outcomes because of this concern, the effectiveness of victim impact statements in promoting recovery will be limited.

Conversely, victims who want a lenient sentence to be imposed on the offender may be reluctant to include all the adverse effects of the offence on them and may not engage with questions about what they have lost as a result of the offending. As I argued in Chapter III, being able to write about these aspects of their experience is also important for victims' recovery. For these reasons, the decision that harm should not be taken into account as a factor in its own right may make victim impact statements more likely to promote victims' recovery. Victims who wish to include information about strengths, resources and positive outcomes could do so with less concern that it will result in a more lenient sentence than would otherwise be imposed. Victims who wish to include information about the adverse effects of the offence and what they have lost as a result of it may do so with less concern that it will result in a more severe sentence than they are hoping for.

Removing harm as a factor in its own right in the assessment of offence seriousness may also help prevent further harm to victims from making their victim impact statement. When harm is taken into account, victims who wish to influence the sentence may make a victim impact statement detailing the harm they have suffered even if it is too early in

See the discussion in Chapter III about the kinds of information victims might need if they are to think about victim impact statements as a tool for recovery, rather than only as a means of having input into the sentence or addressing the offender. 
their recovery for them to be able to do this safely. Similarly, the wish to influence the sentence may lead victims to include effects of the offending which they would not otherwise share with the court, the offender, the offender's supporters, their own supporters, and any members of the public who might hear the victim impact statement. In my discussion of how victim impact statements could assist victims with recovery, I emphasised the importance of victims having the choice whether to make a victim impact statement and what to include if they do make one. This is to assist the victim to regain a sense of control over his or her own life, and to ensure that further harm is not caused through intrusion into the victim's privacy.

If harm is not a factor in its own right, victims can make the decision about whether to make a victim impact statement (and what to include if they do make one) based on what is right for them personally. Those who wish to have their experience acknowledged in the public setting of the courtroom would be free to construct their victim impact statement in a way that would allow this to happen. Those who prefer to keep their experience private or who wish to regain a sense of privacy after the prosecution would be free to decide not to make a victim impact statement, or to make a very limited one. Victims would not have to weigh their desire for acknowledgement or privacy against the likely influence of their victim impact statement on the sentence, so they would have a more genuine choice. The exception is if victims are seeking reparation. In these circumstances, they would still need to provide full details of the harm they have suffered in order for reparation to be awarded. They may have to prioritise their need for reparation over their desire for privacy, which is unfortunate but difficult to avoid.

\section{$B$ The Permissible Content of Victim Impact Statements}

In Chapter II, I discussed the current restrictions on victim impact statements. These restrictions fall into four categories: the facts of the offending, other alleged offending and alleged misconduct of the offender; certain effects of the offending; emotive language and the victim's views on sentence. As I argued in Chapter II, these restrictions follow from the court's decision that the primary purpose of victim impact statements is to provide information about harm relevant to assist the judge to assess the seriousness of the offence. Restricting the content of victim impact statements to information relevant to this enquiry was an attempt to protect the offender from the imposition of a disproportionately severe sentence. However, these restrictions require reconsideration in light of my argument that victim impact statements should not be used to assess the seriousness of the offence, but rather have as their over-arching purpose meeting the needs and protecting the interests of victims. 
The current restrictions would prevent victim impact statements from achieving their proposed purposes. The restrictions on the facts of the offending, certain effects of the offending and the use of emotive language prevent victims from telling their stories in their own way. This limits the extent to which the wrongfulness of the offending can be recognised and the harm to victims acknowledged by the court. These same restrictions limit the extent to which making a victim impact statement could assist victims with recovery. Victims need to be able to include any aspects of their experience they wish to and describe their experience in their own way in order to make sense of it, which is the central task of recovery in my proposal. Moreover, as I argued in Chapter II, the current restrictions limit the extent to which victim impact statements can protect victims' interests in the sentence. First, reparation may not be able to be granted for the full extent of the harm and loss when victims are prevented from including certain effects and from using emotive language, which may be necessary to describe emotional harm. Secondly, victims may not be able to inform the court of the reasons for any concerns about their safety from the offender if they cannot refer to other alleged offending and misconduct by the offender. Thirdly, the court may not be informed about the effects of the sentence on the victim if victims are prevented from including their views on sentence in their victim impact statements.

When victim impact statements have as their over-arching purpose meeting the needs and protecting the interests of victims, as I am arguing they should, relevance is no longer the touchstone for restrictions on the content of victim impact statements. However, some restrictions on victim impact statements are still required, in order to protect the dignity of the offender. In the rest of this section, I discuss the restrictions on content necessary to protect the offender's dignity. I also discuss how these restrictions should be enforced.

In Chapter III, I argued that giving victims the opportunity to make a victim impact statement is one way in which the criminal justice process can show respect for the victim's dignity. I adopted Kant's definition of dignity as intrinsic worth, which all people have in equal measure. ${ }^{23}$ This equality means that the dignity of offenders, no less than victims, must be respected. Some limits need to be placed on the content of victim impact statements in order to ensure that this occurs. It would be understandable for a victim to object to the requirement to respect the offender's dignity. In sexual violation cases, the offender displayed serious disrespect for the victim's dignity, and a victim could quite reasonably feel that as a result the offender does not deserve respect at

$23 \quad$ Immanuel Kant Grounding for the metaphysics of morals $\left(2^{\text {nd }}\right.$ ed, translated by James Ellington, Hackett Publishing Company, Indianapolis, 1983) at 44. 
sentencing. However, as victim impact statements are part of a formal public process, they do need to conform to particular standards, including respect for the offender's dignity.

Victims can still inform the offender of the impact of the offending, which they may hope will make the offender feel guilty. This is consistent with respect for dignity, because the focus is on the offender's behaviour and its consequences rather than the offender as a person. However, if the victim strays into attacking the offender's character, threatening the offender or others, or swearing, there would be interference with dignity. The line between appropriate statements which respect dignity but criticise behaviour and attacks on character is difficult to draw in the abstract. To some extent it will remain a subjective question even when a particular passage can be seen in the context of the victim impact statement as a whole. Attempting to define appropriate content more strictly, however, may result in unnecessarily restrictive rules.

When writing their victim impact statements, people should have clear information about the purposes of victim impact statements and the restrictions on content outlined above (no attacks on character, threats, or swearing). This would help them stay within the rules when writing their victim impact statement. Victims should also be offered support and guidance from a victims' advisor, who can help them write their victim impact statement in a way that stays within the rules. If a prosecutor or defence lawyer believes that inappropriate content has been included, the victim impact statement should be returned to the victim to change, rather than being "censored". The victims' advisor or the prosecutor could discuss it with the victim, acknowledging the legitimacy of the victim's feelings but explaining the need for restrictions because of the formal nature of the process. If the victim is unwilling to change the statement, an application to strike out the parts of the victim impact statement considered inappropriate (as was used in Schofield) could be made by the prosecutor or defence counsel. This would be very unusual, however. The permissive nature of the rules under my proposal and the amount of information and support victims would have should assist most people to write a victim impact statement which stays within appropriate limits. 


\section{Limitations, Likely Objections and Practical Hurdles}

The new role I have proposed for victim impact statements is a significant change from the current approach. Victim impact statements would no longer be used to assess the seriousness of the offending, but would be used to meet some of the needs and protect the interests of victims. In order for victim impact statements to fulfil these purposes, their permissible content must be much wider than it is currently.

The changes I have proposed increase the likelihood that making a victim impact statement will be more helpful and less harmful to victims than is currently the case. However, reform of victim impact statements is most likely to be effective if it is undertaken in combination with reforms aimed at reducing the harm suffered by victims at earlier stages of the process. Further, victim impact statements are not a substitute for counselling and other kinds of emotional support for victims. Access to medical care, financial support if their ability to work is affected, and compensation are also required for victims to recover from the offending.

The resource implications of the changes I have proposed could be quite significant, which may be an objection to the proposal. Increasing the permissible content of victim impact statements may increase their length. ${ }^{24}$ As a result, counsel and judges may find their preparation time for sentencing hearings increases slightly. If victims are reading their victim impact statements aloud, the length of hearings might also increase. In particular, judges may be concerned that court time is being used to hear victim impact statements when most of the content cannot be taken into account in the sentencing decision. Further, under my proposal, sentencing judges are required to take victims' interests into account in a more thorough way than is currently the case, which may also increase workload for judges and counsel. Finally, an expanded role for victims' advisors is key to the successful implementation of my proposal, which again has resource implications.

Finally, successful implementation of the new role of victim impact statements I proposed would require a change in thinking about the role of victims and the responsibilities of criminal justice professionals towards them. As an intermediate step,

$\overline{24}$ In a submission on the Victims of Crime Reform Bill, the Chief High Court Judge raised concerns about increased demand on court time from changes to the rules about oral presentations of victim impact statements in the Bill. See Hon Justice Winkelmann and Judge Doogue "Re Victims of Crime Reform Bill” at 2. 
the changes proposed in the Victims of Crime Reform Bill could be supplemented with processes to give victims clear information about the purpose and use of victim impact statements. In particular, they should be given information about what they are allowed to say in their victim impact statements, before they write them. 


\section{$V$ Conclusion}

In this dissertation, I have argued that victim impact statements should be changed from a tool to assist the court to one designed to meet victims' needs and protect their interests.

I outlined the development of the current purpose of victim impact statements, which is to provide information about the harm suffered by the victim, in order to assist the sentencing judge to assess the seriousness of the offending. I discussed how the adoption of this purpose led the courts to impose restrictions on the permissible content of victim impact statements. These restrictions fall into four categories: the facts of the offending and other alleged offending or misconduct by the offender; consequential harm, loss or damage; emotive language, and views on the sentence. I argued that, with the exception of the victim's views on sentence, the justification for these restrictions is unclear. This is because the courts have not engaged with the question of the appropriate role of harm in the assessment of offence seriousness. Further, the current approach limits the extent to which victim impact statements can meet victims' needs for recognition, acknowledgement, and assistance with recovery, and protect their interests in the sentence. These interests are in reparation and prevention of further harm from the offender and from the sentence imposed on the offender. Finally, the lack of fair and respectful processes for the preparation, submission and consideration of victim impact statements can cause victims further harm.

I set out a new role for victim impact statements in sexual violence cases. I argued that they should have three purposes. First, they could provide an opportunity for the court to recognise more effectively the wrongfulness of the offending and acknowledge the harm suffered by the victim. They could also recognise the relationship between the victim and the offender which exists as a result of the offending. Secondly, they could protect victims' interests in the sentence, by providing the judge with information relevant to these interests. Thirdly, making a victim impact statement could assist victims with recovery from the offending. There are three processes of recovery from sexual violence with which making a victim impact statement could assist victims. These are developing insight into the effects of the offending and the resources available for coping with it, negotiating the vulnerability arising from the fear of exposure and uncertainty about the future, and grief and growth as a result of the experience. I set out five principles which should be followed so that victim impact statements are most likely to be helpful to victims, and to minimise the risk of further harm. These are safety, choice, empowerment, information, and support and guidance. Finally, I argued that victim 
impact statements should not be used to assess the seriousness of the offending. This would be a more principled approach to sentencing, and would make it more likely that making a victim impact statement would be beneficial for victims' recovery.

I argued that in order for victim impact statements to fulfil the purposes I have proposed, more content needs to be permissible than is currently allowed. I argued that the permissible content of victim impact statements should, however, be limited by the need to protect the offender's dignity. In more concrete terms, this means that victims should not attack the character of the offender or include threats or swearing in their victim impact statements. I argued that it is important that victims are given information about the purpose and permissible content of their victim impact statements, and have access to support and guidance when writing them. Finally, I set out a more respectful alternative process to the "censorship" of impermissible content of victim impact statements.

The proposed new role for victim impact statements would more effectively meet victims' needs and protect their interests. This would be a more just response to offending for victims, and be a step towards making the criminal justice process into a space for victims to recover, rather than causing them further harm. 


\section{Bibliography}

\section{A Cases}

$B v R(C A 65 / 11)$ [2011] NZCA 173.

Hessell $v R$ [2010] NZSC 135.

KM v Police HC Auckland CRI 2004-404-440, 8 December 2004.

$R v A M$ (CA27/2009) [2010] 2 NZLR 750.

$R v B$ HC Dunedin S8/89, 14 June 1989.

$R v$ Barrett [1999] 1 NZLR 146 (CA).

$R v$ Burns [2001] 2 NZLR 464 (hc).

$R v$ Clifford [2011] NZCA 360.

$R v H$ CA248/02, 24 October 2002.

$R v$ Haddon (1990) 6 CRNZ 508 (CA).

$R v$ Hadland CA 204/01, 25 September 2001.

$R$ v Hopkirk (1994) 12 CRNZ 216 (CA).

$R v$ Iona CA416/02, 27 March 2003.

$R v$ Ofakineiafu CA301/04, 8 December 2004.

$R v$ Proctor [2007] NZCA 289.

$R v$ Schofield AK HC S5/01 10 April 2001.

$R v$ Taueki [2005] 3 NZLR 372 (CA).

$R v W$ CA352/05, 5 December 2005.

Sargeant $v$ Police (1997) 15 CRNZ 454 (HC).

Singh $v R$ [2010] NZSC 161, [2011] 2 NZLR 322.

Kuwait Airways Corp v Iraqi Airways Co [2002] UKHL 19, [2002] 2 AC 883.

\section{B Legislation}

Crimes Act 1961.

Sentencing Act 2002.

Victims of Crime Reform Bill 2011 (319-2)

Victims of Offences Act 1987.

Victims' Rights Act 2002.

\section{Books}

Diagnostic and Statistical Manual of Mental Disorders $\left(4^{\text {th }}\right.$ ed, text revision, American Psychiatric Association, Washington DC, 2000).

Andrew Ashworth "Victims' Rights, Defendants' Rights and Criminal Procedure" in Adam Crawford and Jo Goodey (eds) Integrating a Victim Perspective within Criminal Justice: International debates (Dartmouth Publishing, Aldershot, 2000). 
Michael Cavadino The Law of Gravity: Offence Seriousness and Criminal Justice (Joint Unit for Social Services Research, Sheffield, 1997).

Judith Daylen, Wendy van Tongeren Harvey and Dennis O'Toole Trauma, Trials, and Transformation: Guiding Sexual Assault Victims through the Legal System and Beyond (Irwin Law, Toronto, 2006).

Jonathan Doak Victims' Rights, Human Rights and Criminal Justice: Reconceiving the Role of Third Parties (Hart Publishing, Oxford, 2008).

Andre du Toit "The Moral Foundations of the South African TRC: Truth as Acknowledgement and Justice as Recognition" in Robert Rotberg and Dennis Thompson (eds) Truth v Justice: The Morality of Truth Commissions (Princeton University Press, Princeton, 2000).

Richard Frase "Limiting Retributivisim" in Andrew von Hirsch, Andrew Ashworth and Julian Roberts (eds) Principled Sentencing: Readings on Theory and Policy $\left(3^{\text {rd }}\right.$ ed, Hart Publishing, Oxford, 2009).

John Gardner and Stephen Shute "The wrongness of rape" in Jeremy Horder (ed) Oxford Essays in Jurisprudence ( ${ }^{\text {th }}$ ed, Oxford University Press, Oxford, 2000).

Hyman Gross Crime and Punishment: A Concise Moral Critique (Oxford University Press, Oxford, 2012).

Hyman Gross $A$ Theory of Criminal Justice (Oxford University Press, New York, 1979).

Matthew Hall "A narrative-based model of victim-centredness in criminal trials" in Victims of Crime: Policy and Practice in Criminal Justice (Willan Publishing, Devon, 2009).

Carolyn Hoyle and Lucia Zedner "Victims, victimization, and criminal justice" in Mike Maguire, Rob Morgan and Robert Reiner (eds) The Oxford Handbook of Criminology (4 ${ }^{\text {th }}$ ed, Oxford University Press, New York, 2007).

Immanuel Kant Grounding for the metaphysics of morals $\left(2^{\text {nd }}\right.$ ed, translated by James Ellington, Hackett Publishing Company, Indianapolis, 1983).

Nicola Lacey "Unspeakable Subjects, Impossible Rights: Sexuality, Integrity and Criminal Law" in Nicola Lacey (ed) Unspeakable Subjects: Feminist Essays in Legal and Social Theory (Hart Publishing, Oxford, 1998).

Lisa Langstraat "Emotion and Community Rhetoric: Victim Impact Statements as Cultural Pedagogy" in Patricia Bizzell (ed) Rhetorical Agendas: Political, Ethical, Spiritual (Lawrence Erlbaum Associates Inc, New Jersey, 2006). 
Elisabeth McDonald and Yvette Tinsley (eds) From "Real Rape" to Real Justice: Prosecuting Rape in New Zealand (Victoria University Press, Wellington, 2011).

Geoff McLay and David Neild "Torts" in Peter Blanchard and others (eds) Civil Remedies in New Zealand (2 ${ }^{\text {nd }}$ ed, Brookers Ltd, Wellington, 2011).

Norval Morris The Future of Imprisonment (University of Chicago Press, Chicago, 1974).

John Murphy "The nature and domain of aggravated damages" (2010) 69 Cambridge Law Journal 353.

Antony Pemberton and Sandra Reynaers "The Controversial Nature of Victim Participation: Therapeutic Benefits in Victim Impact Statements" in Edna Erez, Michael Kilchling and Jo-Anne Wemmers (eds) Therapeutic Jurisprudence and Victim Participation in Justice: International Perspectives (Carolina Academic Press, North Carolina, 2011).

Kent Roach Due Process and Victims' Rights: The New Law and Politics of Criminal Justice (University of Toronto Press Incorporated, Toronto, 1999).

Bruce Robertson (ed) Adams on Criminal Law - Sentencing (online looseleaf ed, Brookers).

RE Smalley Theory for Social Work Practice (Columbia University Press, New York, 1967).

Bas van Stokkom "Victims' Needs, Well-Being and 'Closure': Is Revenge Therapeutic?" in Edna Erez, Michael Kilchling and Jo-Anne Wemmers (eds) Therapeutic Jurisprudence and Victim Participation in Justice: International Perspectives (Carolina Academic Press, North Carolina, 2011).

Andrew von Hirsch "Proportionate Sentences: a Desert Perspective" in Andrew von Hirsch, Andrew Ashworth and Julian Roberts (eds) Principled Sentencing: Readings on Theory and Policy ( $3^{\text {rd }}$ ed, Hart Publishing, Oxford, 2009).

Andrew von Hirsch and Andrew Ashworth Proportionate Sentencing: Exploring the Principles (Oxford University Press, Oxford, 2005).

Andrew von Hirsch Censure and Sanctions (Clarendon Press, Oxford, 1993).

Andrew von Hirsch "Doing Justice: The Principle of Commensurate Deserts" in Hyman Gross and Andrew von Hirsch (eds) Sentencing (Oxford University Press, New York, 1981). 
Sandra Walklate Imagining the Victim of Crime (Open University Press, Berkshire, 2007).

Marvin Wolfgang "Basic Concepts in Victimological Theory: Individualisation of the Victim" in Hans Joachim Schneider (ed) The Victim in International Perspective (de Gruyter, Berlin, 1982).

\section{Journal Articles}

Diann Ackard and Dianne Neumark-Sztainer "Date violence and date rape among adolescents: associations with disordered eating behaviors and psychological health" (2002) 26 Child Abuse \& Neglect 455.

Courtney Ahrens "Being Silenced: The Impact of Negative Social Reactions on the Disclosure of Rape" (2006) 38 Am J Community Psychol 263.

Courtney Ahrens, Giannina Cabral and Samantha Abeling "Healing or Hurtful: Sexual Assault Survivors' Interpretations of Social Reactions from Support Providers" (2009) 33 Psychology of Women Quarterly 81.

Jonathan Allen "Balancing Justice and Social Unity: Political Theory and the Idea of a Truth and Reconciliation Commission" (1999) 49 U Toronto LJ 315.

Andrew Ashworth "Responsibilities, Rights and Restorative Justice" (2002) 42 Brit J Criminol 578.

Andrew Ashworth "Victim Impact Statements and Sentencing” [1993] Crim LR 498.

Jull Astbury, Dorothy Bruck and Deborah Loxton "Forced Sex: A Critical Factor in the Sleep Difficulties of Young Australian Women" (2011) 26 Violence and Victims 53.

Richard Aynes "Constitutional Considerations: Government Responsibility and the Right Not to Be a Victim” (1983) 11 Pepp LRev 63.

Dana Royce Baerger and Dan McAdams "Life Story Coherence and its Relation to Psychological Well-Being” (1999) 9 Narrative Inquiry 69.

Susan Bandes "Victims, "Closure," and the Sociology of Emotion" (2009) 72 Law \& Contemp Probs 1.

Susan Bandes "Reply to Paul Cassell: What We Know About Victim Impact Statements" [1999] Utah LRev 545.

Susan Bandes “Victim Standing” [1999] Utah LRev 331. 
Susan Bandes "When Victims Seek Closure: Forgiveness, Vengeance and the Role of Government" (1999) 27 Fordham Urb LJ 1599.

Susan Bandes "Empathy, Narrative, and Victim Impact Statements" (1996) 63 U Chi LRev 361.

Victoria Banyard and Linda Williams "Women's Voices on Recovery: A Multi-Method Study of the Complexity of Recovery from Child Sexual Abuse" (2007) 31 Child Abuse \& Neglect 275 .

Jayne Barnard "Allocution for Victims of Economic Crimes" (2002) 77 Notre Dame Lrev 39.

Jack Bauer and Dan McAdams "Personal Growth in Adults' Stories of Life Transitions" (2004) 72 Journal of Personality 573.

Douglas Beloof "The Third Model of Criminal Process: The Victim Participation Model" [1999] Utah L Rev 289.

Richard Bierschbach "Allocution and the Purposes of Victim Participation under the CVRA" (2006) 19 Federal Sentencing Reporter 44.

Keith Bletzer and Mary Koss "After-Rape Among Three Populations in the Southwest: A Time of Mourning, a Time for Recovery” (2006) 12 Violence Against Women 5.

Meg Bond and Anne Mulvey "A History of Women and Feminist Perspectives in Community Psychology” (2000) 28 American Journal of Community Psychology 599.

Brene Brown "Shame Resilience Theory: A Grounded Theory Study on Women and Shame" (2006) 87 Families in Society 43.

Jacquelyn Campbell and Karen Soeken "Forced Sex and Intimate Partner Violence: Effects on Women's Risk and Women's Health" (1999) 5 Violence Against Women 1017.

Rebecca Campbell and others "“What Has It Been Like for You to Talk With Me Today?": The Impact of Participating in Interview Research on Rape Survivors" (2010) 16 Violence Against Women 60.

Rebecca Campbell, Emily Dworkin and Giannina Cabral "An Ecological Model of the Impact of Sexual Assault on Women's Mental Health" (2009) 10 Trauma, Violence and Abuse 225.

Rebecca Campbell "What Really Happened? A Validation Study of Rape Survivors' Help-Seeking Experiences With the Legal and Medical Systems" (2005) 20 Violence and Victims 55. 
Rebecca Campbell, Tracy Sefl and Courtney Ahrens “The Impact of Rape on Women's Sexual Health Risk Behaviors" (2004) 23 Health Psychology 67.

Rebecca Campbell, Tracy Sefl and Courtney Ahrens "The Physical Health Consequences of Rape: Assessing Survivors' Somatic Symptoms in a Racially Diverse Population" (2003) 31 Women's Studies Quarterly 90.

Rebecca Campbell and Sheela Raja "Secondary Victimization of Rape Victims: Insights from Mental Health Professionals who Treat Survivors of Violence" (1999) 14 Violence and Victims 261.

Paul Cassell "In Defense of Victim Impact Statements” (2009) 6 Ohio St J Crim L 611.

Paul Cassell "Barbarians at the Gates? A Reply to the Critics of the Victims' Rights Amendment" [1999] Utah LRev 479.

Lauren Bennett Cattaneo and Lisa Goodman "Through the Lens of Therapeutic Jurisprudence: The Relationship Between Empowerment in the Court System and WellBeing for Intimate Partner Violence Victims" (2010) 25 J Interpers Violence 481.

Michael Cavadino and James Dignan "Reparation, Retribution and Rights" (1997) 4 IRV 233.

James Chalmers, Peter Duff and Fiona Leverick "Victim Impact Statements: Can Work, Do Work (For Those Who Bother to Make Them)" [2007] Crim L Rev 360.

Mary Childs “Sexual Autonomy and Law” (2001) 64 MLR 309.

Susan Ann Cornille “Retribution's 'Harm' Component and the Victim Impact Statement: Finding a Workable Model” (1993) 18 U Dayton L Rev 389.

Antonia Cretney, Gwynn Davis, Chris Clarkson and Jon Shepherd "Criminalizing Assault: The Failure of the 'Offence Against Society' Model" (1994) 34 Brit J Criminol 15.

Michele Crossley "Narrative Psychology, Trauma and the Study of Self/Identity" (2000) 10 Theory and Psychology 527.

Hadar Dancig-Rosenberg and Dana Pugach "Pain, Love, and Voice: The Role of Domestic Violence Victims in Sentencing" (2012) 18 Michigan Journal of Gender and Law 423.

Bonnie Dansky and others “The National Women's Study: Relationship of Victimization and Posttraumatic Stress Disorder to Bulimia Nervosa" (1997) 21 International Journal of Eating Disorders 213. 
James Dignan and Michael Cavadino "Towards a Framework for Conceptualising and Evaluating Models of Criminal Justice from a Victim's Perspective" (1996) 4 IRV 153.

Jonathan Doak, Ralph Henham and Barry Mitchell "Victims and the Sentencing Process: Developing Participatory Rights?” (2009) 29 Legal Stud 651.

Emma Dunmore, David Clark and Anke Ehlers “A Prospective Investigation of the Role of Cognitive Factors in Persistent Post-Traumatic Stress Disorder (PTSD) after Physical or Sexual Assault" (2001) 39 Behaviour Research and Therapy 1063.

Claire Burke Draucker "Learning the Harsh Realities of Life: Sexual Violence, Disillusionment, and Meaning" (2001) 22 Health Care for Women International 67.

Ian Edwards "Sentencing Councils and Victims" (2012) 73 MLR 324.

Ian Edwards "The Evidential Quality of Victim Personal Statements and Family Impact Statements" (2009) 13 Int'1 J Evidence \& Proof 293.

Ian Edwards "An Ambiguous Participant: The Crime Victim and Criminal Justice Decision Making” (2004) 44 Brit J Criminol 967.

Ian Edwards "The Place of Victims' Preferences in the Sentencing of "Their" Offenders" [2002] Crim LR 689.

Edwards, Ian "Victim Participation in Sentencing: The Problems of Incoherence" (2001) 40 The Howard Journal 39.

Louise Ellison "Closing the Credibility Gap: The Prosecutorial Use of Expert Witness Testimony in Sexual Assault Cases” (2005) 9 Int'1 J Evidence \& Proof 239.

Edna Erez "Who's Afraid of the Big Bad Victim? Victim Impact Statements as Victim Empowerment and Enhancement of Justice" [1999] Crim L Rev 545.

Edna Erez "Victim Participation in Sentencing: Rhetoric and Reality" (1990) 18 Journal of Criminal Justice 19.

Edna Erez and Pamela Tontodonato "Victim Participation in Sentencing and Satisfaction with Justice" (1992) 9 Just Q 393.

Edna Erez and Pamela Tontodonato "The Effect of Victim Participation in Sentencing on Sentence Outcome" (1990) 28 Criminology 451.

Candice Feiring and Lynn Taska "The Persistence of Shame Following Sexual Abuse: A Longitudinal Look at Risk and Recovery" (2005) 10 Child Maltreat 337.

David Feldman "Human Dignity as a Legal Value - Part I” [1999] Public Law 682. 
David Feldman “Human Dignity as a Legal Value - Part II” [2000] Public Law 61.

R Felson and P Pare "The Reporting of Domestic Violence and Sexual Assault by Nonstrangers to the Police" (2005) 67 Journal of Marriage and Family 597.

Tamara Ferguson, Heidi Eyre and Michael Ashbaker "Unwanted Identities: A Key Variable in Shame-Anger Links and Gender Differences in Shame" (2000) 42 Sex Roles 133.

Chad Flanders "Shame and the Meanings of Punishment" (2006) 54 Clev St LRev 609.

Sam Garkawe "The Role of the Victim During Criminal Court Proceedings" (1994) 17 UNSWLJ 595.

Mary Margaret Giannini "Equal Rights for Equal Rites?: Victim Allocution, Defendant Allocution, and the Crime Victims' Rights Act" (2008) 26 Yale L \& Pol'y Rev 431.

Mary Gilfus "The Price of the Ticket: A Survivor-Centered Appraisal of Trauma Theory" (1999) 5 Violence Against Women 1238.

Julie Grohovsky "Giving Voice to Victims - Why the Criminal Justice System in England and Wales Should Allow Victims to Speak Up for Themselves" (2000) 64 J Crim L 416.

Chris Guthrie, Jeffrey Rachlinski and Andrew Wistrich “Inside the Judicial Mind" (2001) 86 Cornell L Rev 777.

Geoff Hall "Victim Impact Statements: Sentencing on Thin Ice?” (1992) 15 NZULR143.

Jean Hampton "Punishment, Feminism, and Political Identity: A Case Study in the Expressive Meaning of the Law" (1998) 11 Can J L \& Jurisprudence 23.

Jean Hampton "Correcting Harms versus Righting Wrongs: The Goal of Retribution" (1992) 39 UCLA L Rev 1659.

Linda Hartling "Strengthening Resilience in a Risky World: It's All about Relationships" (2008) 31 Women \& Therapy 51.

MR Harvey, E Mishler, KC Koenen and P Harney "In the Aftermath of Sexual Abuse: The Narrativisation of Identity in Survivor Accounts of Trauma and Recovery" (2000) 10 Narrative Inquiry 291.

Mary Harvey "An Ecological View of Psychological Trauma and Trauma Recovery" (1996) 9 Journal of Traumatic Stress 3. 
John Harvey, Katherine Barnett and Amanda Overstreet "Trauma Growth and Other Outcomes Attendant to Loss" (2004) 15 Psychological Inquiry 26.

John Harvey, Terri Orbuch, Ann Weber, Nancy Merbach and René Alt "House of Pain and Hope: Accounts of Loss" (1992) 16 Death Studies 99.

John Harvey and others "Coping with Sexual Assault: The Roles of Account-Making and Confiding” (1991) 4 Journal of Traumatic Stress 515.

Lynne Henderson “Revisiting Victim’s Rights” [1999] Utah L Rev 383.

Lynne Henderson "Co-opting Compassion: The Federal Victim's Rights Amendment" (1998) 10 St Thomas L Rev 579.

Lynne Henderson “Legality and Empathy” (1987) 85 Mich L Rev 1574.

Lynne Henderson “The Wrongs of Victim's Rights” (1985) 37 Stan L Rev 937.

Scott Hemenover "The Good, the Bad, and the Healthy: Impacts of Emotional Disclosure of Trauma on Resilient Self-Concept and Psychological Distress" (2003) 29 Pers Soc Psychol Bull 1236.

Judith Lewis Herman "Justice from the Victim's Perspective" (2005) 11 Violence Against Women 571.

Judith Lewis Herman "The Mental Health of Crime Victims: Impact of Legal Intervention" (2003) 16 Journal of Traumatic Stress 159.

Laura Hickman and Sally Simpson "Fair Treatment or Preferred Outcome? The Impact of Police Behavior on Victim Reports of Domestic Violence Incidents" (2003) 37 Law and Society Review 607.

Julia Hutchinson and Juan Carlos Lema "Ordinary and Extraordinary Narratives of Heroism and Resistance: Uncovering Resilience, Competence and Growth" (2009) 24 Counselling Psychology Review 9.

John Jackson "Justice for All: Putting Victims at the Heart of Criminal Justice?" (2003) 30 Journal of Law and Society 309.

Bronwyn Jones, Julia Müller and Andreas Maercker "Trauma and Posttraumatic Reactions in German Development Aid Workers: Prevalence and Relationship to Social Acknowledgement” (2006) 52 Int J Soc Psychiatry 91.

Jan Jordan "What Would MacGyver Do? The Meaning(s) of Resistance and Survival" (2005) 11 Violence Against Women 531. 
Judith Jordan "Valuing Vulnerability: New Definitions of Courage" (2008) 31 Women and Therapy 209.

Deborah Kelly "What do Victims Want? Why Should their Concerns Be Considered?" (1984) 23 Judges J 49.

Tarunabh Khaitan "Dignity as an expressive norm: Neither vacuous nor a panacea" (2012) 32 OJLS 1.

Dean Kilpatrick and Randy Otto "Constitutionally Guaranteed Participation in Criminal Proceedings for Victims: Potential Effects on Psychological Functioning" (1987) 34 Wayne L Rev 7.

Tyrone Kirchengast "Victim Influence, Therapeutic Jurisprudence and Sentencing Law in the New South Wales Court of Criminal Appeal” (2007) 10 FJLR 143.

Amanda Konradi "Creating Victim-Centered Criminal Justice Practices For Rape Prosecutions” (2010) 17 Research in Social Problems and Public Policy 43.

Amanda Konradi “"I Don't Have to be Afraid of You": Rape Survivors' Emotion Management in Court" (1999) 22 Symbolic Interaction 45.

Amanda Konradi 'Understanding Rape Survivors' Preparations for Court: Accounting For the Influence of Legal Knowledge, Cultural Stereotypes, Personal Efficacy, and Prosecutor Contact" (1996) 2 Violence Against Women 25.

Amanda Konradi and Tina Burger "Having the Last Word: An Examination of Rape Survivors' Participation in Sentencing” (2000) 6 Violence Against Women 351.

Leslie Lebowitz, Mary Harvey and Judith Lewis Herman “A Stage-by-Dimension Model of Recovery From Sexual Trauma” (1993) 8 J Interpers Violence 378.

Heather Littleton "An Evaluation of the Coping Patterns of Rape Victims: Integration with a Schema-Based Information-Processing Model" (2007) 13 Violence Against Women 789.

Shannon Lynch, Amy Keasler, Rhiannon Reaves, Elizabeth Channer and Lisa Bukowski "The Story of My Strength: An Exploration of Resilience in the Narratives of Trauma Survivors Early in Recovery" (2007) 14 Journal of Aggression, Maltreatment and Trauma 75.

Andreas Maercker and Julia Müller "Social Acknowledgement as a Victim or Survivor: A Scale to Measure a Recovery Factor of PTSD" (2004) 17 Journal of Traumatic Stress 345. 
Dan McAdams "The Problem of Narrative Coherence" (2006) 19 Journal of Constructivist Psychology 109.

Dan McAdams "The Psychology of Life Stories" (2001) 5 Review of General Psychology 100.

Doreen McBarnet "Victim in the Witness Box - Confronting Victimology's Stereotype" (1983) 7 Contemporary Crises 293.

Therese McCarthy "Victim Impact Statements: A Problematic Remedy" (1994) 3 Austl Feminist LJ 175.

Clare McGlynn "Feminism, Rape and the Search for Justice" (2011) 31 OJLS 826.

Suzanne McKenzie-Mohr and Michelle Lafrance "Telling Stories Without the Words: 'Tightrope Talk' in Women's Accounts of Coming to Live Well After Rape or Depression" (2011) 21 Feminism \& Psychology 49.

Kate McLean "Stories of the Young and the Old: Personal Continuity and Narrative Identity" (2008) 44 Developmental Psychology 254.

Kate McLean and Marc Fournier "The content and processes of autobiographical reasoning in narrative identity" (2008) 42 Journal of Research in Personality 527.

Kate McLean, Monisha Pasupathi and Jennifer Pals "Selves Creating Stories Creating Selves: A Process Model of Self-Development” (2007) 11 Pers Soc Psychol Rev 262.

Kate McLean and Michael Pratt "Life's Little (and Big) Lessons: Identity Statuses and Meaning-Making in the Turning Point Narratives of Emerging Adults" (2006) 42 Developmental Psychology 714.

Andrea Mercurio and Laura Landry "Self-Objectification and Well-Being: The Impact of Self-Objectification on Women's Overall Sense of Self-Worth and Life Satisfaction" (2008) 58 Sex Roles 458.

Martha Minow “Surviving Victim Talk” (1993) 40 UCLA L Rev 1411.

Jeannine Monnier, Heidi Resnick and Dean Kilpatrick "The Relationship between Distress and Resource Loss Following Rape" (2002) 17 Violence and Victims 85.

Julia Mueller, Hanspeter Moergeli, Andreas Maercker, "Disclosure and Social Acknowledgement as Predictors of Recovery from Posttraumatic Stress: A Longitudinal Study in Crime Victims" (2008) 53 Canadian Journal of Psychiatry 160.

Sharon Murphy, Mary Moynihan and Victoria Banyard "Moving Within the Spiral: The Process of Surviving” (2009) 24 Affilia 152. 
Ncazelo Ncube "The Journey of Healing: Using Narrative Therapy and Map-Making to Respond to Child Abuse in South Africa" (2010) 1 International Journal of Narrative Therapy and Community Work 3.

Kristin Neff, Kristin Kirkpatrick and Stephanie Rude "Self-Compassion and Adaptive Psychological Functioning” (2007) 41 Journal of Research in Personality 139.

Robert Neimeyer, Olga Herrero and Luis Botella "Chaos to Coherence: Psychotherapeutic Integration of Traumatic Loss" (2006) 19 Journal of Constructivist Psychology 127.

Robert Neimeyer and Alan Stewart "Trauma, Healing, and the Narrative Emplotment of Loss" (1996) 77 Families in Society 360.

Helen Neville and Mary Heppner "Contextualizing Rape: Reviewing Sequelae and Proposing a Culturally Inclusive Ecological Model of Sexual Assault Recovery" (1999) 8 Applied and Preventive Psychology 41.

Terri Orbuch, John Harvey, Susan Davis and Nancy Merbach "Account-Making and Confiding as Acts of Meaning in Response to Sexual Assault" (1994) 9 Journal of Family Violence 249.

Jennifer Pals "Narrative Identity Processing of Difficult Life Experiences: Pathways of Personality Development and Positive Self-Transformation in Adulthood" (2006) 74 Journal of Personality 1079.

Jennifer Pals and Dan McAdams "The Transformed Self: A Narrative Understanding of Posttraumatic Growth” (2004) 15 Psychological Inquiry 65.

Monisha Pasupathi "Whither Unity and at What Cost? Fragmentation in the Life Story" (2007) 50 Human Development 124.

Monisha Pasupathi, Kate McLean and Trisha Weeks "To Tell or Not to Tell: Disclosure and the Narrative Self' (2009) 77 Journal of Personality 89.

M Pasupathi, E Mansour and JR Brubaker "Developing a Life Story: Constructing Relations between Self and Experience in Autobiographical Narratives" (2007) 50 Human Development 85.

James Pennebaker "Writing about Emotional Experiences as a Therapeutic Process" (1997) 8 Psychological Science 162.

James Pennebaker "Putting Stress into Words: Health, Linguistic and Therapeutic Implications" (1993) 31 Behav Res Ther 539. 
James Pennebaker and Janel Seagal "Forming a Story: The Health Benefits of Narrative" (1999) 55 Journal of Clinical Psychology 1243.

James Pennebaker and Martha Francis "Cognitive, Emotional and Language Processes in Disclosure" (1996) 10 Cognition and Emotion 601.

James Pennebaker, Michelle Colder and Lisa Sharp "Accelerating the Coping Process" (1990) 58 Journal of Personality and Social Psychology 528.

Ronan Perry “Empowerment and Tort Law” (2009) 76 Tenn LRev 959.

Amy Propen and Mary Lay Schuster "Understanding Genre Through the Lens of Advocacy: The Rhetorical Work of the Victim Impact Statement" (2010) 27 Written Communication 3.

Jeffrey Rachlinski and others "Does Unconscious Racial Bias Affect Trial Judges?" (2009) 84 Notre Dame L Rev 1195.

Cheryl Regehr, Elsa Marziali and Karen Jansen "A Qualitative Analysis of Strengths and Vulnerabilities in Sexually Assaulted Women" (1999) 27 Clinical Social Work Journal 171.

Jennifer Robbennolt "Evaluating Juries by Comparison to Judges: A Benchmark for Judging?” (2005) 32 Florida State University Law Review 469.

Julian Roberts "Victim Impact Statements and the Sentencing Process: Recent Developments and Research Findings" (2002) 47 Crim LQ 365.

Julian Roberts and Edna Erez "Communication in Sentencing: Exploring the Expressive Function of Victim Impact Statements” (2004) 10 IRV 223.

Rupert Ross "Victims and Criminal Justice: Exploring the Disconnect" [2002] 46 Crim LQ 483.

Susan Roth and Leslie Lebowitz "The experience of sexual trauma" (1988) 1 Journal of Traumatic Stress 79.

Rebecca Saunders "Lost in translation: Expressions of Human Suffering, the Language of Human Rights, and the South African Truth and Reconciliation Commission" (2008) 9 SUR Int'1 J on Hum Rts 51.

Dennis Saleebey "The Strengths Perspective in Social Work Practice: Extensions and Cautions" (1996) 41 Social Work 296.

Andrew Sanders and others "Victim Impact Statements: Don't Work Can't Work" [2001] Crim L Rev 447. 
Peter Sankoff "Is Three Really a Crowd? Evaluating the Use of Victim Impact Statements under New Zealand's Revamped Sentencing Regime" [2007] NZ L Rev 459.

Stephen Schulhofer "Taking Sexual Autonomy Seriously: Rape Law and Beyond" (1992) 11 Law and Philosophy 35.

Joanna Shapland and Matthew Hall "What Do We Know about the Effects of Crime on Victims?" (2007) 14 IRV 175.

Daniel Shuman“The Psychology of Compensation in Tort Law" (1995) 43 U Kan LRev 39.

Marilyn Smith and Lillian Kelly "The Journey of Recovery After a Rape Experience" (2001) 22 Issues in Mental Health Nursing 337.

Marlys Staudt, Matthew Howard and Brett Drake "The Operationalization, Implementation, and Effectiveness of the Strengths Perspective" (2001) 27 Journal of Social Service Research 1.

Vanja Stenius and Bonita Veysey "“'It's the Little Things": Women, Trauma and Strategies for Healing" (2005) 10 Journal of Interpersonal Violence 1155.

Richard Tedeschi and Lawrence Calhoun "Posttraumatic Growth: Conceptual Foundations and Empirical Evidence" (2004) 15 Psychological Inquiry 1.

Mark Thelen, Michelle Sherman and Tiffany Borst "Fear of Intimacy and Attachment among Rape Survivors" (1998) 22 Behavior Modification 108.

Margaret Thornton "The Development of Feminist Jurisprudence" (1998) 9 Legal Educ Rev 171.

Tom Tyler "What is Procedural Justice?: Criteria Used by Citizens to Assess the Fairness of Legal Procedures” (1988) 22 Law and Soc'y Rev 103.

Maria Elena Vidal and Jenny Petrak "Shame and Adult Sexual Assault: A Study with a Group of Female Survivors Recruited from an East London Population" (2007) 22 Sexual and Relationship Therapy 159.

Andrew von Hirsch "Hybrid Principles in Allocating Sanctions: A Response to Professor Robinson" (1988) 82 NWUL Rev 64.

Andrew von Hirsch and Nils Jareborg "Gauging Criminal Harm: A Living Standard Analysis" (1991) 11 OJLS 1.

Jeremy Waldron “How Law Protects Dignity” (2012) 71 CLJ 200. 
Anthony Walsh "Placebo Justice: Victim Recommendations and Offender Sentences in Sexual Assault Cases" (1986) 77 J Crim L \& Criminology 1126.

Sharon Wasco "Conceptualizing the harm done by rape: Applications of trauma theory to experiences of sexual assault” (2003) 4 Trauma, Violence \& Abuse 309.

Vicki Waye "Judicial Fact-Finding: Trial by Judge Alone in Serious Criminal Cases" (2003) 27 Melb U L Rev 423.

Ann Weick, Charles Rapp, Patrick Sullivan and Walter Kisthardt "A Strengths Perspective for Social Work Practice” (1989) 34 Social Work 350.

Karen Weiss "Too Ashamed to Report: Deconstructing the Shame of Sexual Victimization" (2010) 5 Feminist Criminology 286.

David Wexler “An Orientation to Therapeutic Jurisprudence” (1994) 20 New Eng J on Crim and Civ Confinement 259.

Cathy Winkler "Rape as Social Murder" (1991) 7 Anthropology Today 12.

\section{E Parliamentary and Government Materials}

Victims of Crime Reform Bill 2011 (319-2) (select committee report).

Victims’ Rights Bill (331-2) (select committee report).

Cabinet Domestic Policy Committee "Enhancing Victims' Rights Review” (17 February 2011).

The Hon Justice Winkelmann and Her Honour Judge Doogue "Victims of Crime Reform Bill."

Justice and Electoral Committee Inquiry into Victims' Rights (December 2007).

\section{F Reports}

A Focus on Victims of Crime: A Review of Victims' Rights (Ministry of Justice, Public Consultation Document, 2009).

Multiple Victimisation in New Zealand: Findings from the 2009 New Zealand Crime and Safety Survey (Ministry of Justice, Wellington, 2011).

New Zealand Crime Statistics 2011: A Summary of Recorded and Resolved Offence Statistics (Police National Headquarters, Wellington, 2011). 
Restoring Soul: Effective Interventions for Adult Victim/Survivors of Sexual Violence (Ministry of Women's Affairs, Wellington, 2009).

Sexual Abuse and Mental Injury: Practice Guidelines for Aotearoa New Zealand (Accident Compensation Corporation, 2008).

Towards Equality in Criminal Justice: Report to the Minister of Justice (Victims' Taskforce, 1993).

Carolyn Hoyle and others Evaluation of the 'One Stop Shop' and Victim Statement Pilot Projects (Home Office, London, 1998).

Venezia Kingi and others Pathways to Recovery: Responding to Sexual Violence (Ministry of Women's Affairs, Wellington, 2009).

Elaine Mossman and others Responding to Sexual Violence: A Review of Literature on Good Practice (Ministry of Women's Affairs, Wellington, 2009).

Allison Morris and James Reilly New Zealand National Survey of Crime Victims 2001 (Ministry of Justice, Wellington, 2003).

Sandra Wallace Victim Impact Statements - A Monograph (Department of Justice Policy and Research Division, Wellington, 1989).

Colin Meredith and Chantal Paquette Summary Report on Victim Impact Statement Focus Groups (Department of Justice, Canada, 2001).

\section{G Dissertations}

Janet Foliano "Listening to the Voices of Survivors: The Effects of Rape on Self-Esteem and Self-Blame" (PhD Dissertation, Indiana University of Pennsylvania, 1995).

Suzanne McKenzie-Mohr “Out From and Beyond Trauma: Women's Experiences of the Process from Rape to Living Well" (PhD Dissertation, Memorial University of Newfoundland, 2008).

Leslie Walberg-Hegan "Voices of Victims: The Experience of Preparing a Victim Impact Statement for Use in Court, as Described by Adolescent Sexual Abuse Survivors" (PhD Dissertation, University of Toronto, 1997).

\section{H Internet Resources}

"Victim impact statements censored for whose benefit?" Close Up (11 December 2009) $<w w w . t v n z . c o . n z>$. 
“Sophie's dad says victim impact statement censored" (Wellington, 13 November 2009) $<$ http://www.stuff.co.nz/national/crime/3059154/Sophies-dad-says-victim-impactstatement-censored $>$.

Andrea Vance "Children's drawings to be allowed in court" (Wellington, 16 August 2011) <www.stuff.co.nz $>$ $<$ http://www.stuff.co.nz/national/crime/5453267/Childrens-drawings-to-be-allowed-incourt>.

Andrea Vance "Reforms to give victims greater freedom in court" (Wellington, 20 April 2011)

$<$ http://www.stuff.co.nz/national/politics/4911146/Reforms-to-give-victims-greaterfreedom-in-court>.

Juliet Rowan "Let victims speak out: law expert" The New Zealand Herald (online ed, Auckland, 17 May 2007) <www.nzherald.co.nz>.

\section{Other Resources}

Simon Power "Unanimous support for bill to enhance victims' rights" (press release, 4 October2011).

$<$ http://beehive.govt.nz/release/unanimous-support-bill-enhance-victims039-rights> 